\title{
Plan for the Large Coil Program
}

P. N. Haubenreich

W. C. Anderson

J. N. Luton

P. B. Thompson

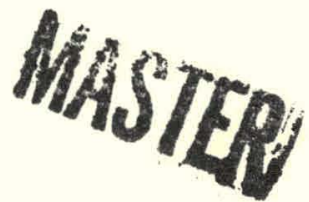

\section{OAK RIDGE NATIONAL LABORATORY}




\section{DISCLAIMER}

This report was prepared as an account of work sponsored by an agency of the United States Government. Neither the United States Government nor any agency Thereof, nor any of their employees, makes any warranty, express or implied, or assumes any legal liability or responsibility for the accuracy, completeness, or usefulness of any information, apparatus, product, or process disclosed, or represents that its use would not infringe privately owned rights. Reference herein to any specific commercial product, process, or service by trade name, trademark, manufacturer, or otherwise does not necessarily constitute or imply its endorsement, recommendation, or favoring by the United States Government or any agency thereof. The views and opinions of authors expressed herein do not necessarily state or reflect those of the United States Government or any agency thereof. 


\section{DISCLAIMER}

Portions of this document may be illegible in electronic image products. Images are produced from the best available original document. 
Printed in the United States of America. Available from National Technical Information Service

U.S. Department of Commerce 5285 Port Royal Road, Springfield, Virginia 22161

Price: Printed Copy $\$ 5.00$; Microfiche $\$ 3.00$

This report was prepared as an account of work sponsored by the United States Government. Neither the United States nor the Energy Research and Development Administration/United States Nuclear Regulatory Commission, nor any of their employees, nor any of their contractors, subcontractors, or their employees, makes any warranty, express or implied, or assumes any legal liability or responsibility for the accuracy, completeness or usefulness of any information, apparatus, product or process disclosed, or represents that its use would not infringe privately owned rights. 
Contract No. W-7405-eng-26

FUSION ENERGY DIVISION

PLAN FOR THE LARGE COIL PROGRAM

P. N. Haubenreich

W. C. Anderson

J. N. Luton

P. B. Thompson

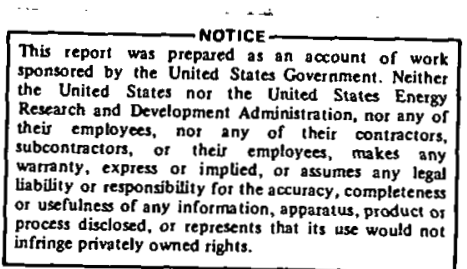

Date Published - February 1977

NOTICE This document contains information of a preliminary nature. It is subject to revision or correction and therefore does not represent a final report.

OAK RIDGE NATIONAL LABORATORY

Oak Ridge, Tennesșee 37830

operated by

it
UNION CARBIDE CORPORATION
for the

ENERGY RESEARCH AND DEVELUPMENI' AUMINISTRATION

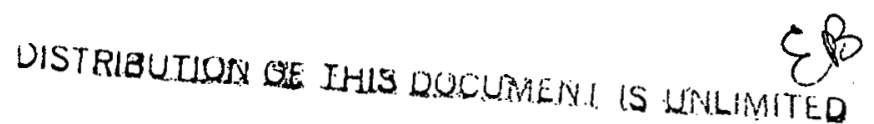


THIS PAGE

\section{WAS INTENTIONALLY \\ LEFT BLANK}


CONTENTS

$\underline{\text { Page }}$

ACKNOWLEDGEMENT . . . . . . . . . . . . . . . . v v

1. INTRODUCTION . . . . . . . . . . . . . . . 1

2. SUMMARY . . . . . . . . . . . . . . . . 2

2.1 Objectives . . . . . . . . . . . . . 2

2.2 Strategy .................... 3

2.3 Recomnendations. .............. 3

2.4 Schedules. ................. 6

3. SCOPE AND CORRELATION WITH OTHER PROGRAMS . . . . . . 8

3.1 Scope . . . . . . . . . . . . . . . . . . 8

3.2 Correlation with Other Programs. . . . . . . . 9

4. TASK DESCRIPTIONS ................. 10

5. COIL CONSTRUCTION AND TEST REQUIREMENTS . . . . . . . 13

5.1 General Considerations . . . . . . . . . 13

5.2 Fabrication. ................. 14

5.3 Test Coll Size................. 15

5.4 Demonstration. . . . . . . . . . . . . 17

5.5 Testing ................. . . 20

6. SElECtion OF A teSting ARRANGEMENT. . . . . . . . . . 27

6.1 Test Arrangement Criteria. . . . . . . . 27

6.2 Descriptions................. 30

6.3 Performance Data . . . . . . . . . . . . . 37

6.4 Vacuum Topology Considerations.......... 55

6.5 Digcussion and RatIngs . . . . . . . . . . . . . . 57

6.6 Conclusions and Decision... . . . . . . . . 65

7. COST ESTIMATION .................. 67

8. DESCRIPTION OF FIRST TEST COILS . . . . . . . . . . . 80

8.1 Basic Concepts ................. 80

8.2 Technical Specifications ........... . 81

9. REFERENCES . . . . . . . . . . . . . . 85 
THIS PAGE

WAS INTENTIONALLY

LEFT BLANK 


\section{ACKNOWLEDGEMENT}

This Plan incorporates ideas on bullding and testing large colls from many people throughout the U.S. superconducting magnet community. Their ideas are so interwoven in the fabric of the Plan that it is impossible now to give credit in detall. This broad interaction 1s, in large part, due to the guidance and encouragement of C. D. Henning and E. J. Ziurys, of the Magnetics Branch, USERDA-DMFE. Other specific contributions, which the authors of this report gratefully acknowledge, are as follows.

In the early planning from which the Large Co11 Program evolved, H. M. Long was responsible for defining many of the coil testing requirements and for the compact torus concept. Several in the Superconducting Magnet Development Program, notably M. S. Lubell, P. L. Walstrom, and $J$. $K$. Ballou, helped resolve the basic considerations in the use of subsize colls to test designs, materlals, and fabrication techniques for reactor scale colls. R. E. Stamps and J. R. Moore, of UCC-ND Engineering, were responsible for generating most of the detalled information for the comparisons and provided original insights into the magnetic and mechanical constraints of various test arrangements. Finally, a workshop on large coll testing, at which portions of the first draft of this report were presented, produced constructive criticlsm which resulted in several revisions in this final version. 


\section{INTRODUCTION}

Development of speciallzed superconducting magnets for fusion reactors is a major activity in the D\&T program of the USERDA Division of Magnetic Fusion Energy. Timely development of effective, rellable, and economical magnets for tokamaks requires the early resolution of existing uncertainties by the design, fabrication and testing of several different large, superconducting toroidal field colls. This is being accomplished through the Large Coll Program, established specifically for this purpose at the Oak Ridge National Laboratory. The program plan for the LCP has evolved from ERDA-sponsored reviews of the U.S. magnet development program, discussions between DMFE and ORNL, and detalled analyses and comparisons by ORNL,

Th1s document has been prepared by the Large Coll Program to make genera1ly available the information that has been generated up to this point and to indicate the direction of future work. Chapter 2 is a summary of objectives, general strategy, and implementation of the LCP. Subsequent chapters give expanded descriptions of program content, technical requirements, selection of testing arrangements, tentative schedule and method of preliminary cost estimation. 


\section{SUMMARY}

\subsection{Objective}

It is the primary purpose of the Large Coll Program to accomp11sh the national fusion program objective of fabricating, testing, and demonstrating the reliable operation of superconducting colls that are large enough to prove the design principles, materials, and fabrication techniques proposed for the toroldal magnet of a tokamak fusion reactor. The program w11l move as quickly as practicable Into fabrication of several different large toroldal fleld colls in order to ldentify, to confront reallstically, and to solve the spectrum of new and/or greater problems involved in design and fabrication of large superconducting tokamak magnets. Testing of the LCP colls will permit a cholce to be made among the different designs so that detalled criterla can be prepared for fullecale reactor colls that are optimal from the standpoints of fabricability, performance, cost, and dependability.

The long-range focus of the Large Coll Program at its. inception in 1976 was the Experimental Power Reactor (EPR) that was being consldered for construction around 1985. It has since shifted to the needs of The Next Step (TNS), which now appears in U.S. fusion program plans as a D-T Ignit1on device somewhat smaller than the EPR. Studies presently in progress to define TNS reference designs indicate that most likely the toroldal field colls must be superconducting, with an opening about $5 \times 7 \mathrm{~m}$, and producing a peak field of 8 to 12 tesla. The LCP is being counted on to produce experimental data supporting TNS design decisions in 1980.

Achievement of the broad objective of the LCP Involves the following accomplishments:

- resolutinn of reactor magnet requircmenta,

- orfination of coil concepts meeting these requirements,

- application of technology and engineering to produce detailed designs of test coils capable of proving the most promising concepts, 
- fabrication of test colls of these designs,

- thorough testing of these coils,

- demonstration of rellable operation of coils and supporting systems under simulated reactor conditions, and

- recommendation of design criteria for TNS colls.

\subsection{Strategy}

The strategy or general program outline shown in Fig. 2.1 was laid out to accomplish the LCP objective. The Large Co11 Program is managed by an ORNL team with magnet technology, design engineering, project eng1neering, and management skills. The capabilities of U.S. Industry will be utilized and the results of R\&D in the Superconducting Magnet Development Program (SCMDP) will be disseminated by contracting for the conceptual design, detailed design, and fabrication of the large colls. Guidance, technical input, and evaluation w111 be provided by ORNL, with reviews and approvals by DMFE. The Superconducting Magnet Development Program will perform the basic R\&D and In addition will perform coll design and developmental fabrication concurrently with the industrial work in LCP. ${ }^{1}$ ORNL will be responsible for design and construction of a test fac1lity and conduct of the tests.

\subsection{Implementation}

The principal technical decisions that were made and approved during 1976 are summarized in Items 2.3.1-2.3.6. A Technical Specitication (TS14700-01) has been 1ssued by Union Carbide Corporation Nuclear Division (operator of ORNL and other ERDA plants at Oak Ridge) giving detalled requirements on the first test colls to be procured. A conceptual design for the test facility has been developed by ORNL and 18 being incorporated in a Major Project Proposal to be submitted to ERDA-DMFE.

\subsubsection{Number of Different Test Coilg}

Several promising concepts for reactor colls were originated in the EPR conceptual designs and the EPR-TF studies in the LCP. These employ 


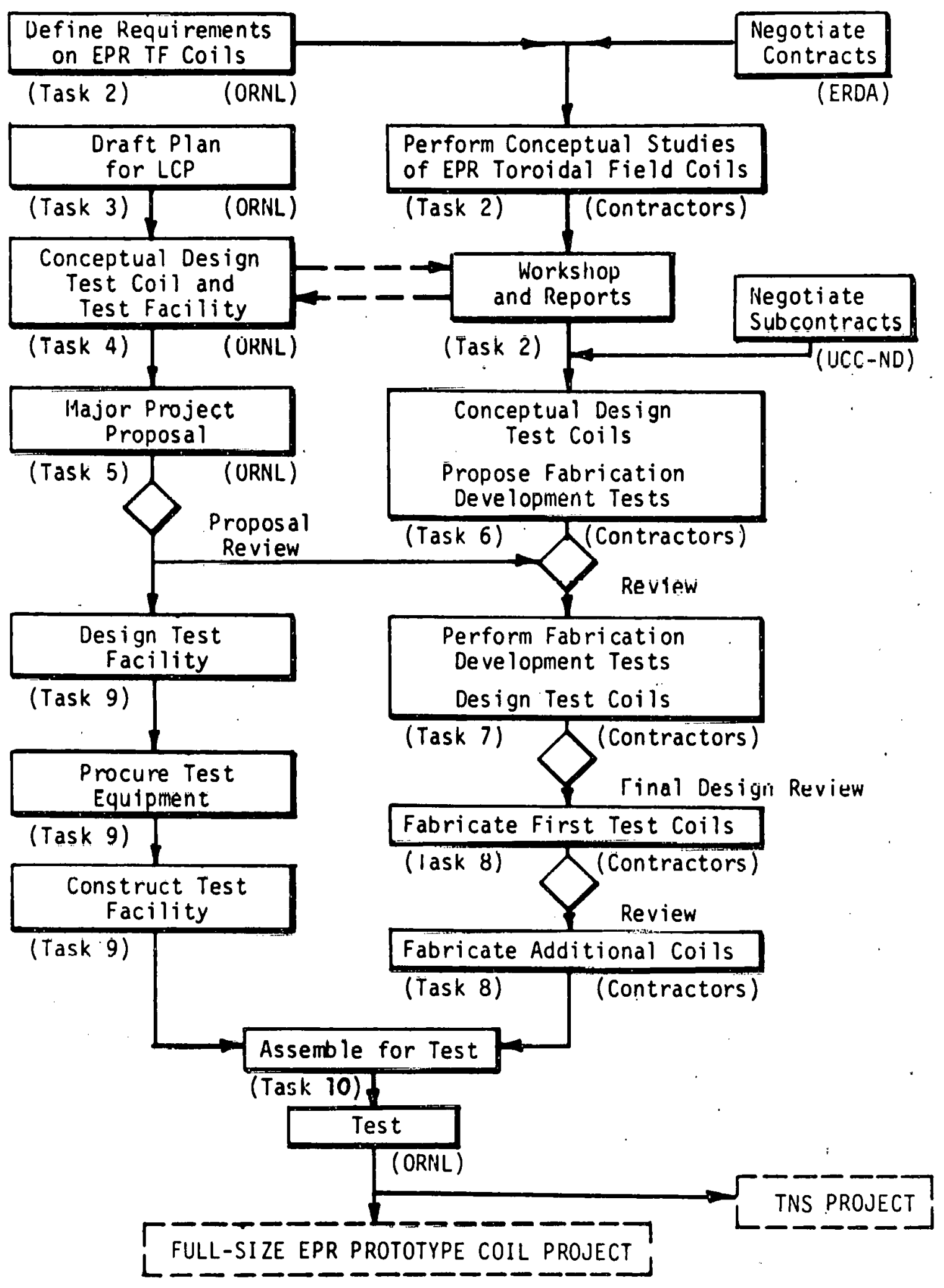

Fig. 2.1 Principal Features of Large Coil Project Strategy 
different combinations of coolant conditions (forced and natural convection), conductor configurations, methods of winding or instailation of conductors, and ways of Incorporating structural materials... Because there is presently insufficient experimental basis for choosing the best design for reactor coils and concentrating all efforts on it, it was decided that three concepts would be chosen for fabrication, testing, and demonstration.

\subsubsection{Peak Field}

The first industrial coll subcontracts will produce colls operable at a peak field of at least 8 tesla. Consideration w111 be given to subsequent procurement of test colls that can produce substantially higher flelds and the test stand is being designed to permit testing at peak flelds up to 12 tesla.

The 8-tesla criterion was chosen in view of information from TNS studies and the status of high-fleld conductor and magnet technology. Decisions on higher field colls will be made on the basis of progress in these areas that is expected in FY-1977.

\subsubsection{Conductor Material}

The specification for the 8-tesla colls permits prospective subcontractors to propose use of either $\mathrm{NbTi}$ alloys or $\mathrm{Nb}_{9} \mathrm{Sn}$ as the conductor material. The choice of concepts to be purgued in the first coils will take Into account both the probability of timely achlevement of the 8-tesla goal and the relevance of the fabrication and testing results to possible subsequent higher-field coils.

\subsection{4 lest Coll Size and Shape}

The 8-tesla test coil specifications define a coll shape approximating a "pure-tension $\mathrm{D}^{\prime \prime}$ and having $2.5 \times 3.5 \mathrm{~m}$ winding bore dimensions. Analyses of test coll requirements by ORNL and the EPR-TF study contractors indicated that a coll bore of approximately 3 meters represents a reasonable compromise among factors that argue for larger or smaller test colls. Conceptual studies of tokamak reactors agree that the TF colls should be elongated in the vertical direction to fit the enclosed components in the most economical and practical manner. The shapes 
favored by reactor designers on the basis of structural and fabrication considerations are elther a "pure-tension $D$ " or some varlation from 1 t.

\subsubsection{Test Arrangement}

The reference test arrangement is a 6-coll toroidal array, in which the peak field in one coll reaches 8.0 tesla when that coll 1 s operated at rated current dengity and the other five colls are operated at 0.8 of rated current density. The test stand will permit testing with only three 8-tesla colls in place (at lower peak fleld). The test stand structure is also being designed to permit testing of one or more colls with high-field conductor and more ampere-turns at a peak field of 12 tesla,

\subsubsection{Principal Vacuum Enclosure}

The multiple coil test arrangements will be enclosed in a single, large vacuum chamber of the simplest, most economical design consistent with coll test requirements.

\subsection{Schedules}

The schedule for the early stages of the Large Coll Program is shown in Fig. 2.2. The schedule for subsequent stages of the program will depend upon the times required by the industrial contractors for design, procurement and coll fabrication. The fusion program goal is to provide evaluated test results for selection of INS design criterla in FY-1980. 


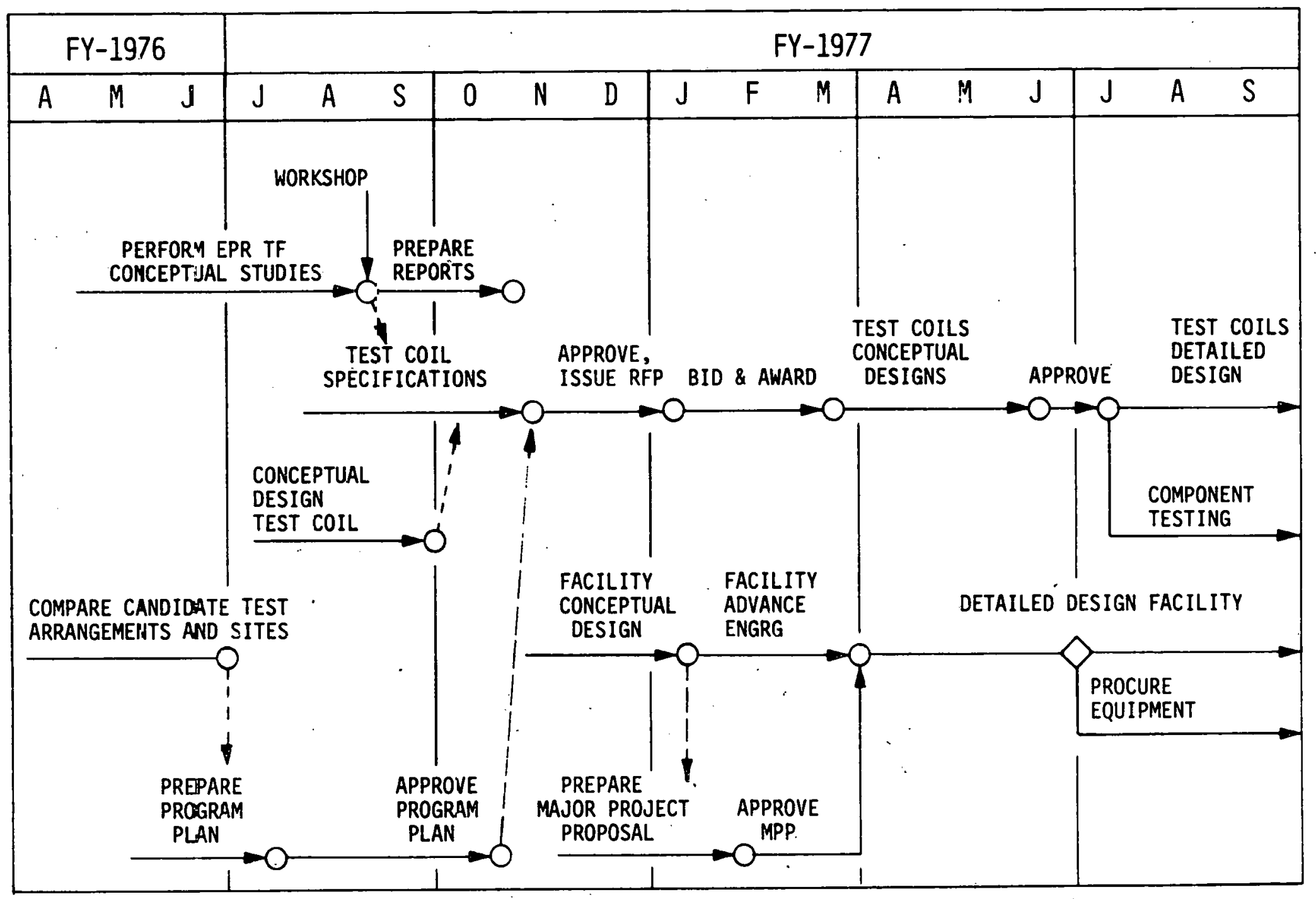

Fig. 2.2. Schedule for Early Stages of Large Coil Program 


\section{SCOPE AND CORRELATION WITH OTHER PROGRAMS}

\subsection{Scope}

The Large Coll Program (LCP) provides for the design, fabrication, testing, evaluation and demonstration of large-bore, superconducting, toroidal magnet coils.

An early activity of the LCP, which supplied input for selection of test coll design criteria, was the generation by three industrial contractors ${ }^{*}$ of concepts for the toroldal magnet of the tokamak Experimental Power Reactor (EPR), including both moderate- and high-field options (8 and 11-16 tesla peak fields). Smaller test colls will be designed so that their fabrication and testing will prove leading design concepts and manufacturing capabilitles, provide necessary design data, and constitute a basis for choice of design criteria for full-size reactor colls. It is anticipated that three concepts will be pursued through conceptual design, detailed design, fabrication, and testing.

Industrial superconducting magnet design and fabrication capabilities will be utilized in test coil conceptual design, detalled design, and fabrication under subcontracts with Union Carbide Corporation - Nuclear Division. ORNL has produced specifications which provide functional requirements, guidelines, and conceptual criterla to the subcontractors and ORNL will monitor their efforts. As part of the LCP, ORNL will also perform conceptual design, evaluate alternative testing arrangements and sites, design the test factlity and oversee its construction, and perform program planning and management functions. Coil testing will be açcomplished under the direct supervision of the Superconducting Magnet Development Program.

*Westinghouse, Magnetic Corporation of America, and a team of General Electric and Intermagnetics General Corporation. 


\subsection{Correlation with Other Programs}

The Large Coil Program is an esgential element of the overall ERDADMFE program for development of superconducting magnet systems for fusion power reactors. It is closely integrated with the other activities in the tokamak-oriented Superconducting Magnet Development Program at ORNL, which includes conductor selection and test, coil shielding and protection, structural analysis, coll design, cryogenics, developmental fabrication, and testing. ${ }^{1}$

The functional requirements of reactor coils were obtained from the scoping studies and preliminary conceptual design for the EPR that were conducted at ORNL, Argonne National Laboratory, and the General Atomic Company ${ }^{2-5}$ and from the studies on The Next Step that are being directed by ORNL and General Atomic. The results of concept evaluation, fabrication, and coil testing in the Large Coll Program will provide input for the ongoing TNS design efforts. The experience in fabrication of large conductors and toroldal magnet colls will benefit all subsequent superconducting magnet activities.

The Large Coil Program will utllize to the maximum practical extent the results of superconductor development under the DMFE-sponsored programs at Lawrence Livermore Laboratory directed at magnets for high-field mirror reactors and at Los Alamos Sclentific Laboratory directed at magnetic energy transfer and storage.

To the extent provided for in agreements among governments, there will be information exchange with programs developing superconducting magnets for fuston power in other countries. There is an ongoing exchange under the US-USSR program of cooperation in fusion power development and an agreement for more substantial cooperation under the auspices of the International Energy Agency is under consideration. 


\section{TASK DESCRIPTIONS}

The program outlined in Fig. 2.1 and scoped in Chapter 3 has been broken down into ten major tasks. A brief. description of each follows.

Task 1 - Management. The management task in essence is to develop and execute program plans to achleve assigned objectives in a timely, effective, and economical manner. It includes organization and planning; preparation of program and budget proposals; evaluation and generalization of reactor magnet requirements from varlous conceptual studies; administration of industrial subcontracts, including technical input and evaluation; coordination and liaison with the SCMDP; interaction with the USERDA; and general guidance and monttoring of the program.

Task 2 - EPR TF System Conceptual Studies. The Large Coil Program, in cooperation with the three EPR design teams at ANL, GA, and ORNL, extracted from the preliminary conceptual studies of the tokamak EPR the princlpal requirements placed on the magnet systems. The LCP staff reduced these requirements to a consistent set of guidelines, conceptual criteria, and design data. The USERDA then let contracts to industrial organizations with experience and capability in superconducting magnets to produce conceptual designs of toroidal field coils meeting these EPR requirements. These conceptual designs, together with those produced by the reactor design teams, provided'a referenre hase for furthor coil design in the Large Coil Program.

Each contractor was required to produce two concepts, one with a peak fleld of 8 tesla, the other with a peak field as high as practicablc (in the 11-16 tesla range). An important consideration was the reliability of magnet system operation, which requires coils that are thermally stable and protected against disabling damage in any credible event. At the completion of the conceptual study; each contractor prepared and delivered a written report that describes his concepts, identifies major uncertainties, and recommends research and development to minimize the uncertainties. Included in the last point is the contractor's recommendation of the smallest coil that can provide a conclusive demonstration of the practicability of the concept. Fach contractor also made an oral presentation of interim results and engaged in a workshop discussion. 
Task 3 - Testing Plans. Concurrently with the EPR studies in Task 2, the LCP developed plans for coil testing. The test coll size required for confident extrapolation of test results to the TNS was also analyzed. Different testing arrangements (e.g., cluster and compact torus) were compared on technical and economic grounds.

Task 4 - Conceptual Design (Oak RIdge). ORNL and UCC-ND Engineering forces performed conceptual design of test coils and a facility required to test three different test colls. These conceptual designs and detailed cost estimates based upon them are being incorporated in a formal Major Project Proposal (Task 5). Results will also provide a basis for evaluation of industrial proposals and conceptual designs (Task 6) and input to SCMDP subprograms (coil design, fabrication, and testing) to be conducted at Oak Ridge.

Task 5-Major Project Proposal. A proposal meeting the requirements for such a major project ${ }^{*}$ will be prepared for review and approval by ERDA-DMFE before the heavy commitment of funds to LCP detailed design and fabrication (Tasks 7-9).

Task 6-Conceptual Degign (Indugtry). Each of three industrial subcontractors will develop a conceptual design of a test coil that will prove a selected reactor magnet concept. In conjunction with conceptual design, the contractor will identify uncertainties and the further development and testing that will be required before fabrication of the test coil. He will propose those component tests and fabrication development that should be performed by him under a subsequent stage of his contract. Results and proposals will be revlewed and decislons made for further work by selected subcontractors under Task 7 .

Task 7 - Detailed Design, Component Tests, and Advance Procurement. Each selected subcontractor will perform preliminary design (corresponding to Title I Engineering) on a test coil of a specified conceptual design. Concurrently he will also perform those fabrication tests that have been

* Procedures Governing the Initiation and Fabrication of Major Projects and Major Devices within the Controlled Thermonuclear Research Program, ERDA-5 (February 1975). 
proposed and approved. Final design (equivalent to Title II) will proceed as test results become avallable. Advance procurement of materials can begin during this task whenever the specifications can be determined. This task will culminate in a Final Design Review.

Task 8 - Coll Fabrication. Each contractor will specify and procure materials and fabricate one test coll of an approved final design. Additional colls will be fabricated as required for the test arrangement; cholce of designs and fabricators for these coils will be made after review of the results of earlier stages.

Task 9 - Test Facility. This task will cover the detalled design, procurement of test support equipment and other materials, building modifications, and construction required to provide for testing and demonstration of the test coils.

Task 10-Assembly. This task will include receipt, Inspection, installation, and performance of preliminary checks on the test coils.

Further Tasks. Testing and demonstration of LCP coils will be performed under the Coil Testing and Evaluation subprogram of the SCMDP. 


\section{COIL CONSTRUCTION AND TEST REQUIREMENTS}

\subsection{General Considerations}

The purpose of the Large Co1l Program 18 to complete an adequate base for confident design of the toroldal field colls in a tokamak reactor. The requirements which must be met before the technologically complex toroldal field colls can be regarded as fully developed and proven must be arrived at by consideration of the specific points which involve substantial advances in technology and engineering and the service conditions that the reactor colls will be required to meet. The latter will include primary and secondary performance characterlstics, operating life cycles, environments, and interaction with connected systems under normal and credible fallure conditions. A detalled review of all requirements leads to a determination of the specific method and teat conditions necessary to verify that all requirements have been met.

Verification is generally accomplished by a sequence of inspection, testing, analysis, and demonstration. Inspection will serve to vertfy dimensional accuracy or that the materlals, parts and processes used are proper. Development tests are conducted for design evaluation purposes, to determine design feasibility and margins, functional parameters, technological data, and to verify assembly and fabrication techniques. The tests are orlented to verify that performance requirements have been met, to indicate critical areas where design improvements are required, and to prove that the test item is capable of operation in the specified environments. Analyses can be employed to expand basic test-derlved information or to calculate related 1tems such as stress from measured strain or deflection data. Demonstration might be defined as operation that is sufficlently extensive in conditions and time to show conclusively that the item or system, as designed and built, is capable of meeting all service requirements with a high degree of reliablilty. 


\subsection{Fabrication}

Fabrication of the LCP test coils will serve to develop and to demonstrate the manufacturing technology that will, be required for the EPR toroldal field colls. The test coils must therefore be designed so that the extrapolation in size from the test coll to the TNS coll will be within the state of the art. This general guideline leads to the following specific requirements.

- The electrical conductor used in the test coll should be identical to that expected in the TNS coll. This cholce will result In a significant fabrication information base for specific candidate conductors before the final selection for the TNS.

- The electrical insulation should be of a type that meets TNS requirements including resistance to irradiation damage.

- The fabrication practices and quality assurance procedures should be prototypical of TNS practice. This will involve assignment of quality levels and development of standard practice procedures that are appropriate for fusion reactor magnets.

The nature of the program places the following additional requirements on coil fabrication.

- The test colls must be amenable to transportation from the fabrication site to the test oite without regultant damage.

- Fabrication must include incorporation of appropriate instrumentation for monitoring coil behavior during testing.

- For future reference, a record of design decisions, analysis, procurement, manufacturing procedures and inspections must be maintained and provided to the LCP management at appropriate intervals. 


\subsection{Test Co11 S1ze}

A basic premise of the Large Coll Program is that subsize test colls can be designed to produce the data that are necessary and suffictent for the destgn of much larger colls for a tokamak reactor. A thorough understanding of the modeling and scallng relationships for large superconducting colls is essential to assure that the data from the test coils Is unequivocally applicable to the design of the full size coils.

From the viewpoint of the large coll detall design, the most important design elements to be retained are those related to the conductor and 1ts performance in an operating coll. This is true not only from the standpoint of electrical and thermal design but also from the standpoint of structural design. A review of structural stiffness relationships between large and small colls indicates that a reasonable match of strain, bending, and shear criteria can be made provided the winding cavity cross sections are nearly the same. The uncertainties of simulating a large coll design in a small test coll can be minimized if both the conductor size and winding cavity dimensions can be preserved within a reasonable range, say $\pm 10 \%$. Th1s would allow evaluation of the large coll conductor, arranged in the proper number of columns and rows within the winding cavity. Detailed analyses of the large coll designs structural responses must be taken into account in the design of the test coil structure to provide simllar interface characteristics between the coil case and the windings. If the test coll bore is made smaller than approximately $2-1 / 2$ to $3 \mathrm{~m}$, however, then the winding 1 tself becomes so relatively stiff that it is difficult to reach the strains of the full-size coll simply by reducing the coll structure.

A second criterion essential to the relevance of coll test data to larger coll design is a reasonable match of field and force distributions around the coll. This can be accomplished in a toroidal array of test colls if the aspect ratio (major radius to coil horizontal bore radius) can be held to a value corresponding to the large toroldal magnet. As described in the following paragraphs, a study was made of toroidal testing arrangements in which the winding cavity cross section dimensions and 
the aspect ratio were held close to those in the EPR to determine the minimum acceptable size test coll. The result turned out to be approximately 3 meters.

The study involved the application of the following approach. Beginning with a full torus of twenty colls with the proportions of the ORNL EPR Reference Design, ${ }^{2}$ reduce the coll bore until the coll aspect ratio is $10 \%$ beyond the design point. In order to limlt the change in field and force distributions, further reductions in coll bore are accompanied by decreases in the major radius which maintain the coil aspect ratio within a $10 \%$ band. This is accomplished by reduction in the number of coils, which allows the remaining coils to be moved radially lnward to the most compact arrangement permitted by structural clearances. Minor variations in winding cavity dimensions and proportions permit adjustments to be made to maintain the peak field value at the design current density.

A reasonable limit to this process is reached when the number of coils has been reduced to six. Although further reduction in the number of colls is possible, the central clearance at the coll noses for the six-coil case. is considered to be the minimum consistent with providing proper simulation of external support interfaces. Two versions of such a 6-coll compact toroldal array were evaluated with respect to varfations in coll bore size. Both versions were required to meet the peak field, current density, and winding cavity cross section size. In one version, referred to hereafter simply as the compact torus, the spectfled peak field can be reached in one coil if it operates at a current density (over the winding) of $2500 \mathrm{~A} / \mathrm{cm}^{2}$ while the five other identical coils are operating at $2000 \mathrm{~A} / \mathrm{cm}^{2}$. In the other version, the peak field is reached only when all six coils operate at $2500 \mathrm{~A} / \mathrm{cm}^{2}$. Less conductor is required in this version which is called the "minimum compact torus" in this report.

A simple performance index consisting of the ratio of radial forces at the coil midplane inboard leg (coil nose) to the radial forces at the coil midplane outboard leg was used. It was assumed that this ratio of forces is sufficiently indicative of the distribution of forces around the coil. This simplified the comparison of forces over a range of test coil sizes and aspect ratios with the value calculated for the full size EPR 
reference coll set. Detalled force values were calculated for two specific test coll sizes and relationships established to corresponding values of the average fleld strengths at the coll 1 eg mfdplanes. Subsequent calculations for varying coll size were made based on average field calculatlons with force rat1os determined by application of the previously determined correction factors. The results are presented in Figs. 5.1 and 5.2.

Figure 5.1 indicates that a narrow range of coll aspect ratio exists in which the force rat1o would be within $\pm 20 \%$ of the EPR reference magnet value. These aspect ratios are somewhat lower than in the EPR reference case due primarlly to the reduced number of colls in the compact tort.

Figure 5.2 presents the force ratio versus coll bore size. Within the assumed allowable range of radial force rat1o of $\pm 20 \%$ from the reference coil design point, the smallest coil would be about three meters in horizontal bore for a compact torus or about two and one-half meters for the slimmer colls of the minimum compact torus. A coil size of three meters for the minimum compact torus would result in a force ratio value close to the reference EPR point.

In summary, various considerations lead to a minimum coll size of approximately three meters if the conditions of large coll winding cavity size and aspect ratio preservation are required. While many other variat lons and comparisons are posstble, the approaches used lead to a logical conclusion while emphasizing retention of the major design elements of a large $\cot 1$.

\subsection{Demonstration}

Although the test coll may be only half the size of the colls eventually required for tokamak reactors, a multicoil test assembly of 3-m colls with 8-tesla maximum field and asymmetric forces of many meganewtons is itself a substantial step upward from what has been accomplished previously. The initial operation of the test facllity will demonstrate in detall how well the LCP colls meet their design parameters, e.g., that the cooldown proceeds at design rate in all portions of the apparatus, 


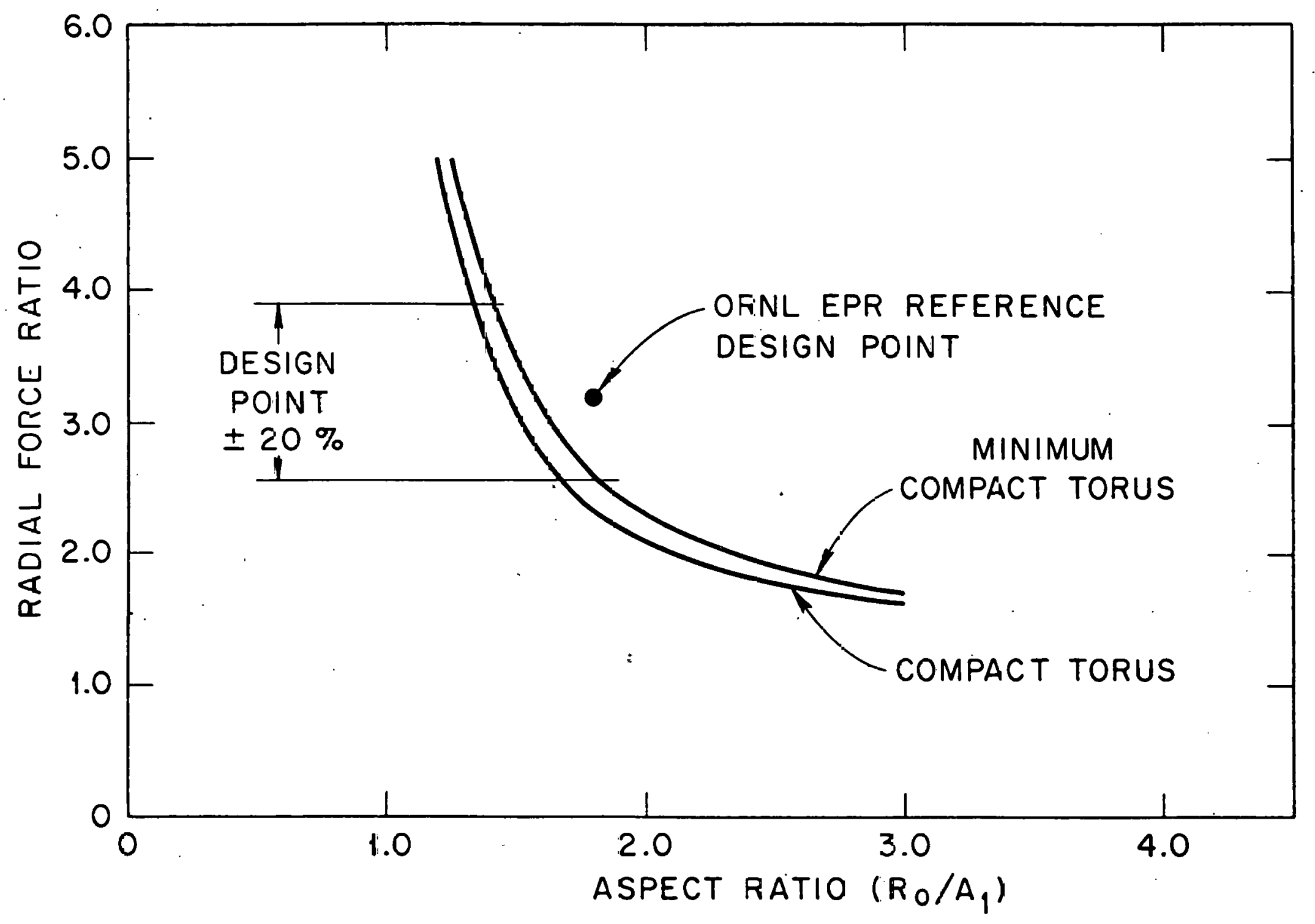

Fig. 5.1 Radial Force Ratio versus Test Coll Aspect Ratio 


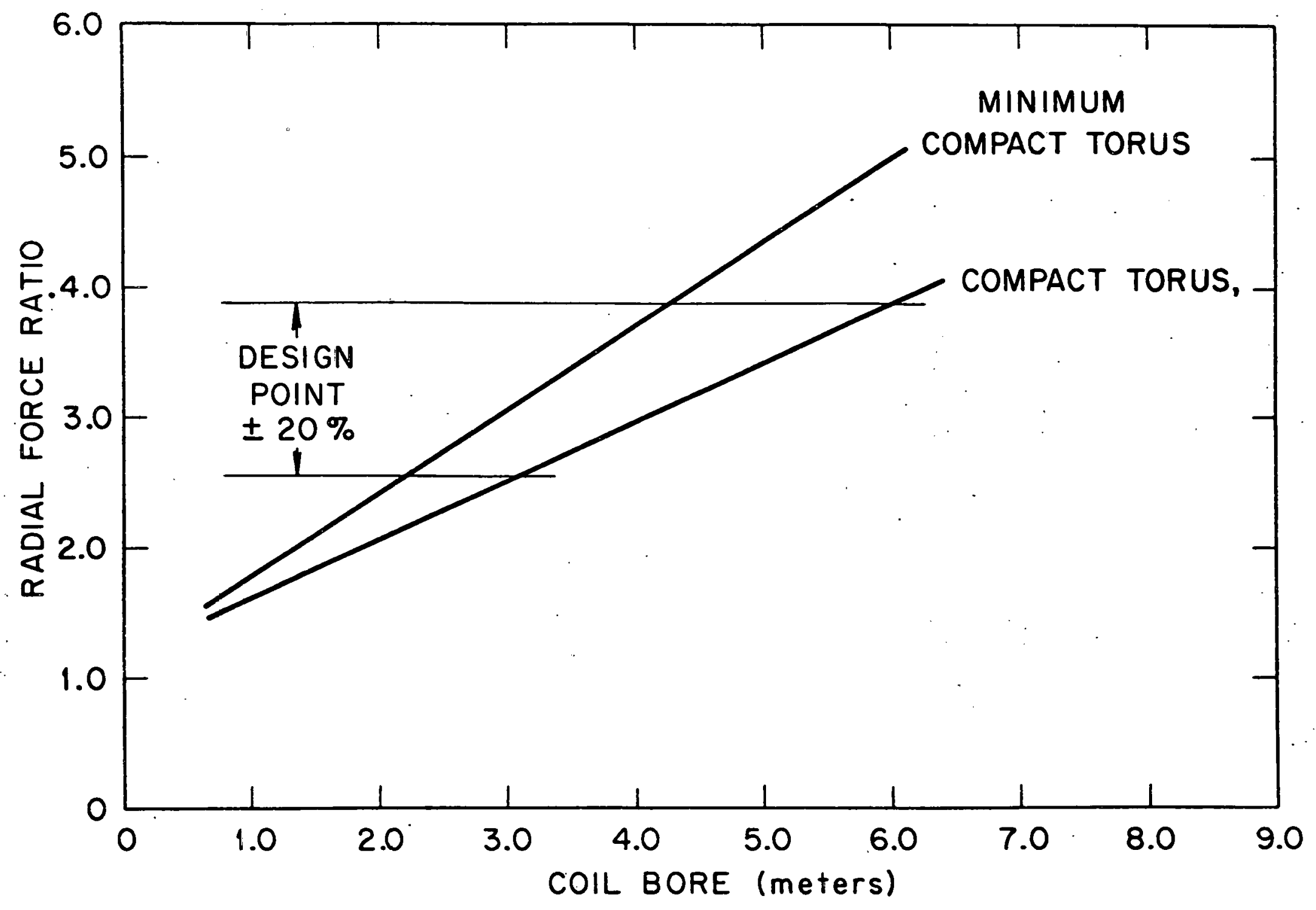

Fig. 5.2 Radial Force Ratio versus Test Coil Bore 
that the heat inputs at joints and leads are as predicted, that coll dump occurs as planned, and that design current is reached when ambient cond1tions (field, field change, coolant temperature, strains, and heater power are simultaneously at design values. Achievement of full field will be an obvious demonstration that the analysis, design, and fabrication of colls and facility were adequate, and that the quality of the production materials was satisfactorily known or predicted from test samples. This latter point is particularly important in the case of the conductor, but is not trivial for the other materials.

If the LCP coll system is demonstrated in this way it greatly enhances confidence in the application of the design analysis and construction techniques to larger coils, but only if the design remains essentially the same. Therefore, all design concepts which are candidates for use in larger systems must be constructed and demonstrated as part of the LCP, and there must be a sufficient number of promising candidates to give con-' fidence of having at least one final success.

Successful operation at design values will not, however, give sufficient basis for extrapolation to more severe ambient conditions or to larger currents. For this reason subsequent testing is required to determine design margins, and the testing must be arranged so as to minimlze any such extrapolations required to reach 'INS conditions.

\subsection{Testing}

In this phase the factors determining coll performance will be eluctdated by varying selected operating conditions and making detailed measurements and analyses of coil responses. Both the nature of the responses and the ultimate limits on coll performance will be compared to qualitative and quantitative predictions. Predicted and observed behavior will be analyzed to identify reasons for the discrepancies.

Testing must be penetrating and thorough in order to provide the greatest benefit to the magnet development program. Instrumentation must provide adequate data which can be thoroughly analyzed and evaluated in order to resolve all key questions. Conclusions can then be drawn which 
can be translated into 1mproved colls. Unanticlpated behavior that reflects deficiencies in methods of prediction must lead to efforts for improvement which will bring calculated predictions into line with observations. If deficiencies in materials or fabrication are indicated, improvements in quality must be sought in subsequent coll manufacture.

An example of the investigation of response and operating limits will be the measurement of the tolerance for overall heat input. An extensive system of heaters will be built into the test coil to simulate the heating of a reactor coll by neutrons and gamma rays and pulsed flelds. In a series of tests, the magnitude and duration of the heater power pulses will be stepped up wh1le the changes in helium pressures, temperatures, and other variables are measured and compared with predictions. This escalation will be continued until finally a limit is reached at which the coil quenches. The design of the test coils will be such that their limiting conditions:should be at least slightly more severe than the normal operating conditions for the first tokamak reactor colls. Thus, the design of the reactor colls will be based, as far as possible, on measured rather than extrapolated data.

The test colls will be tested to determine responses to a sequence of fault conditions of increasing severity as well as to normal operation.

For convenience in the evaluations described in Chapter 6 , we have divided the following discussions of parameters and conditions influencing coll performance Into two groups: the second group dependent on test geometry for 1.t. attainment, the first relatively independent of test configuration. In some cases a clearcut distinction cannot be made.

\subsubsection{Requirements Independent of Test Arrangement}

1. The conductor-coolant configuration and the design heat fluxes In the test coll should be the same as in the larger coil. This is necessary primarily because of unavoldable uncertaintles in heat transfer calculations for the different configurations, orlentations, surface heat fluxes, and dimensions (length and cross section) of coolant channels encountered in the coils.

2. The design current density over the winding of the test coll should be equal to that of the full-size coll. This is a critical factor 
In determining the adequacy of the coll design from the standpoint of stabilization.

3. Full size conductor shall be used in the-test coll. The comb1nation of requirements 1 and 2 demands this.

4. Hellum pressure, pressure drop, and quality should duplicate conditions in the large coll. The helium temperature should be controllable from below the value for the full size coil (for study of conductor instability and increase of critical current) to above (to define nperability 11mits).

5. Kadiation lieating in the reactor coil shall be simulated; radiation damage will not. The heating effect can be simulated by heatcrs which affecl at least a tull cooling circuit, but there appears to be no practical way of simulating neutron damage to the completed test coil.

6. Local heat inputs shall be provided to test the coil's electrical, thermal, and mechanical responses and to measure stabllity margins, recovery currents, and velocities of propagation and contraction of the normal front. To this end, local heaters will be bullt into the coil.

7. For test colls with cooling by forced flow down the conductor, the flow path length must be the greatest anticipated for a full scale coll, approximately $1 \mathrm{~km}$. At the same time there should be at least two adjacent parallel paths to check their interaction. Thus the test coll should have a minimum total conductor length of approximately $2 \mathrm{~km}$. There should, of course, be intermediate helium taps so that the coll could be tested with a larger number of shorter flow paths.

8. For test colls cooled by bolling of a fraction of the hellum, whether the circulation is entirely natural or is slightly forced to aid in bubble removal, provision must be made to simulate the effects of a larger winding by varying the overall pressure, introducing hellum of controllable quality, and energizing properly located heaters. The objective

$\star$

'The resistivity of the matrix will increase and the mechanical and electrical properties of the insulation will degrade during extended reactor operation. 
w11l be to reproduce, as nearly as possible in a subsize coll, the overall patterns of circulation, quality, and pressure in a full size pancake or layer, so that each part of the winding is in 1 ts correct environment.

\subsubsection{Requirements Dependent upon Test Arrangement}

The test requirements that are more or less dependent upon the speciflc test arrangement are summarlzed as follows.

1. Provide design peak fleld in test coll winding when test coll current is at design value.

2. Produce a pattern of stresses and strains in test coll similar to that in full size coll.

3. Produce maximum strains in conductor of test coil the same as in full size coll.

4. Provide pulsed fields at test coll winding equal in magnitude and simflar in orlentation to those in tokamak application.

5. Provide specific stored energy of $6 \mathrm{~J} / \mathrm{g}$ in test coil.

6. Accommodate test coll in vertical plane, with longer axis vertical, as in a tokamak.

Each of the above requirements 18 discussed in the paragraphs which follow.

1. The magnetic field degrades the basic physical parameters of superconductor critical current vs temperature and electrical and thermal conductivities of the stabllizing metal. Thus it is essential that the test arrangement provide design maximum field when the test coll current is at design value.

2. Conductor critical current, insulation and conductor integrity, efficacy of the adhesive, potting, or bonding, structural stability, and local heat Inputs due to internal slippage, cracking, plastic flow or other Inelastic behavior, are all dependent on the forces on conductors produced by the interaction of the magnetic fleld with the coll current. These magnetic loads can be accurately calculated, but any deviation from the characteristics of the composite structure that were used in design can result in strains different from those that were predicted. An obfective 
of testing is to observe the effects of such behavior. Therefore a pattern of loads and strains should be produced in the test coil as nearly as practlcable like those in the full size coll.

3. The test coll structure should be designed to translate the load distribution into an approximately correct strain distribution, and the thickness or Young's modulus of the structure should be adjusted to give the proper magnitude of strain. Strain gauges can be used to verify elastic strain calculations, but an omnipresent system (perhaps sonic triangulation) may be required to determine the locations where slip occurs.

4. The full size colls will be exposed to pulsed fields which tend to drive the coil normal by increasing its leuperaluse and way shorten its life by cyclic loading. The character of these pulsed fields in the EPR cannot be predicted with a high degree of accuracy since they will depend on presently unresolved factors of plasma startup requirements, and such design features as shielding windings and eddy current shields. A field change of 0.2 tesla in $1 \mathrm{sec}$, which is presently being used as a design criteirion in the LCY, represents a reasonable upper limit. If it should prove to be prohibitively expensive to produce this field over the whole volume of the test col.1, the tert arrangement mugt at least provide a pulsed fleld over a large enough region to produce magnetic loads on the test coll such that fatigue testing may be carried out. The heat produced by the pulsed flelds in the affected regions of the coil will be measured and compared to the calculated value. From this a power level will be set for the global "pulse heaters" which simulate the overall heating effect of a pulsed field. Coll operation with the pulsed field, "pulse heaters," and "nuclear heaters" will show under what condition a normalcy is caused by local heating (presumably via transition from nucleate to film boiling), local pulsed heating (same mechanism, different values), and global heating (via increase of temperature or quality of the helium). In sumary, 
the test arrangement should provide parallel and perpendicular pulse flelds of 0.2 tesla in 1 sec, over about a meter length of the test co11, without quenching the background colls.

5. During quench, a coll may be damaged as a result of either high temperature or high voltage. Since merely changing the dump reslatance aggravates one problem while rectifying the other, the full size colls most likely will be electrically subdivided for dump purposes. However, each resulting section requires current leads to the warm environment, and so there will be as few sectIons as possible. The test coll should have more stored energy than one section of the large coll, approximately $150 \mathrm{MJ}$, to establish the performance limits of the dump circuitry and the coll. One can release a large fraction of the stored energy as heat in the coll by reducing the dump resistance, thus testing for hot spot temperature and thermal straln. Alternatively, one can raise the dump restotance and verffy adequacy of the turnto-turn and coll-to-ground insulation. However, this is best done when there is still sufficlent energy released in the coll to ralse its temperature significantly, since insulation electrical performance may be serfously influenced by strain and hellum bubble formation. Assuming that $90 \%$ of the stored energy 18 removed by the energy dump, that the heated region of the coll is restricted by thermal 18olation to $10 \%$ of the coll, and that the desired final temperature is $80 \mathrm{~K}$ then the test arrangement should provide a speciflc stored energy $Q / M$ of approximately $6 \mathrm{~J} / \mathrm{g}$, where $Q$ is the change in total energy in the magnetic field as the test coll current 1 s reduced to zero, and $M$ is the mass of the test coll winding. This value of $Q / M$ should provide ample hellum gas while the magnetic forces are st1ll large, and with a packing fraction of 0.8 represents a $Q / V$ of 43 Joules per $\mathrm{cm}^{3}$ of winding volume, which is nearly two-thirds the EPR value. However, these values are not sufficient to produce large thermal strains, and we conclude that still larger values of $Q / V$ would be useful. 
6. Because of heat transfer considerations, in any test arrangement the test coll must be orlented with respect to gravity as will the large coll, 1.e., the coll axis should be horfzontal and its largest diameter vertical. 


\section{SELECTION OF A TESTING ARRANGEMENT}

Several different testing arrangements were proposed as having the potential of meeting the requirements of the Large Coll Program that are described in Chapter 5. Different advantages were claimed for each of the arrangements, and cursory comparisons were inadequate to show which was the best overall cholce. A methodical comparison in depth was required. The method that was laid out involved first a numerical scoring on speciflc criteria, then a cholce from among those with highest scores, taking into account factors that are not amenable to quantitative evaluaction, such as prospects for funding.

The first step was the generation of a 11st of criteria pertaining to speciflc testing goals, facility requirements, costs, and rlsks that could serve as a basis for evaluation and comparison. Each criterion was assigned a weight that reflects its Importance to the accomplishment of overall program objectives. Each candidate testing arrangement was then evaluated and awarded a rating (between zero and ten) on each criterion. The product of the rating and the criterion value 18 the score for that arrangement on that criterion.

This section gives the criteria, descriptions of the candidate arrangements, the ratings and how they were arrived at, a discussion of more subjective evaluations and judgements, and finally our recomendations.

\subsection{Test Arrangement Criterta}

Table 6.1 is an annotated 11st of criteria, selected upon the basis of considerations which are discussed in other chapters. Despite the difficulties inherent in assigning rational weights to criteria that differ widely in klnd, the weights that are shown in the table are regarded as a we11-balanced assessment of the relative importances of varlous benefits and of costs, risks, and problems. They were arrived at by a version of the Delph1 method, and represent the collective judgement of ORNL personnel involved in the technical management of the Large Col1 Program. 
Table 6.1 Criteria Used as Bas1s for Comparing Large Coll Testing Arrangements

\begin{tabular}{llc}
\hline Criterion $:$ & $\begin{array}{c}\text { Assigned } \\
\text { Weight }\end{array}$ & Comments \\
\hline
\end{tabular}

\section{Benefits}

1. Co11 Test Realism

1.1 Field distribution in winding

1.2 Field distribution around bore

1.3 Radial pressure in winding

1.4 Out-of-plane forces

1.5 Total stored energy

1.6 Unit stored energy

1.7 Pulsed fields

2. Coil Test Versatility

2.1 Capability for higher tield

2.2 Adaptability

3. Demonstration Value
7 Relation between field vectors and conductor dxes affect critical curs rent. Fleld reversal in outer turns af fects location of peak force in windings.

8 Field variation around coll affects normal zone propagation.

10 Distribution and magnitude affects bending forces; magnitude, the radial compression of windings.

9 Distribution and magnitude affects bending; magnitude, the lateral forces in windings.

6 Relevant to energy handling by protecrion system.

8 Affects propagation of normal zone, heatup on dump.

7 Realistic pulsed fields are essential; criterion measures pract1cality of providing.

8 Measures feastbility of tect coll with more amp turns reaching $11 \mathrm{~T}$ while other colls are at $<7.5 \mathrm{~T}$.

6 Practicality of testing different intercoll structureo, individual dewars, etc.

9 Value of system operation as visible evidence of maturing technology for tokamak reactors. 
Table 6.1 Criterla Used as Bas1s for Comparing Large Coll Testing Arrangements

(continued)

\begin{tabular}{ccc}
\hline Criterion & $\begin{array}{c}\text { Assigned } \\
\text { We1ght }\end{array}$ & Coments \\
\hline
\end{tabular}

\section{$\underline{\operatorname{Cos} t 8}$}

4. Program Costs and Schedule

4.1 Scheduled test completion

4.2 Scheduled early results

4.3 Estimated program cost 10

4.4 Investment in nonrelevant coils

4.5 Conductor production rate

5. Program Risks

5.1 Impact of low performance

5.2 Impact of fabrication delays

6. Facllity Problems

6.1 Stray fields

6.2 Coll weight
6 Earliest date to completely test three different test colls.

4 Earliest date for test data for one test coil at full fleld and current.

Total program cost through start of testing.

5 Relevance measured in value of fabrication and test data to design of superconducting tokamak.

4 Measure of practicality of producing required conductor in rime comparable to coil winding time.

7 Probability and possible consequences of coll(s) not operable to full design field and current.

8 Delay in test data due to delay in dellvery.

4 Extent of flelds of significance to personnel health and equipment operation in normal and abnormal operation.

2 Practicality of handling colls in test facility. 


\subsection{Descriptions}

The five arrangements 1dentified briefly below were selected for detailed comparison. All appeared to have promise of meeting at least the minimum requirements for testing efther oval or D-shaped coils and each of fered some advantage in one area or another.

A. Compact torus of six "identical" coils in which the specified peak field is reached in a single coll when 1 t operates at design current and the others operate at a lower current.

B. Minimum compact torus of six "identical" coils designed for achleving the specifled peak field when all colls operate at the full design current.

C. Cluster of three "identical" colls in which the two outside coils are operated at lower current density and field.

D. Cluster of three coils, one test coil, and two background coils which operate at lower field and current density.

E. Split eccentric array of three colls, one test coll and two background colls which operate at lower current density and field.

Consideration has also been given to another arrangement, recently proposed by the General Atomic Company, In which a racetrack-shaped background coll is located on elther side of and at right angles to a D-shaped test coll. From the appearance in plan view, this 18 referred to as a " $T$ " arrangement.

\subsubsection{Reference Concept of Test Co11}

For the purpose of making a quantitative comparison it is necessary to adopt a set of reference dimensions for the coils to be tested. For the comparison of arrangements $A-E$, it was assumed that the test colls would have the same shape as the TF coils in the ORNL EPR reference design. ${ }^{2}$ One basic specification for all of the test colls was that they

"Identical" here means that the coil size shape, and design current density are the same. Detalls of internal design could be quite different. 
operate at a current density (averaged over the windings) of $2500 \mathrm{~A} / \mathrm{cm}^{2}$ * and a peak fleld in the winding of 7.5 tesla. The coll currents (and winding cross sectional areas) of the test colls vary somewhat depending upon the demands 1mposed by the geometry of the arrangement: Most of the test colls provide about $5 \mathrm{MA}$-turno; two have somewhat lower currents.

It should be noted that the comparisons and cholce of testing arrangement.will not be invalidated if the actual test colls should turn. out to be of "a somewhat different slize and/or shape than the reference test coll. Most of the quantities of interest elther do not vary or can be easily scaled. In the discussion which follows some of the calculated values are scaled to a coll helght/width ratio of 1.5 while others are calculated only for a coll with rat 101.34 .

The coll shape and some dimensions of the test coll used in the numerical comparisons are shown in F18. 6.1. Other dimensions specific to the testing arrangement are indicated In F1g8. 6.2 and 6.3 .

\subsubsection{Testing Arrangements}

A. Compact Torus. The compact torus concept that is now under consideration ${ }^{\dagger}$ consists of $81 x$ cotls, uniformly spaced in a toroidal array, having the same coll shape, size, and ampere-turns. Compatibility is insured by making these characteristics the same; internal designs of the colls could be quite different. Sufficient winding cross section 1s provided so that any one coll can be operated at 1ts design field and current density while the other colls are operating at lower currents. (Each coll In turn can be tested in this way.) Figure 6.2 shows dimensions of colis for a compact torus in which the test coll operates at $2500 \mathrm{~A} / \mathrm{cm}^{2}$ and a peak field of 7.5 tesla while the other five colls operate at $2000 \mathrm{~A} / \mathrm{cm}^{2}$.

* $1700 \mathrm{~A} / \mathrm{cm}^{2}$ is the value of current density averaged over the total area of winding and coll case of EPR thickness.

tEarlier considerations included toroldal arrays of 5 to 8 colls, In which one or two were test $\operatorname{colls}$ and the others were background colls of less advanced design, operating at lower current density. 


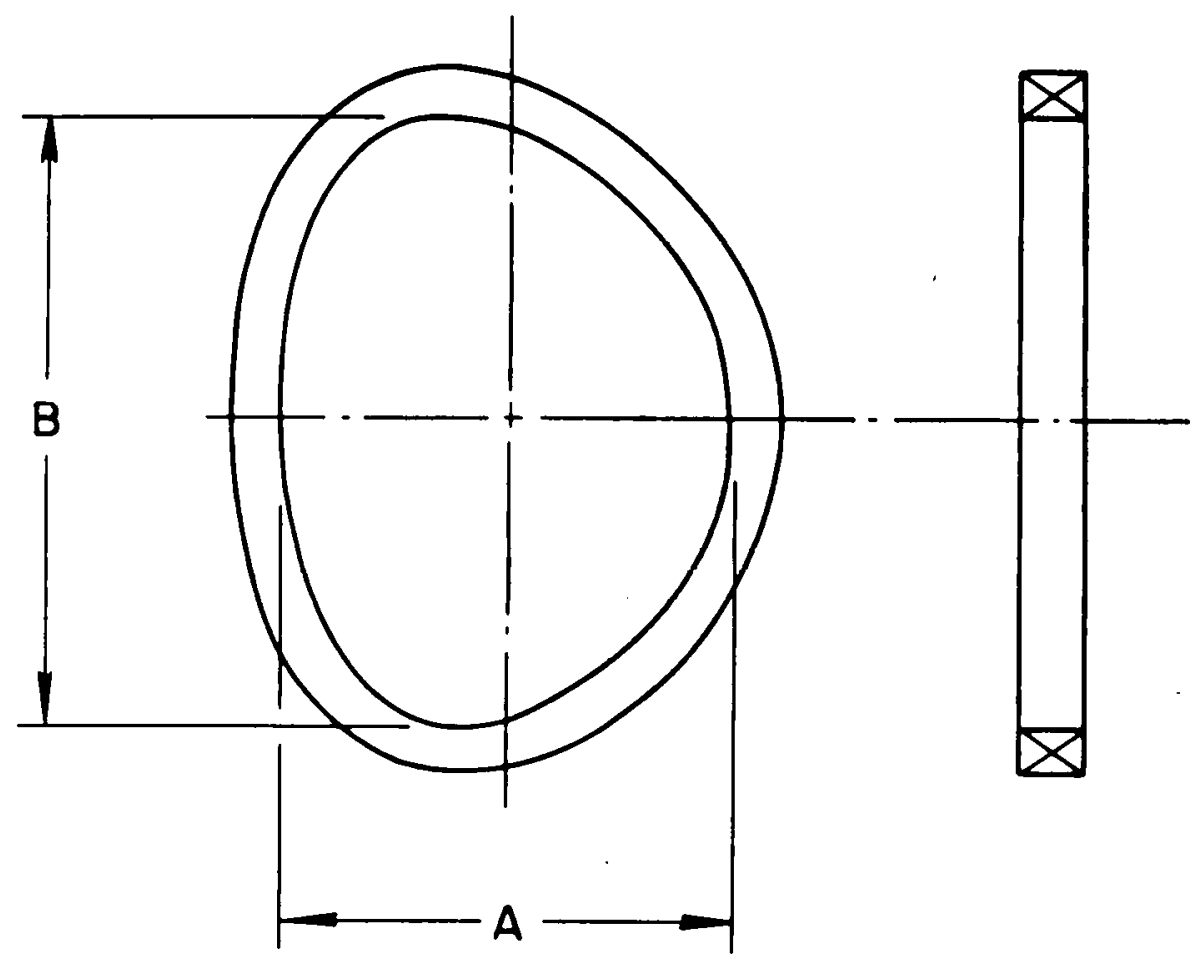

CURRENT DENSITY

MAXIMUM FIELD

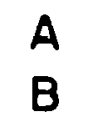

$B / A$

WINDING AREA

AMPERE TURNS

AMPERE METERS
$2500 \mathrm{~A} / \mathrm{cm}^{2}$

7.5 TESLA

$3.0 \mathrm{~m}$

4.0 TO $5.0 \mathrm{~m}$

1.3 TO $1.5 \mathrm{~m}$

$0.20 \mathrm{~m}^{2}$

$5.1 \times 10^{6}$

$70 \times 10^{6}$

Fig. 6.1 General Characteristics of Test Colls 


\begin{tabular}{|c|c|c|c|c|c|c|c|c|c|c|c|c|}
\hline \multirow{2}{*}{\multicolumn{2}{|c|}{. }} & \multicolumn{5}{|c|}{ Meters } & \multirow{2}{*}{$\begin{array}{c}\text { Winding } \\
\text { Area } \\
\left(m^{2}\right)\end{array}$} & \multirow{2}{*}{$\begin{array}{l}\text { Current } \\
\text { Density } \\
\text { (A/cm })\end{array}$} & \multirow{2}{*}{$\begin{array}{l}\text { Amp. Turns } \\
\text { Per } \\
\text { Coil }\end{array}$} & \multirow{2}{*}{$\begin{array}{l}\text { Amp. Turns } \\
\text { For } \\
\text { Test }\end{array}$} & \multirow{2}{*}{$\begin{array}{l}\text { Ampere } \\
\text { Meters } \\
\text { Per Coil }\end{array}$} & \multirow{2}{*}{$\begin{array}{c}\text { Ampere } \\
\text { Meters } \\
\text { For Test }\end{array}$} \\
\hline & & $\overline{R_{0}}$ & d & $a_{1}$ & $a_{2}$ & $2 b$ & & & & & & \\
\hline $\begin{array}{c}\text { Minfmum } \\
\text { Compact Torus }\end{array}$ & All cotls & 2.33 & .05 & 1.50 & p.883 & .524 & .2007 & 2500. & $5.02 \times 10^{6}$ & $30.1 \times 10^{6}$ & $66.2 \times 10^{6}$ & $397 \times 10^{6}$ \\
\hline Compact Torus & $\begin{array}{l}\text { Test coil } \\
\text { Other coils }\end{array}$ & 2.51 & .05 & 1.50 & h. .948 & 532 & .2383 & $\begin{array}{l}2500 . \\
2000 .\end{array}$ & $\begin{array}{l}5.96 \times 10^{6} \\
4.77 \times 10^{6}\end{array}$ & $29.8 \times 10^{6}$ & $79.8 \times 10^{6}$ & $479 \times 10^{6}$ \\
\hline
\end{tabular}

Values are for 1.5 Aspect Ratio Colls.

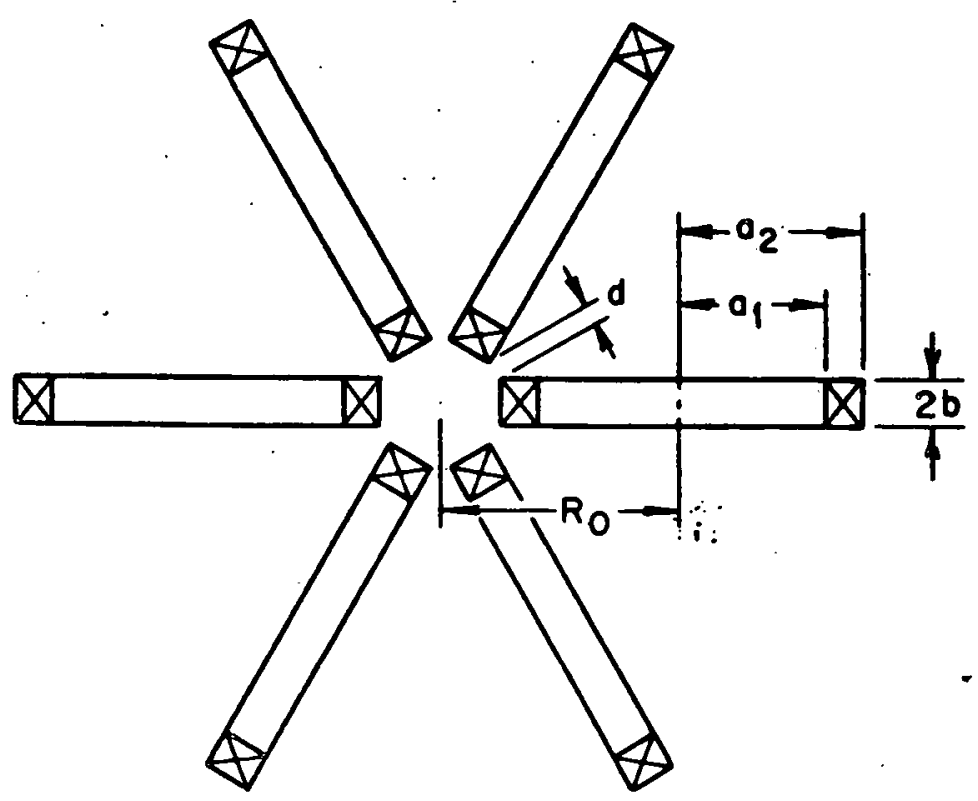

Fig. 6.2 Compact Torus Tests Data 
The maximum field in the other colls in this situation is 6.5 tesla. If all six colls were operated at $2500 \mathrm{~A} / \mathrm{cm}^{2}$, the peak field in each would be 8.1 tesla. The proportions were chosen to permit an array with near minimum aspect ratio consistent with a near-square winding cross section.

B. Minimum Compact Torus. The minimum compact torus is also composed of all test coils. The difference is that each coll is designed to carry fewer ampere-turns at the design field than are the coils in the compact torus. Figure 6.2 shows dimensions used in the quantitative comparisons; In this case a peak fleld of 7.5 tesla $1 \mathrm{~s}$ produced when all coils are operating at $2500 \mathrm{~A} / \mathrm{cm}^{2}$.

C. Cluster of Identical Colls. The dimensions of this arrangement, assuming 7.5 tesla peak field in the center (test) coil when it carries $2500 \mathrm{~A} / \mathrm{cm}^{2}$ and the outside coils carry $2000 \mathrm{~A} / \mathrm{cm}^{2}$, are shown in $\mathrm{Fig} .6 .3$. (The peak field in the outside coils is 5.6 tesla.) The angle, $\phi$, between colls and the offset distance $\Delta$ can be varied to affect the field and force distributions. The values chosen afford a reasonable approximation of the distributions in the EPR coils.

D. Cluster with Background Coils. If the background coils can be different from the test coll, they can be tallored to reduce the total amount of conductor required to test a given test coll. Figure 6.3 shows a cluster test in which the test coll is the same as in arrangement $B$ (minimum compact torus) but the background colls are smaller in both the horizontal and vertical dimensions.

E. Split Eccentric. By moving the background coils as close as possible to the test coll, the conductor requirements can he further reduced. In the split-eccentric arrangement, the test coil is sandwiched between two parallel background coils as shown in Fig. 6.3. As in arrangement $D$, the background coils are smaller than the test coil. (A split eccentric using three identical colls is less attractive than a cluster of Identical colls; $1 . e ., \phi=0$ is not the best in this case.)

T Arrangement. The basic idea of this concept is to use two background coils that are specially shaped and positioned so as to minimize the conductor required to provide a specified field at a given test coil. FIgure 6.4 depicts the particular arrangement proposed by General Atomic, 


\begin{tabular}{|c|c|c|c|c|c|c|c|c|c|c|c|c|c|}
\hline & & \multicolumn{6}{|c|}{ Meters } & \multirow{2}{*}{$\begin{array}{r}\text { Winding } \\
\text { Area } \\
\left(\mathrm{m}^{2}\right)\end{array}$} & \multirow{2}{*}{$\begin{array}{l}\text { Current } \\
\text { Density } \\
\left(\mathrm{A} / \mathrm{cm}^{2}\right)\end{array}$} & \multirow{2}{*}{$\begin{array}{l}\text { Amp. Turns } \\
\text { Per } \\
\text { Coil }\end{array}$} & \multirow{2}{*}{$\begin{array}{l}\text { Amp. Turns } \\
\text { For } \\
\text { Test }\end{array}$} & \multirow{2}{*}{$\begin{array}{l}\text { Ampere } \\
\text { Meters } \\
\text { Per Coil } \\
\end{array}$} & \multirow{2}{*}{$\begin{array}{l}\text { Ampere } \\
\text { Meters } \\
\text { For Test }\end{array}$} \\
\hline & & d & $\Delta$ & $\phi$ & $a_{1}$ & 22 & 26 & & & & & & \\
\hline $\begin{array}{l}\text { Ciuster of } \\
\text { Three } \\
\text { Identical } \\
\text { Coils } \\
\end{array}$ & $\begin{array}{l}\text { Test coil } \\
\text { Other coils }\end{array}$ & .12 & .25 & $20^{\circ}$ & 1.50 & 2.04 & .42 & .2268 & $\begin{array}{l}2500 \\
2000\end{array}$ & $\begin{array}{l}5.67 \times 10^{6} \\
4.54 \times 10^{6}\end{array}$ & $14.8 \times 10^{6}$ & $77.6 \times 10^{6}$ & $233 \times 10^{6}$ \\
\hline $\begin{array}{l}\text { Cluster Test } \\
\text { With } \\
\text { Background } \\
\text { Coils }\end{array}$ & $\begin{array}{l}\text { Test Coil } \\
\text { Background } \\
\text { Coils }\end{array}$ & .12 & .65 & $20^{\circ}$ & $\begin{array}{l}1.50 \\
1.25\end{array} \mid$ & $\begin{array}{l}1.883 \\
1.913\end{array}$ & $\begin{array}{l}.524 \\
.332\end{array}$ & $\begin{array}{l}.2007 \\
.2200\end{array}$ & $\begin{array}{l}2500 \\
2000\end{array}$ & $\begin{array}{l}5.02 \times 10^{6} \\
4.40 \times 10^{6}\end{array}$ & $13.8 \times 10^{6}$ & $\begin{array}{l}66.2 \times 10^{6} \\
53.1 \times 10^{6}\end{array}$ & $172 \times 10^{6}$ \\
\hline $\begin{array}{l}\text { Eccentric } \\
\text { Test With } \\
\text { Background } \\
\text { Coils }\end{array}$ & $\begin{array}{l}\text { Test coll } \\
\text { Background } \\
\text { Cofls }\end{array}$ & .12 & .32 & $0^{\circ}$ & $\begin{array}{l}1.50 \\
1.34\end{array}$ & $\begin{array}{l}1.883 \\
2.08\end{array}$ & $\begin{array}{l}.524 \\
.29\end{array}$ & $\begin{array}{l}.2007 \\
.2146\end{array}$ & $\begin{array}{l}2500 . \\
2000 \text {. }\end{array}$ & $\begin{array}{c}5.02 \times 10^{6} \\
4.29 \times 10^{6}\end{array} \mid$ & $13.6 \times 10^{6}$ & $\begin{array}{l}66.2 \times 10^{6} \\
49.0 \times 10^{6}\end{array}$ & $164 \times 10^{6}$ \\
\hline
\end{tabular}

Values are for 1.5 Aspect Ratio Colis

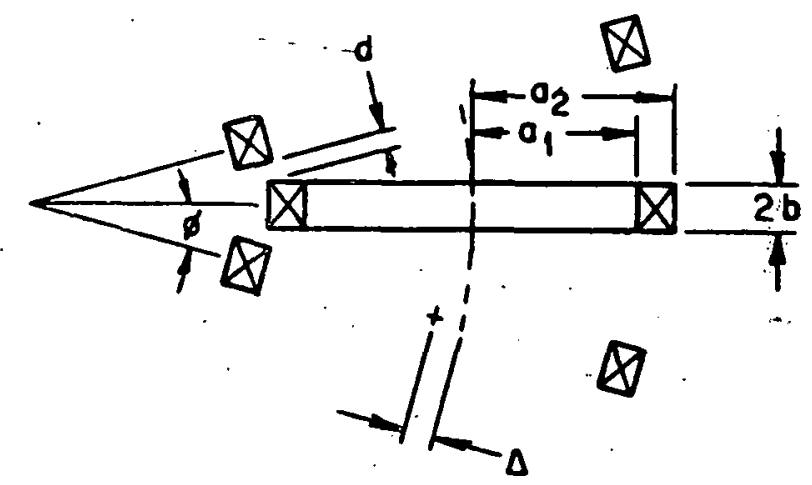

F1g. 6.3 Three-Co11 Test Configurations Data 


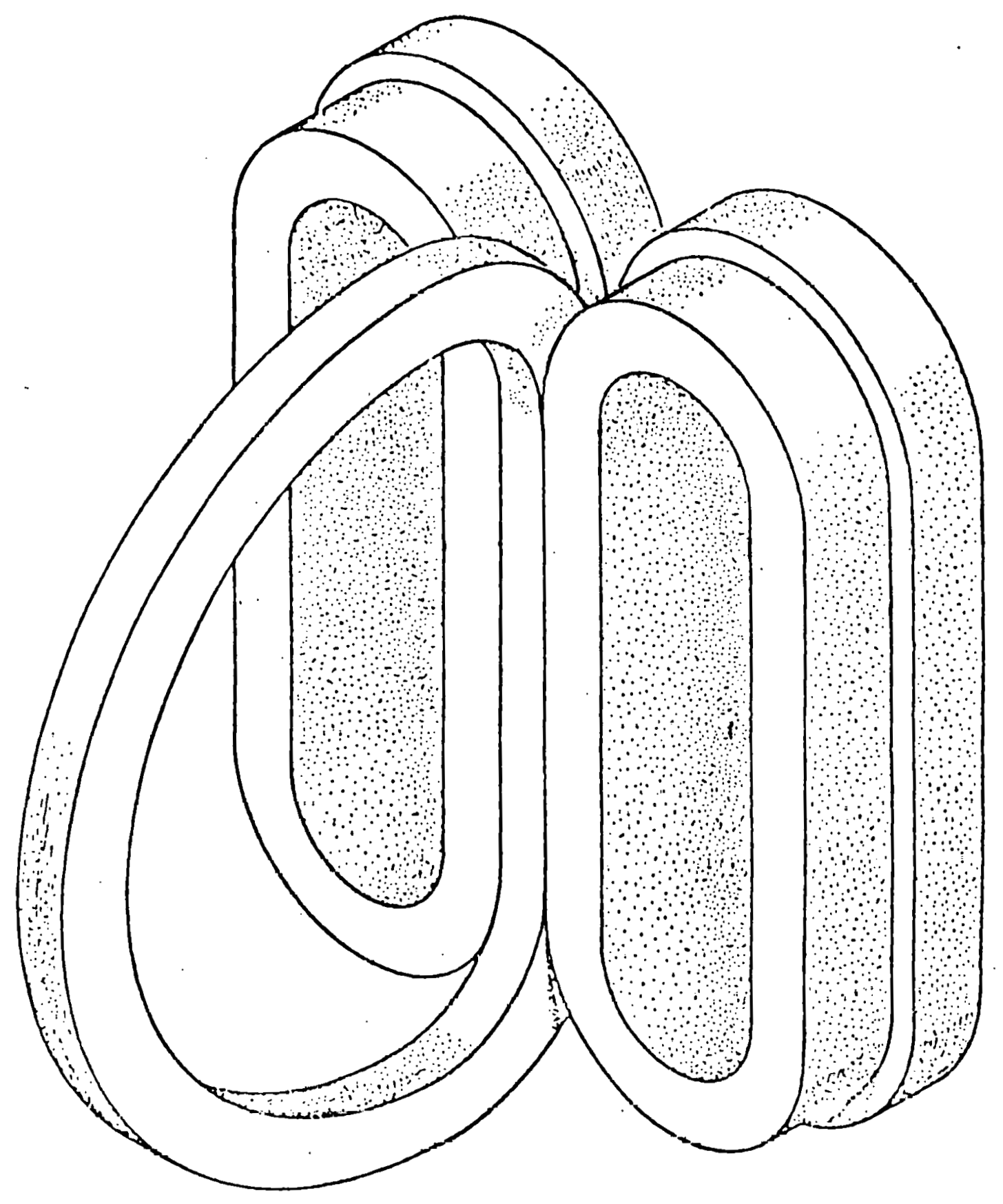

Fig. 6.4 General Atomic Test Bed Concept 
In which the test coll has a straignt inner leg and the background coils are racetrack shape, at right angles to the test coll.

Two test configurations that are simflar to the GA concept but which are capable of testing somewhat larger colls have been defined and evaluated. To allow meaningful comparison with other LCP candidates under consideration, the current densities are $2,000 \mathrm{~A} / \mathrm{cm}^{2}$ in the background coils and $2,500 \mathrm{~A} / \mathrm{cm}^{2}$ in a test co11 the s1ze of a minimum compact torus coil. Space 18 not allowed for structure, which means that the actual current density in the winding area will be higher than the nominal figures fust quoted or the colls must be further apart which means that more ampereturns will be required. F1gure 6.5 shows schematically the arrangement and size of the coils in the two configurations. The hole in the center of the first configuration reduces the radial fleld component in the outside corners of the inner leg of the test coll. The second configuration does not have that hole and consequently has smaller background colls.

Vacuum Enclosure. The vacuum required for the thermal insulation of the colls and cold structure can be provided either by a single chamber ("bell-far") surrounding the entire assembly or by closer-fitting enclosures ("dewars"). The diameter and helght of the minimum size bel1-jar for each of the arrangements are listed in Table 6.2. Section 6.4 discusses the relative advantages and disadvantages of bell-jars and dewars.

\subsection{Performance Data}

Figures 6.2 and 6.3 summarize characteristic dimensions and data that are pertinent to a comparative evaluation of arrangements $A-E$. (Data for arrangements like that proposed by General Atomic are presented later.) Other pertinent information is presented in Figs. $6.6-6.16$.

Magnetic fleld and force distributions for each of the testing concepts were calculated using the computer code BOVAL, wh1ch takes full account of the winding cross section and coil shapes. The magnetic field distribution in the nose region of the coll windings are shown in Fig. 6.6. The stray fields in the vicinities of the different test setups are shown in Fig. 6.7. This figure shows that the fields around the compact torus 


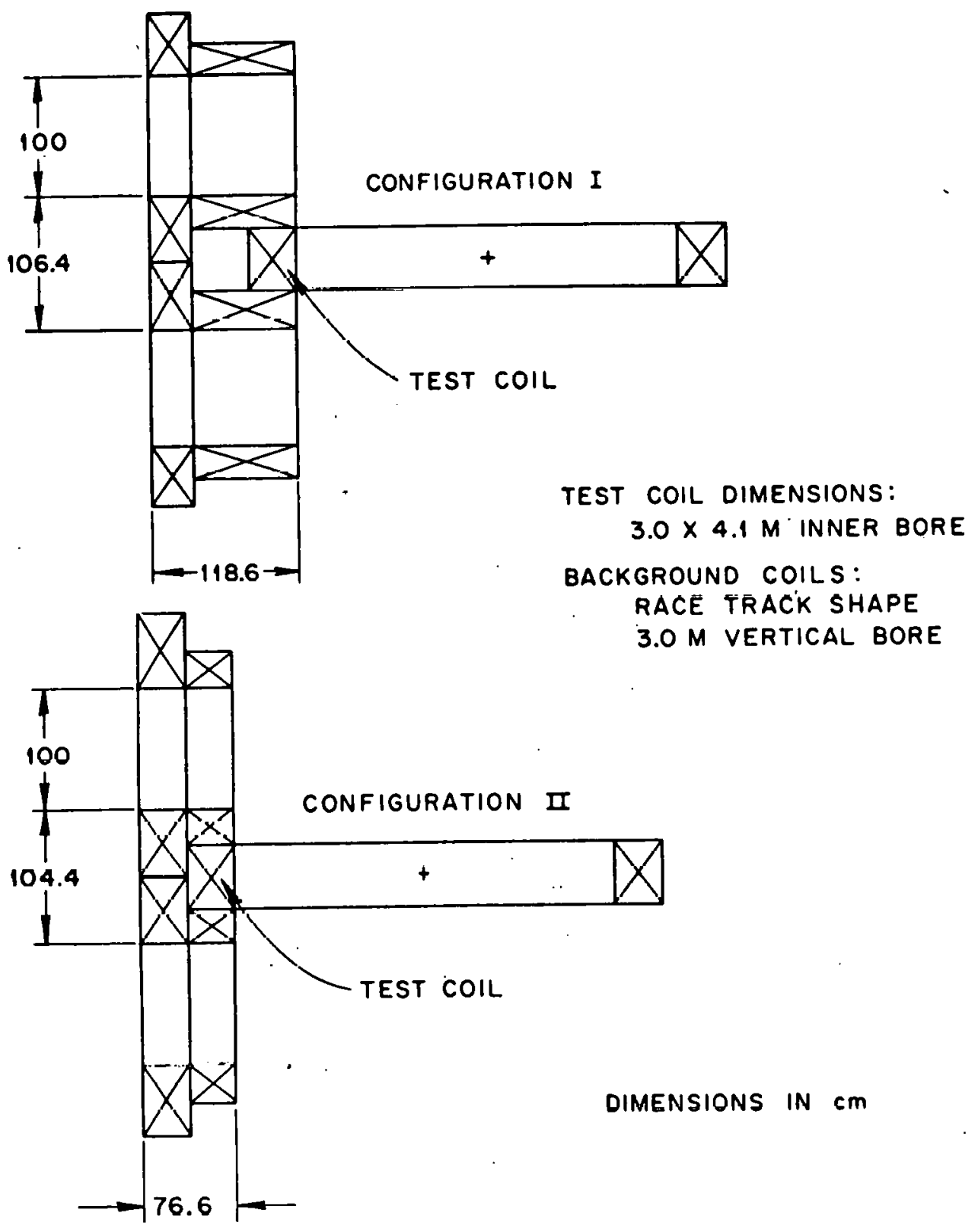

F1g. 6.5 Alternate GA Configurations 
Table 6.2 Vacuum Enclosure Requirements

\begin{tabular}{lcc}
\hline \multicolumn{1}{c}{ Configuration } & \multicolumn{2}{c}{ Vacuum Bell Jar Size } \\
\cline { 2 - 3 } & Diameter - m & He1ght - m \\
\hline A. Compact Torus & 10.4 & 9.3 \\
B. Minimum Compact Torus & 10.4 & 9.3 \\
C. Cluster of Ident1cal Co1ls & 8.3 & 9.5 \\
D. Cluster with Background Co118 & 8.3 & 9.5 \\
E. Split Eccentric & 7.2 & 9.8 \\
\hline
\end{tabular}




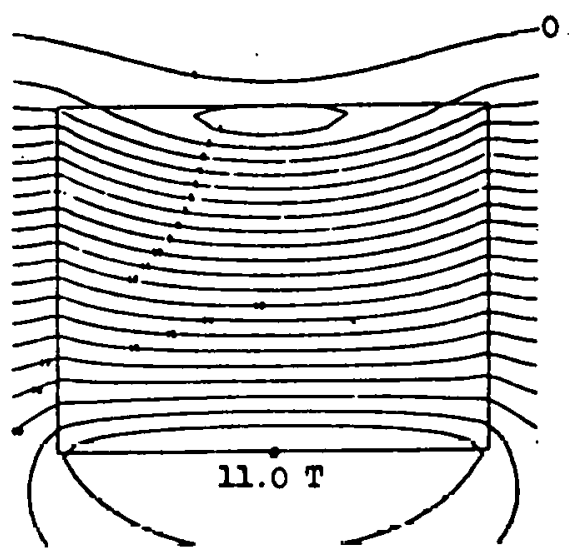

ORNL-EPR

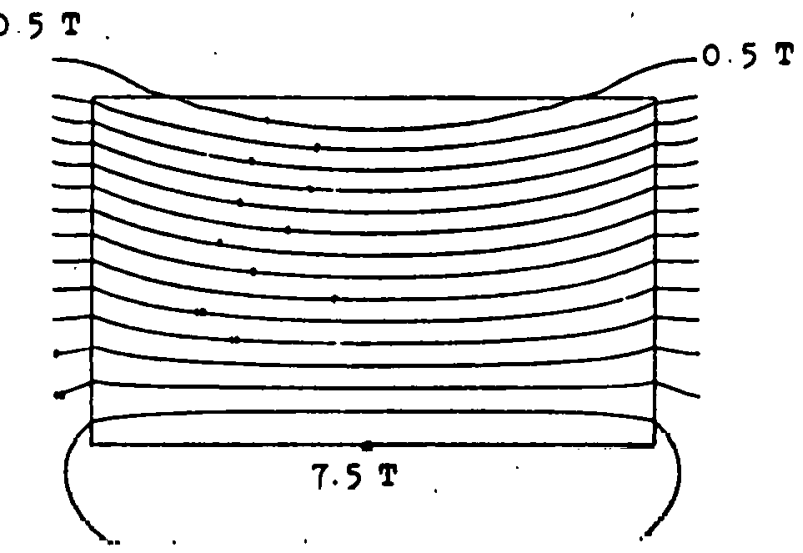

ANI-EFR

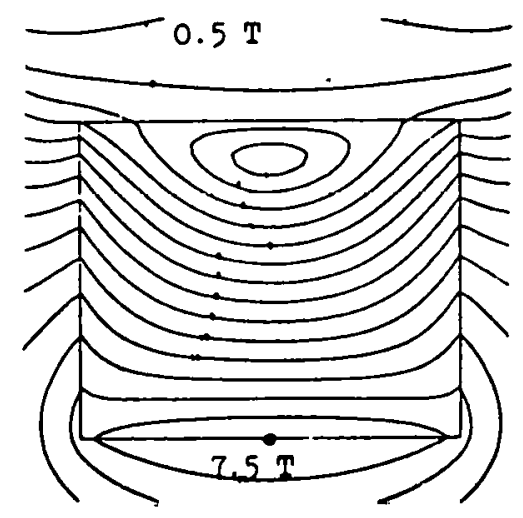

Derated Campect Torus

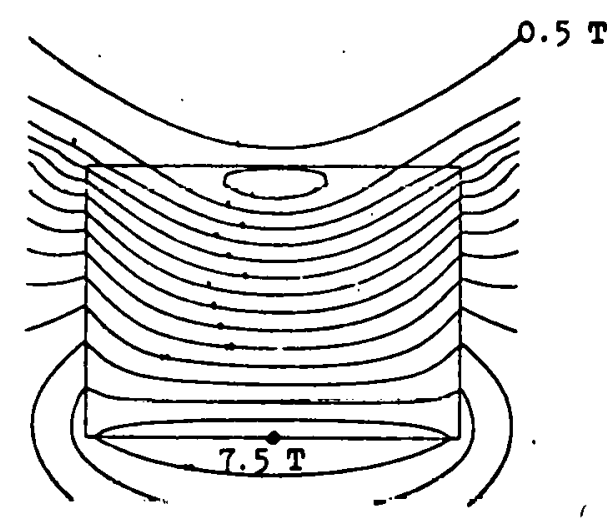

Compact Torus
Contours are at

0.5 Tesla intervalo

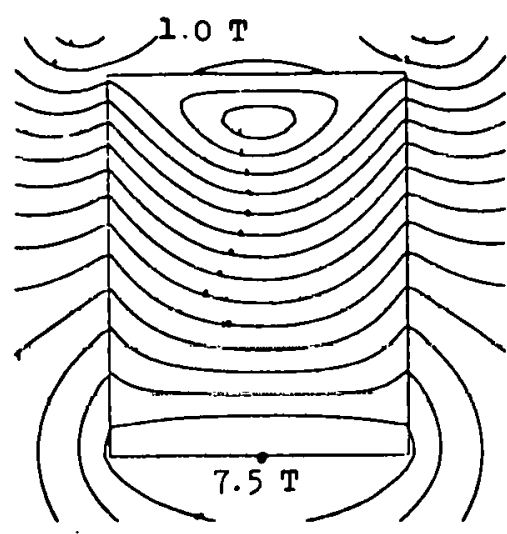

cluster of Identical Collo

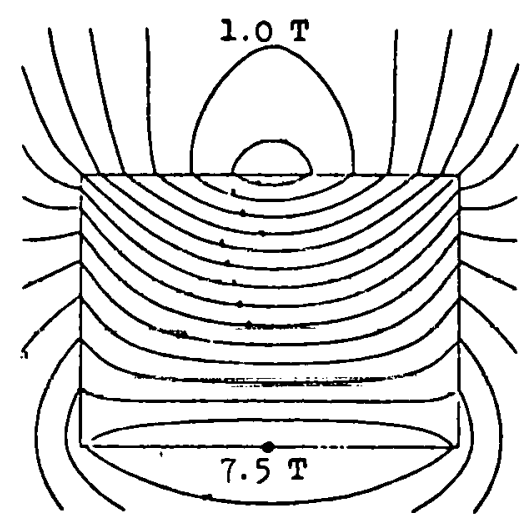

Cluster with Background Co1ly

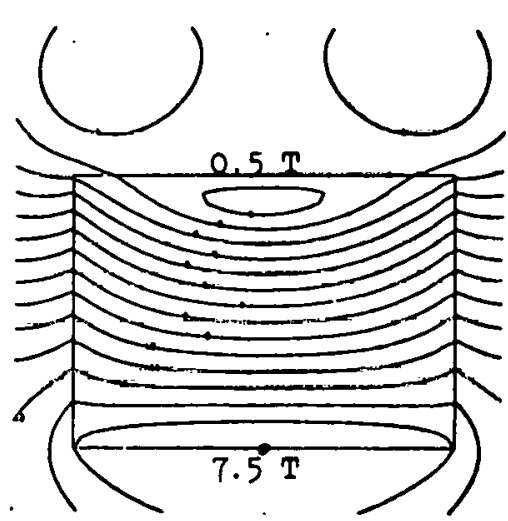

Split Eccentr1c Tést

Fig. 6.6 Magnet Field Distribution in Coll Nose Midplane 

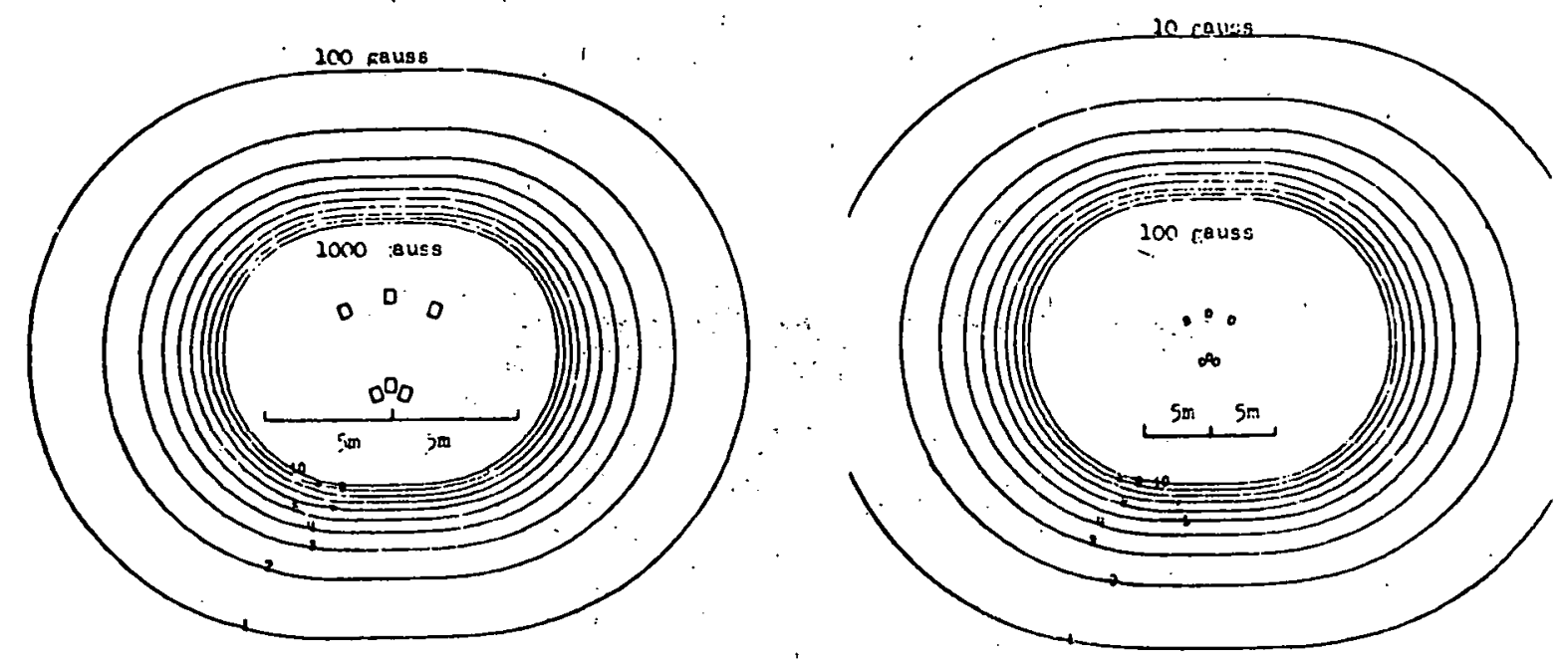

CLUSTER TESTS

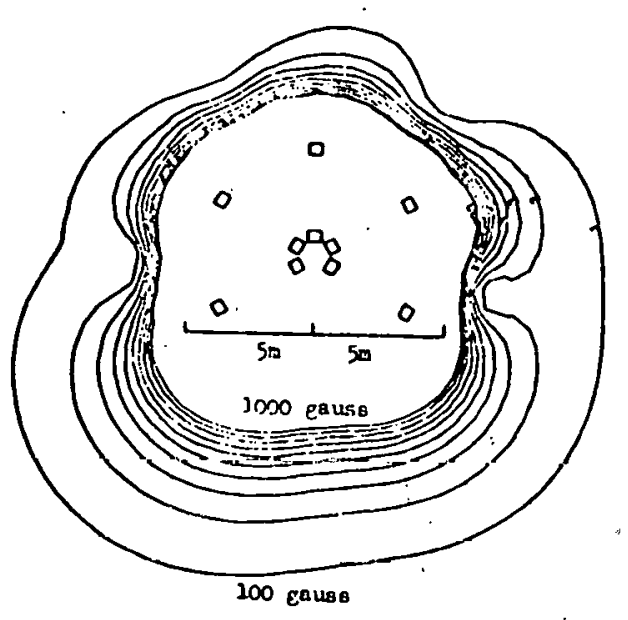

PARTIAL COMPACT TORUS TESTS

Contours at 100 gauss interva 1.8

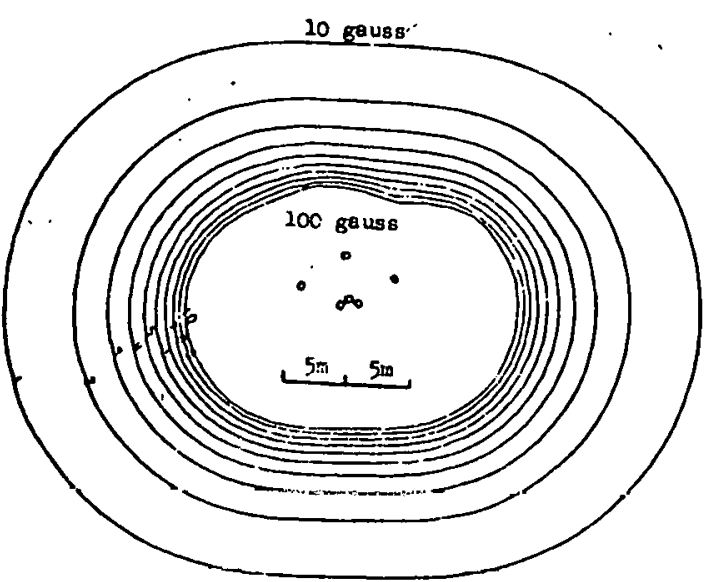

Contours at 10

gauss intervals

Fig. 6.7 Stray Field Distributions 


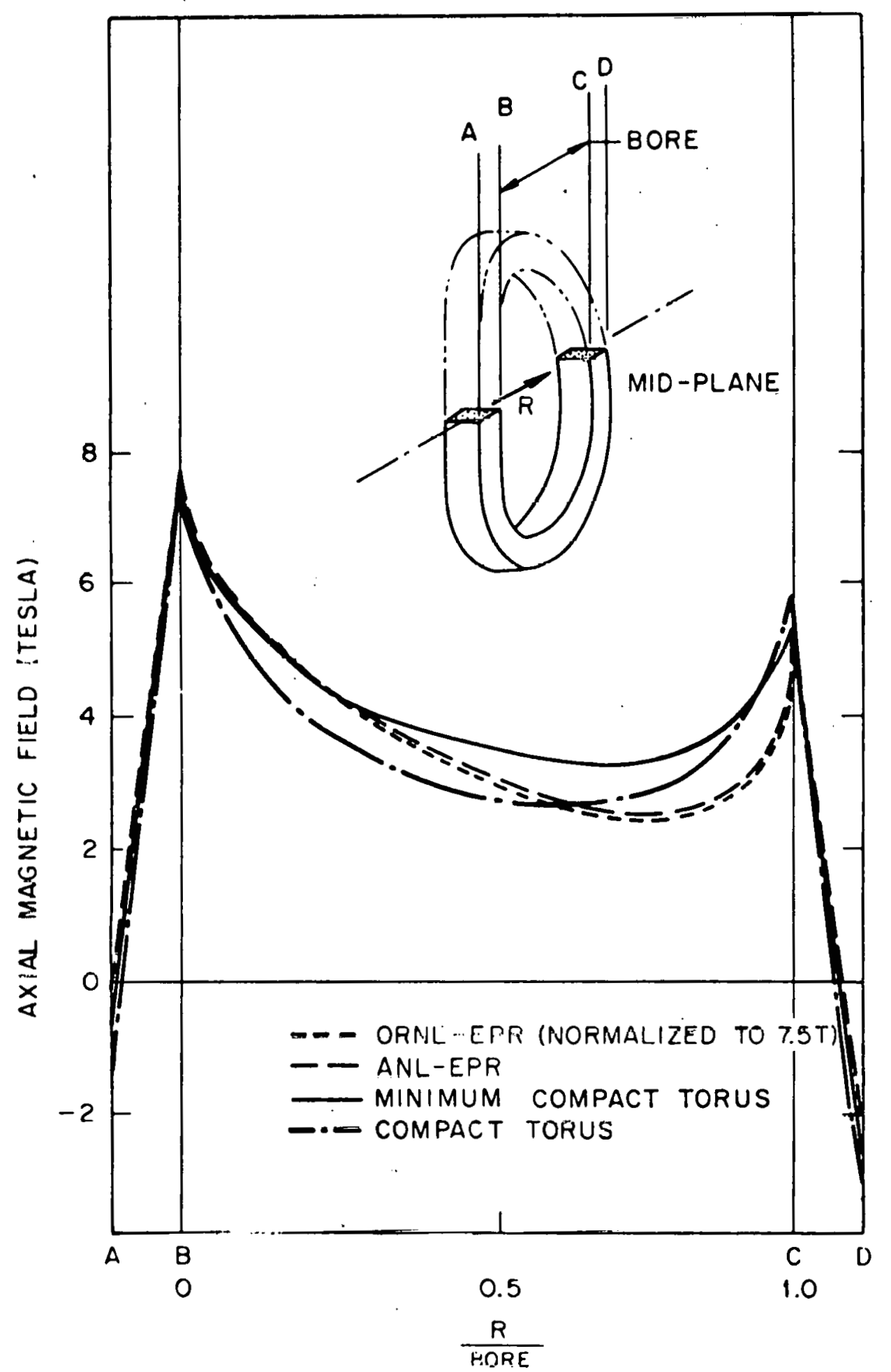

Fig. 6.8 Comparison of Axial Magnet1c Field at Coil Mid-Plane; Compart Tori. 


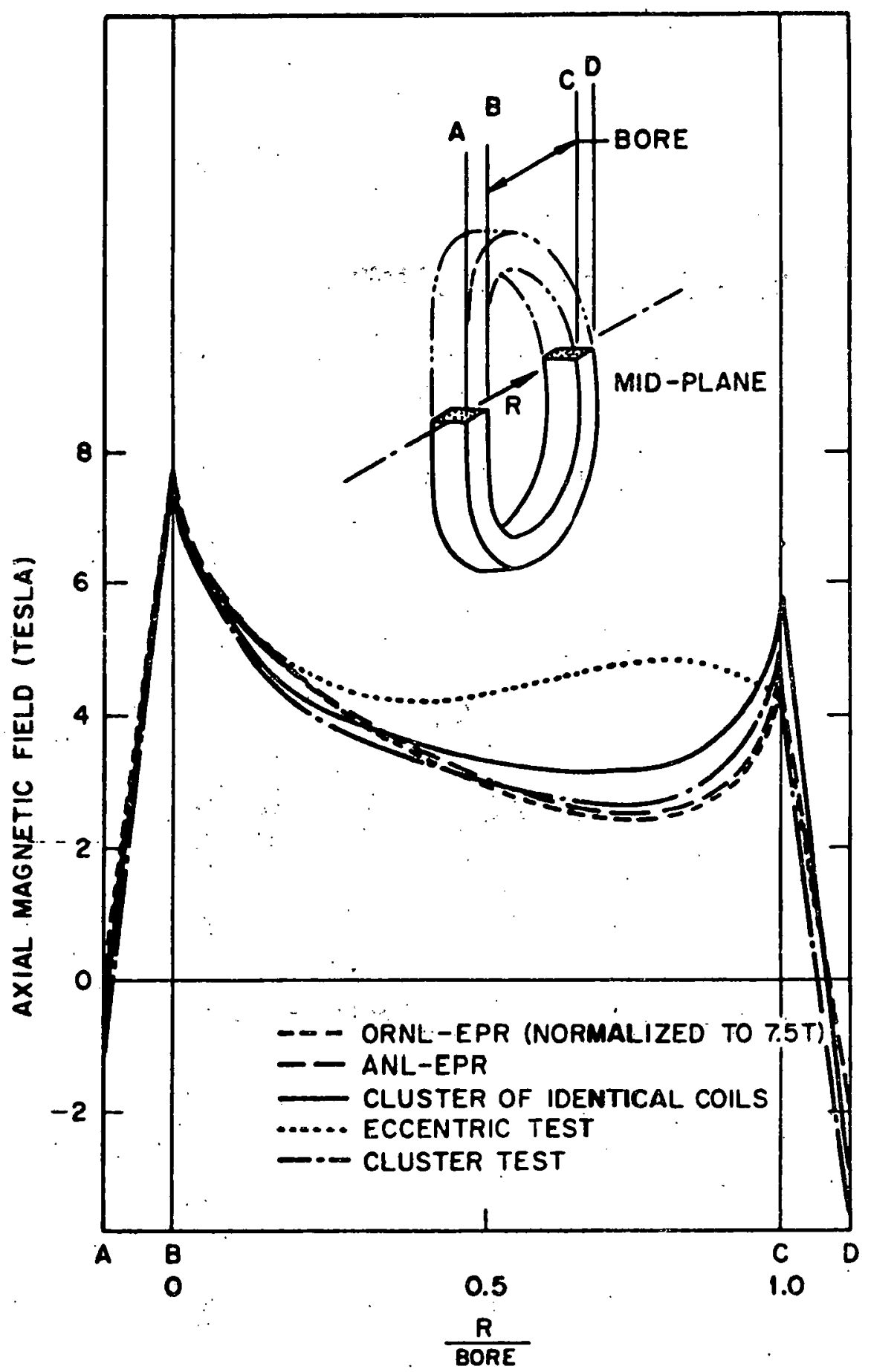

Fig. 6.9 Comparison of Axial Magnetic Field at Cotl Mld-Plane: Three Coll Arrangements 


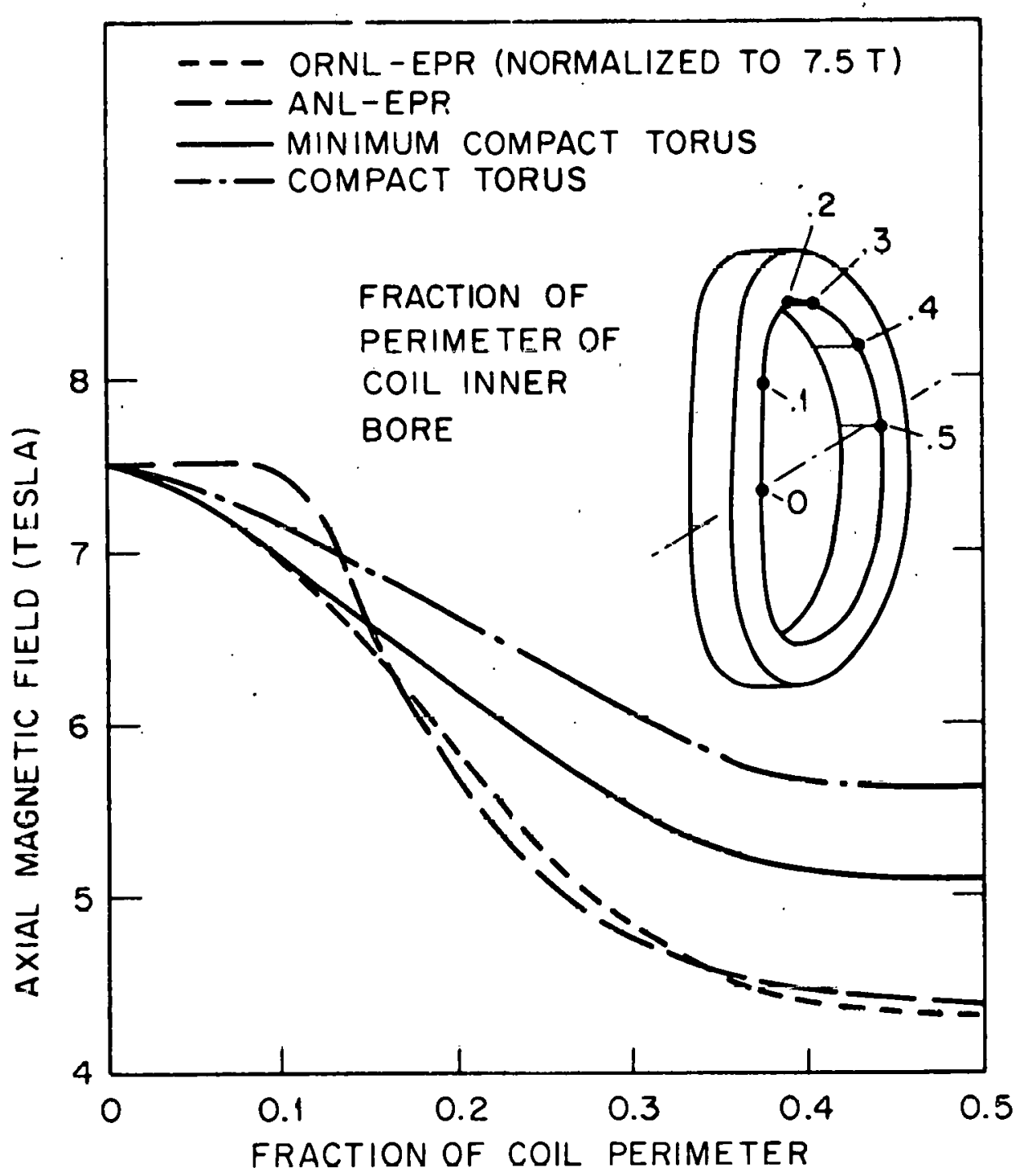

Fig. 6.10 Comparison of Axtal Magnetic Field at Col1 Inner Bore: Compact Tor 1 . 


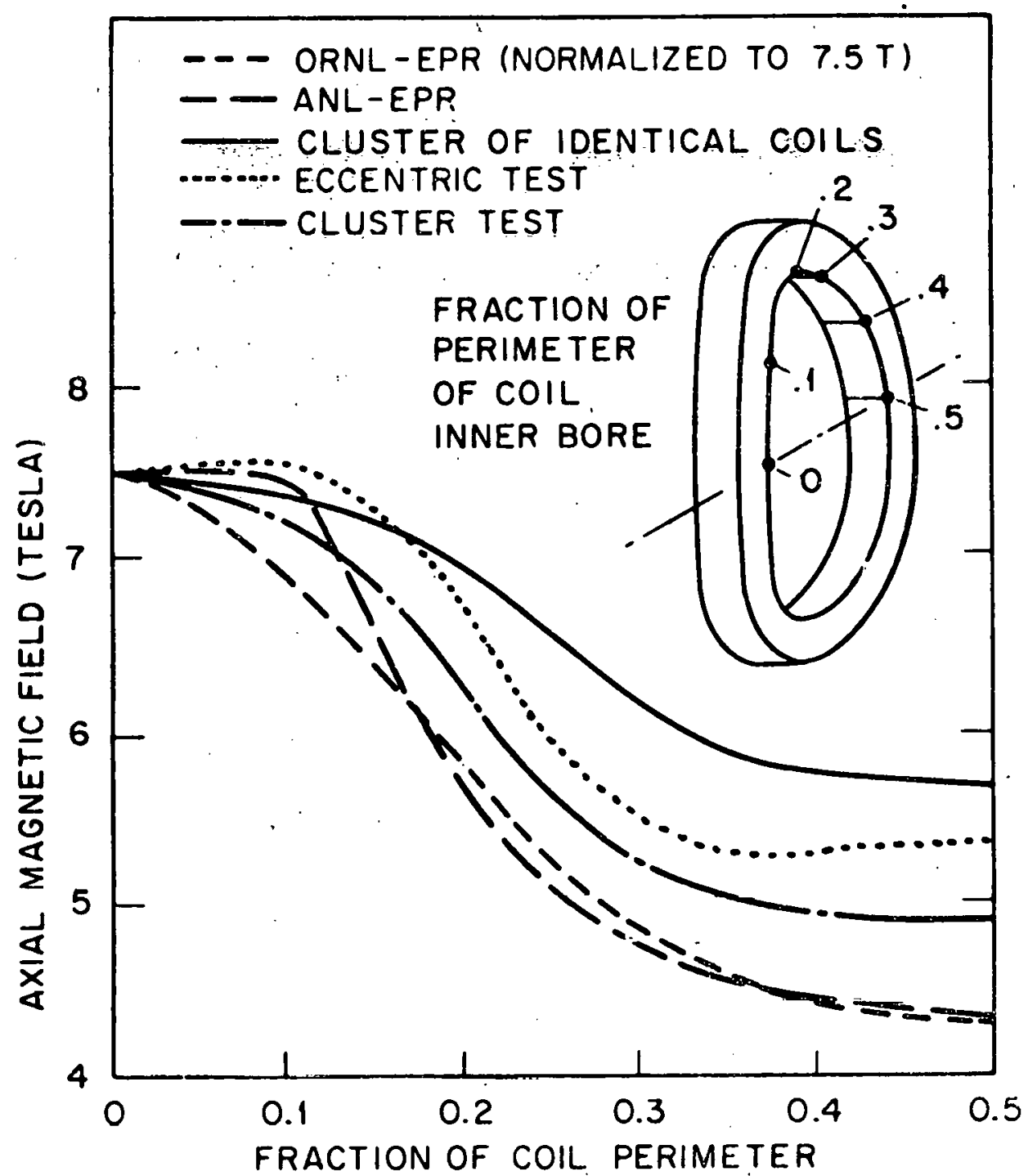

Fig. 6.11 Comparison of Axial Magnetic Field at Coil. Inner Bore: Three Coll Arrangements. 


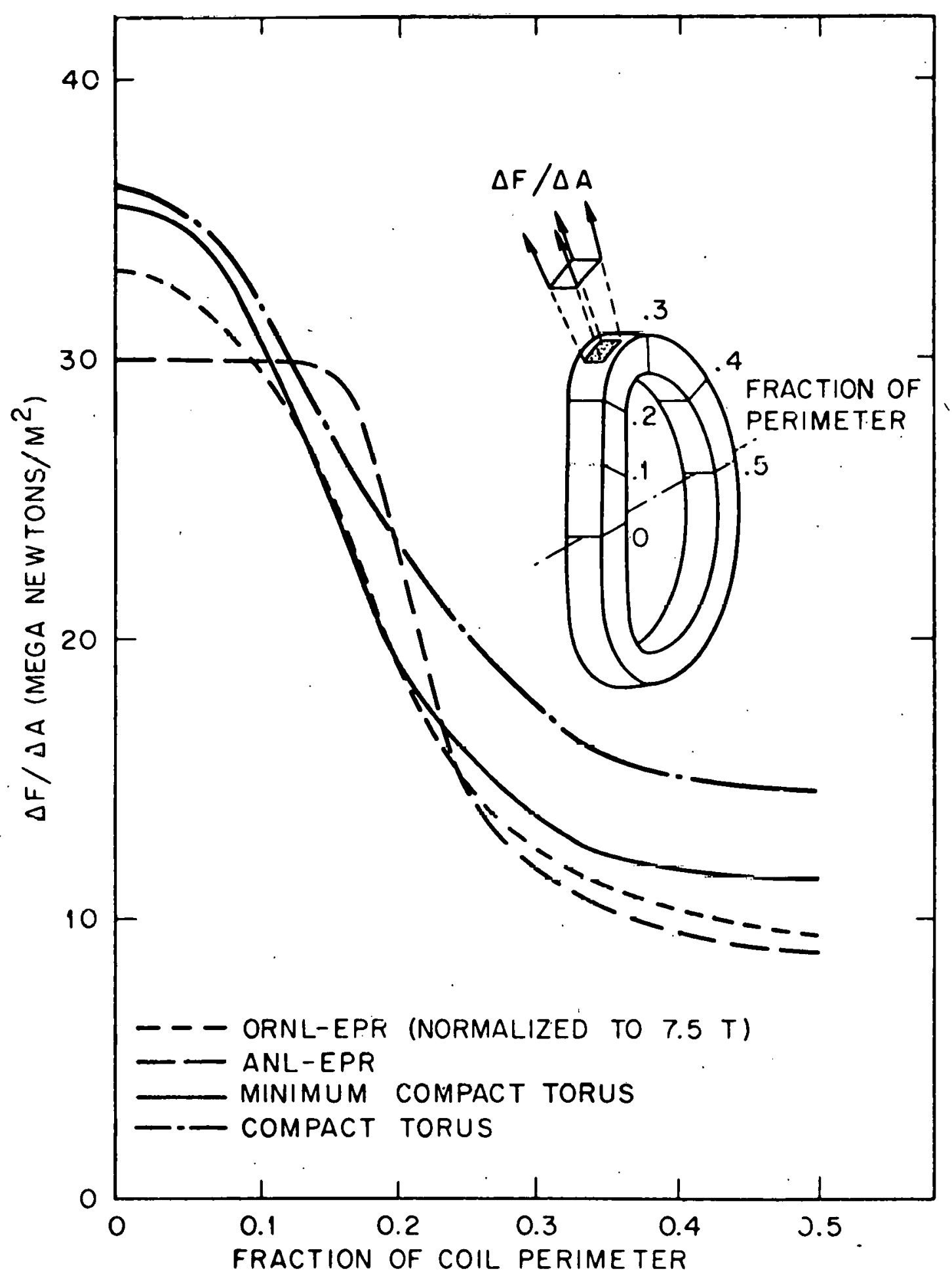

Fig. 6.12 Comparison of In-Plane Force per Unit Winding Area of Coll: Compact Tor1. 


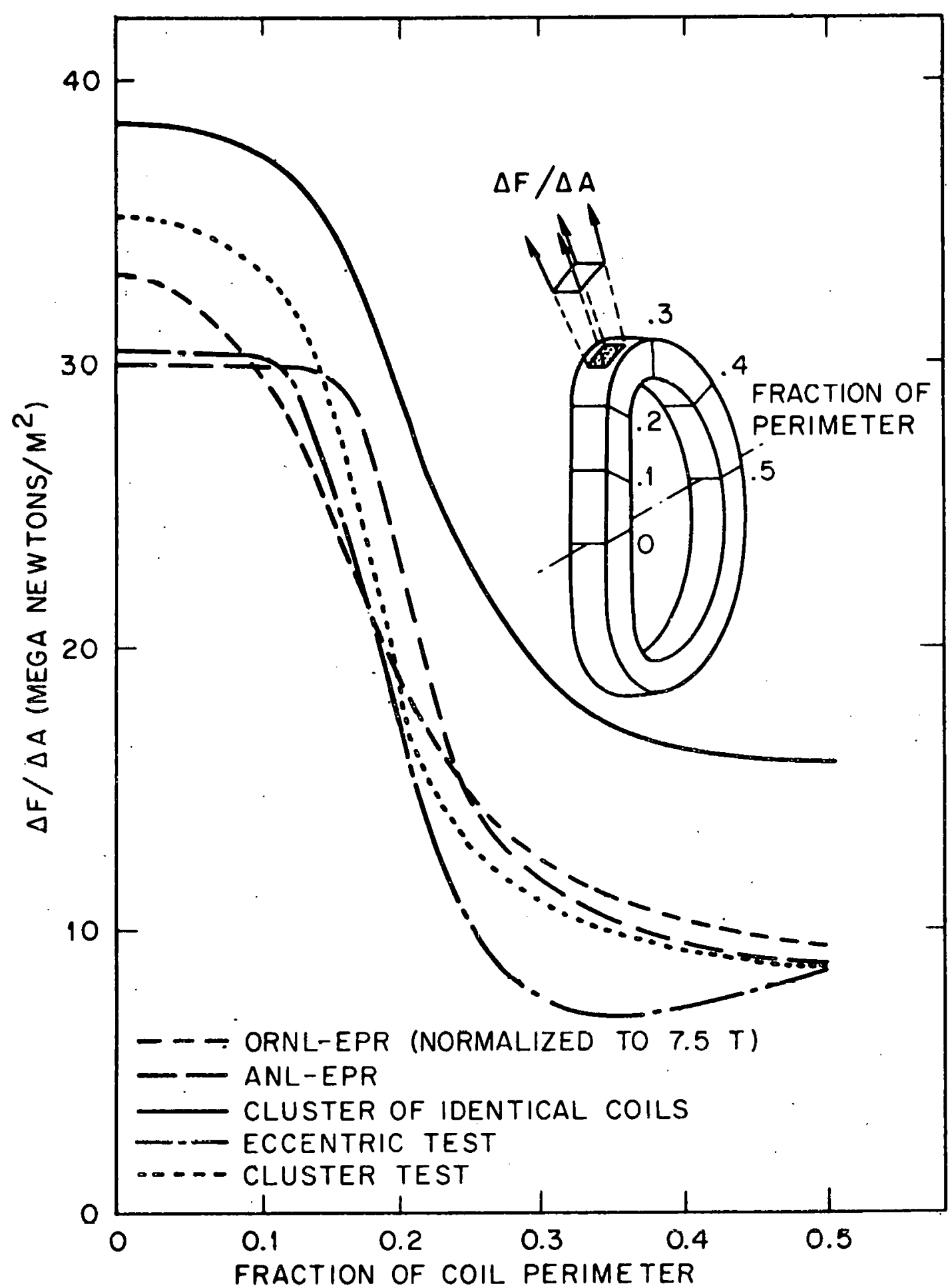

F1g. 6.13 Comparison of In-Plane Force per Unit Winding Area of Coll: Three Coll Arrangements, 


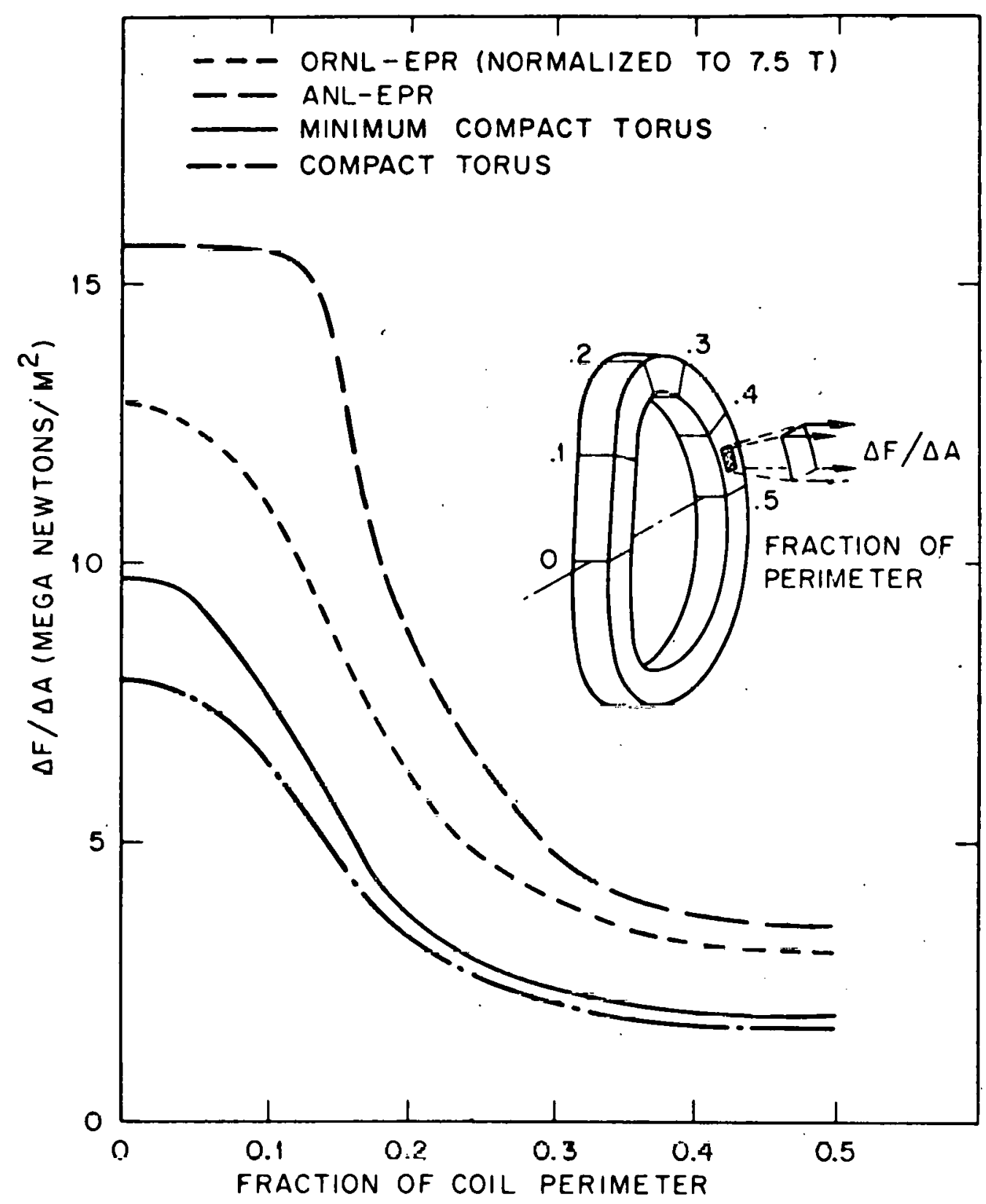

Fig. 6.14 Comparison of Out-of-Plane Force per Unit Winding Area of Coll: Compact Tori. 


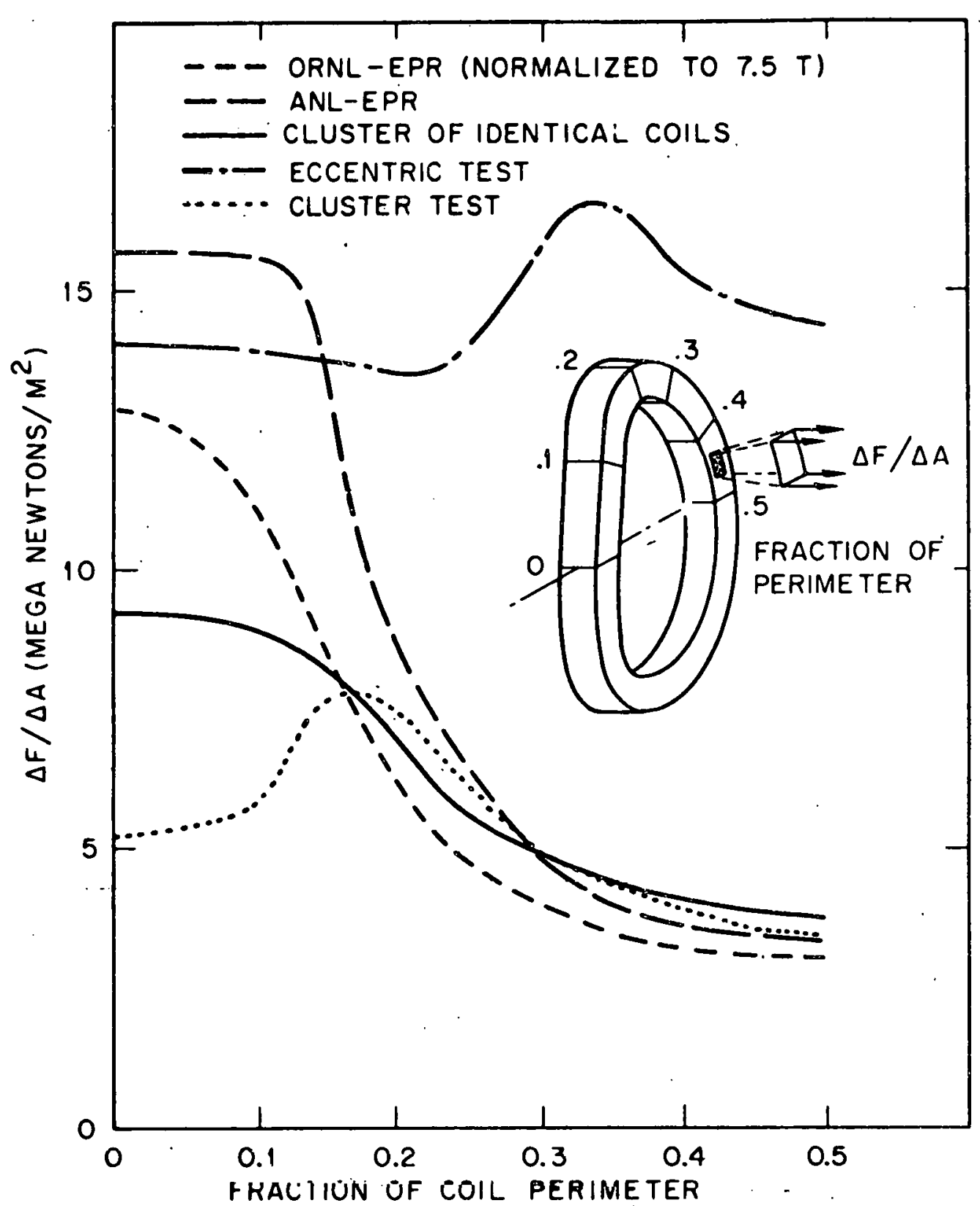

F1g. 6.15 Comparison of Out-of-Plane force per Un1t Winding Area of Coll: Three Coll Arrangements. 


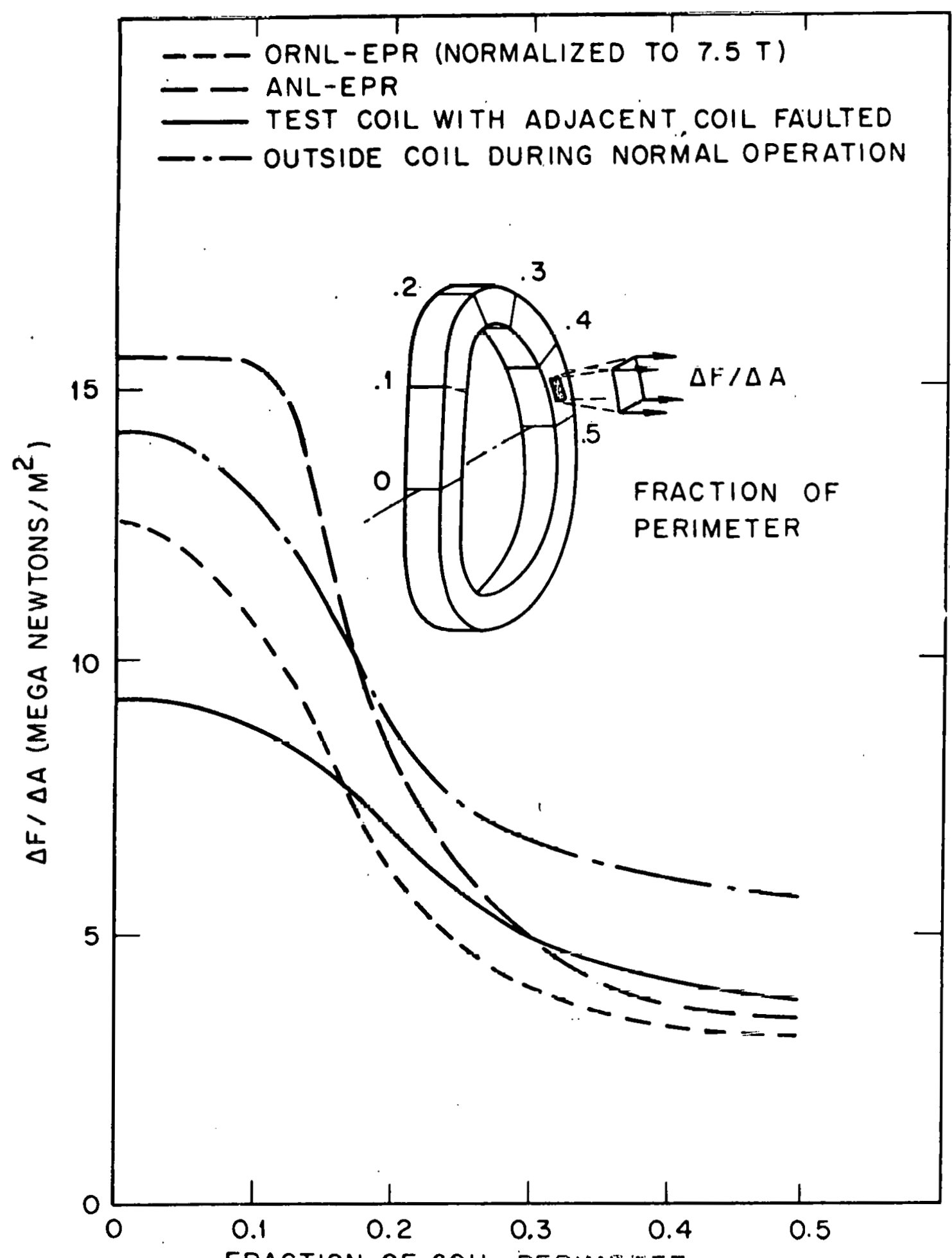

FRACTION OF COIL PERIMETER

Fig. 6.16 Comparison of Out-of-Plane Force per Unit Winding Area of Coll: Cluster of Three Idenelcaj. Coris 
with one or more colls deenergized are higher than in its normal operation, but sti1l lower than for the other kinds of arrangements.

Figures 6.8 and 6.9 show radial profiles of the torotdal field strength across the horizontal midplane of test colls in the various arrangements. Shown for reference are the toroldal field distributions in the ANL and ORNL EPR reference designs. (The distribution in the GA $E P R$ deslgn is not shown because it is practically the same as in the ANL design.) From the standpoint of coll structural deslgn, the field variation around the winding is of greater importance. This is shown in Figs. 6.10 and 6.11 .

The vector product of the toroidal field and the conductor currents are the in-plane forces on the windings. Figures 6.12 and 6.13 compare forces per unit area at the outside of the winding, assuming that none of the force is restratned by the winding, but is transmitted to a surrounding structural hoop. This shows the magnitude of this component of the winding stress-strain problem.

Figures 6.14 and 6.15 show out-of-plane forces on test colls in the varlous arrangements and in the EPR colls for the case in which one adjacent coll is completely deenergized while other coll currents remain constant. In normal operation of the cluster test arrangement, the outside colls are subjected to large out-of-plane loads as shown in Fig. 6.16.

The $T$ arrangement was analyzed by calculating flelds and forces in the test coil, using the computer program BOVAL. Figures 6.17 and 6.18 show the fleld values at the coil mfdplane and the lateral fault load distributions compared with the corresponding distributions of other arrangements. Both T-type conflgurations have a maximum field of 7.2 tesla compared with 7.5 tesla for the other configurations that were evaluated. Table 6.3 compares these two T-type test arrangements and the original GA verefon wth the nther LCP candidates with respect to ampere-meters of conductor required. The values in the table for the two modified test arrangements have been scaled up from the 7.2 tesla values to 7.5 tesla values. 


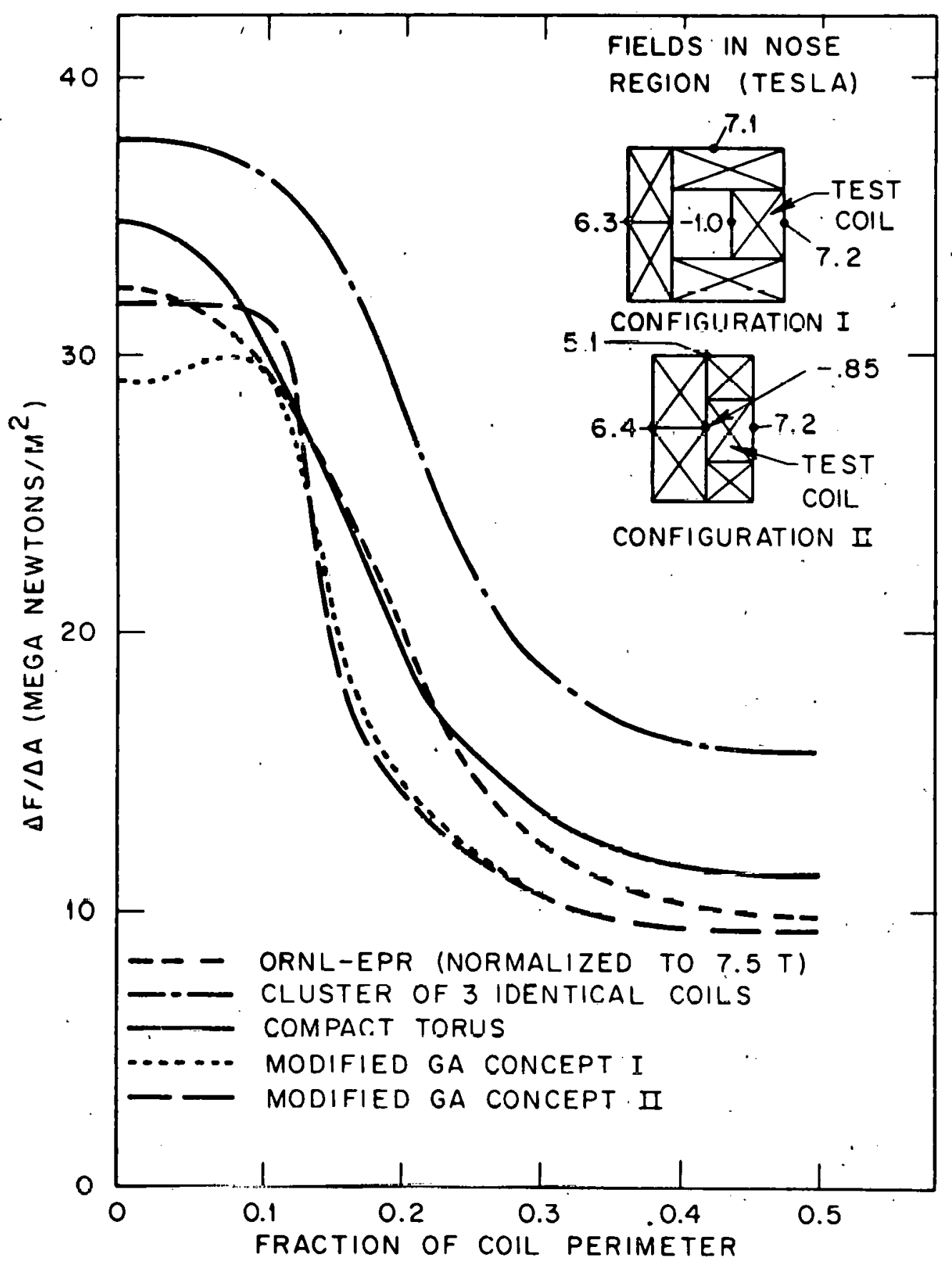

Fig. 6.17 Comparison of In-Plane Force per Unit Winding Area of Co1l: GA Concept. 


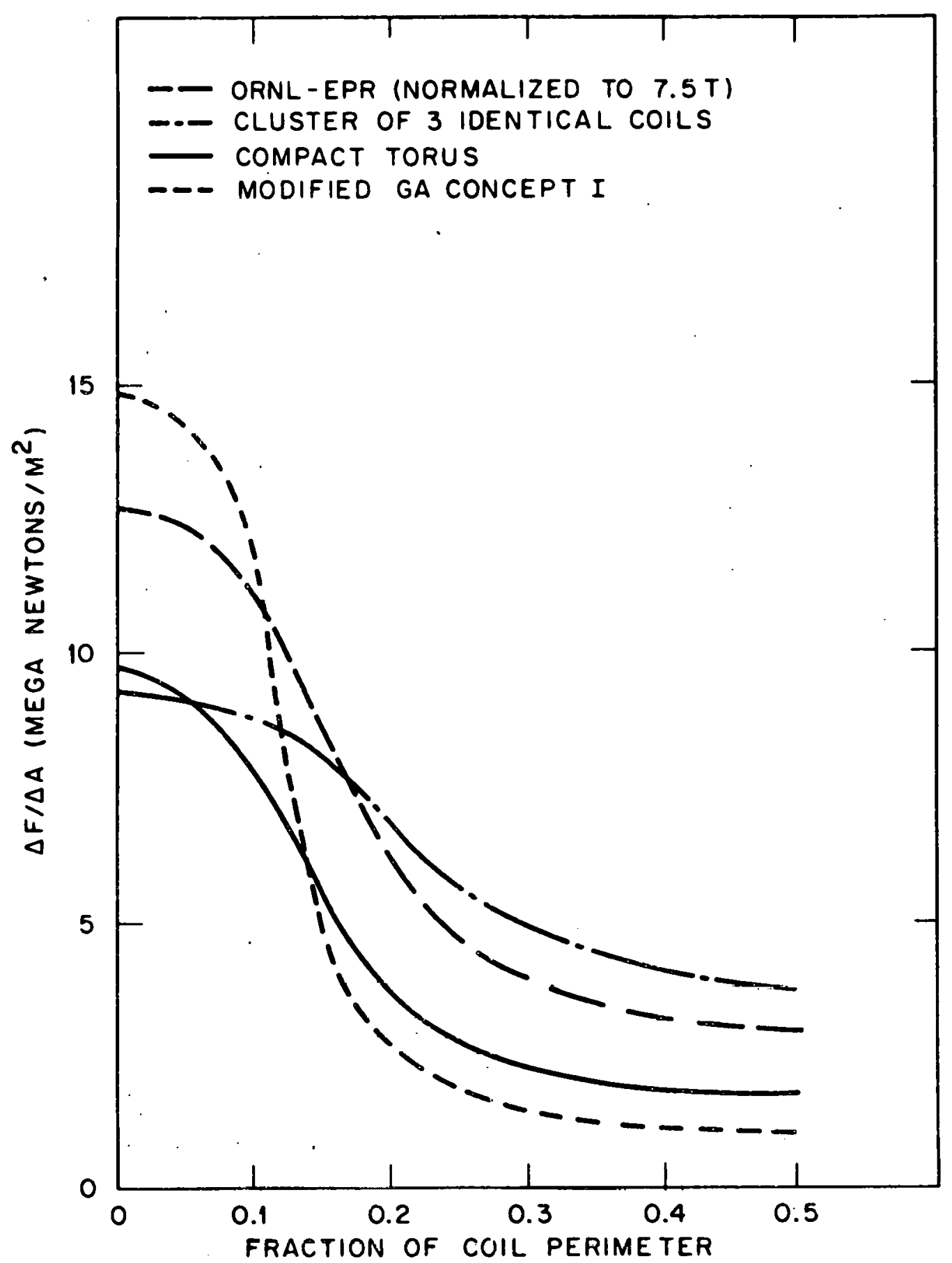

Fig. 6.18 Comparison of Out-of-Plane Force per Unit Winding Area of Coll: GA Concept. 
Table 6.3 Comparison of " $T$ " Arrangements w1th Other Concepts

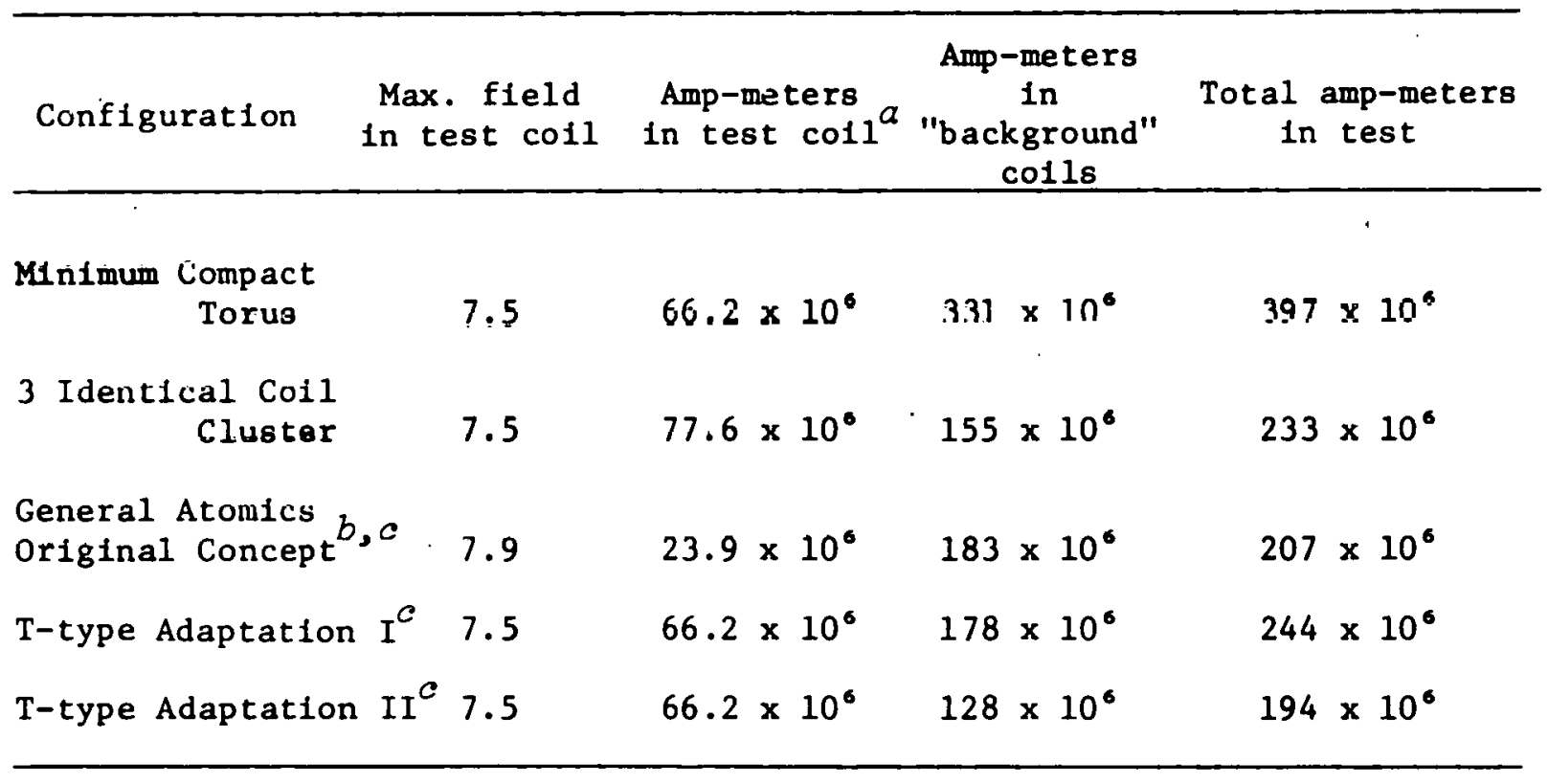

$a_{\mathrm{All}}$ test colls have $3.0 \times 4.5$ meter inner bore.

$b$ Maximum field in the background coll of $9.1 \mathrm{~T}$.

clio space alluwed for coll struçeture. 


\subsection{Vacuum Topology Considerations}

In the design of the LCP test fac1lity, the type of vacuum enclosure that is chosen not only affects the design of auxillary vacuum and cooling systems, but also constrains the range of experiments that can be performed in the facility. The following is a general discussion of factors which. have been considered in deciding which type of vacuum enclosure to recommend.

Two systems were considered: (1) a large, cylindrical vacuum vessel (bell far) which would enclose the entire assembly of colls and structure, and (2) a form-fitting dewar consisting of a small central vacuum cylinder housing the noses of all the colls with individual coll dewars extending from it. The factors involved in the comparison include fabrication, Interfaces and penetrations, cost, pumpdown and cooling tradeoffs, adaptability to experiment variations, and relevance to operational tokamak Installa tions.

Fabrication - The detalled design and fabrication of a bell far enclosure would be very similar to that of numerous vacuum chambers that have been bullt for the aerospace industry and others. The bell far could therefore be designed and constructed with a minimal amount of risk or delay. A fitted dewar, on the other hand, would require innovative design and possibly some new construction techniques.

Interfaces - Plumbing, thermal 1solation of supports, and vessel penetrations would all be simpler in a bell far design. The entire coil array and its assoclated structural support system would be within the bell jar. Therefore, interfaces for instrumentation and control leads can be designed as typical vacuum wall penetrations entering at just a few selected points without constraints due to interactions with coll designs. Thermal isolation can also be accomplished efficiently by groupling items to minimize heat leaks.

With a fitted dewar, special thermal isolation supports would be required to transition from the colls and support structure to an external foundation. Also, plumbing and diagnostics penetrations could be expected to be more numerous. 
Cost - Preliminary conceptual design studies have been made and the fabrication tasks sketched out to provide an approximate estimate of costs of material and labor to construct a bell far or a fitted dewar. In the estimates, the increased cost of labor due to complicated sealing surfaces and contours in the fitted dewar make up for larger material costs of the bell jar. As a result the estimated total costs are within 20 percent of each other. A considerable degree of uncertalnty exists in the estimates for the fltted dewar because they are based purely on 11mted conceptual studies of a complicated system and might be expected to increase when the design is more fully engineered. The bell jar costs, on the other hand are directly related to cost data recelved in response to preliminary inquiries to industry. The conclusion is that because of uncertainty in the cost estimates, no significant cost advantage can be ascribed to elther the bell jar or the dewar.

Pumpdown - The pumpdown volume in a bell jar is estimated to be about three times that of the fitted dewar. However, the bell far will have substantially better conductance than the dewar and will require less than three times the pumping capacity. The surface area for outgassing and thermal (radiation cooling) considerations is approximately the same in both cases. Pumpdown times and cold wall requirements are essentially equal for the two concepts. The physical building space required is also nearly identical for both syscems.

Adaptability - The dewar system does not easlly lend 1tse1f to variations in coll shape, size, or test arrangements. Modifications to the coil design or test arrangement would have to consider dewar restrictions rather than only coll related options. In a bell far, various test arrangements and coil shapes could more easily be accommodated. For example, a bell jar designed for a compact torus could accommodate any of the other arrangements.

Relevance - Conceptual studies have not yet firmly established the optimum boundaries of the vacuum enclosure in a tokamak reactor. It is already clear, however, that a simple, all-encompassing bell far will not be suitable. Separate dewars, closely fitted to each coil are also unlikely. Most probably the reactor vacuum enclosure will house the toroldal 
field colls, their intercoll structure and hellum piping, and at least some parts of the ohmic heating coll system. The fitted dewar in a large Co11 Test may not model a reactor enclosure in all regards, but clearly many more of the engineering design problems of this type of enclosure would be encountered than if a bell far were used. Because the solutions of these problems would be relevant to the design of a reactor, the fitted dewar would offer more benefits in this particular regard.

Conclusions - The use of a fitted dewar for vacuum enclosure entails more design and fabrication problems than does a bell jar, with increased risk of cost overruns and delays. The testing program can be more quickly accomplished in a bell jar, especially if the test arrangement requires shifting the positions of colls. The bell far would allow greater flexibility for different sizes of colls or arrangements. On the other hand, solutions of the englneering problems of the fitted dewar would be of greater benefit to reactor conceptual design.

\subsection{Discussion and Ratings}

The ratings of the different test arrangements against each criterion were arrived at by considering the data shown in section 6.3 in light of the basic significance of the criterion as presented in Chapter 5. On each criterion the best arrangement in that particular regard was awarded a rating of 10 . For criteria where there is little practical difference among the arrangements, the range of ratings was rather narrow. For other criteria, arrangements with substantially poorer performance were rated as low as 3 .

Table 6.4 sumarizes the ratings and scores of each arrangement. Dlscussion of the conslderations of the three-person rating panel follows.

Fleld Distribution in Windings - The field strength profiles through the windings at the coll midplane, shown in F1gs. 6.6, 6.8, and 6.9, reveal field reversals both in the EPR cases and in all the test arrangements. The magnitude of the reversed fleld is greater in the test arrangements than in the EPR. 
Table 6.4 Ratings and Scores

\begin{tabular}{|c|c|c|c|c|c|c|c|c|c|c|c|c|}
\hline \multirow{2}{*}{\multicolumn{2}{|c|}{ Critertion }} & \multicolumn{7}{|c|}{ Rating } & \multicolumn{3}{|c|}{ Score } & \multirow[b]{2}{*}{$\underline{E}$} \\
\hline & & A & B & c 1 & D & $\mathbf{E}$ & Max. & A & B & c & D & \\
\hline \multicolumn{13}{|c|}{ Benef1ts } \\
\hline \multicolumn{13}{|c|}{ 1. $\mathrm{c}$} \\
\hline & 1.1 Field distribution in winding & 10 & 9 & 10 & 8 & 9 & 70 & 70 & 63 & 70 & 56 & 63 \\
\hline & 1.2 Field distribution around bore & 8 & 9 & 8 & 10 & 7 & 80 & 64 & 72 & 64 & 80 & 56 \\
\hline & 1.3 Radial pressure 1n winding & 8 & 9 & 8 & 10 & 5 & 100 & 80 & 90 & 80 & 100 & so \\
\hline & 1.4 Out-of-plane forces & 8 & 9 & 10 & 3 & 4 & 90 & 72 & 81 & 90 & 27 & 36 \\
\hline & 1.5 Total stored energy & 10 & 10 & 6 & 5 & 6 & 60 & 60 & 60 & 36 & 30 & 36 \\
\hline & 1.6 Un1t stored energy & 7 & 7 & 8 & & 10 & 80 & 56 & 56 & 64 & 64 & 80 \\
\hline & 1.7 Pulsed E1elds & 10 & 10 & 8 & 8 & 5 & 70 & 70 & 70 & 56 & 56 & :e \\
\hline \multicolumn{13}{|c|}{ 2. Co1l Test Versat1lity } \\
\hline & 2.1 Capabillty for higher fleld & 8 & 7 & 9 & 10 & 10 & 80 & 64 & 56 & 72 & 80 & 80 \\
\hline & 2.2 Adaptab1l1ty & 9 & 9 & 10 & 10 & 5 & 60 & 54 & 54 & 60 & 60 & 30 \\
\hline \multirow[t]{2}{*}{3.} & Demonstration Value & 10 & 10 & 8 & 7 & 5 & 90 & 90 & 90 & 72 & 63 & 45 \\
\hline & Total & & & & & & 780 & 680 & 692 & 664 & 616 & 511 \\
\hline
\end{tabular}

\section{Costs}

4. Program Costs and Schedule

4.1 Scheduled test completion

$\begin{array}{rrrrrrrrrrr}10 & 10 & 10 & 6 & 6 & 60 & 60 & 60 & 60 & 36 & 36 \\ 8 & 8 & 10 & 4 & 5 & 40 & 32 & 32 & 40 & 20 & 20 \\ 5 & 6 & 10 & 0 & 0 & 100 & 30 & 60 & 100 & 80 & 80 \\ 10 & 10 & 10 & 6 & 6 & 50 & 50 & 50 & 50 & 30 & 30 \\ 9 & 10 & 9 & 6 & 6 & 40 & 36 & 40 & 36 & 24 & 24\end{array}$

5. Program Risks

5.1 Impact of non-performance

$\begin{array}{lllllllllll}10 & 5 & 10 & 8 & 8 & 70 & 70 & 35 & 70 & 56 & 56\end{array}$

5.2 Impact of fabrication delays

$\begin{array}{lllllllllll}10 & 9 & 6 & 9 & 9 & 80 & 80 & 72 & 48 & 72 & 72\end{array}$

6. Fac1lity Problems

6.1 Stray flelds

6.2 Co11 weight

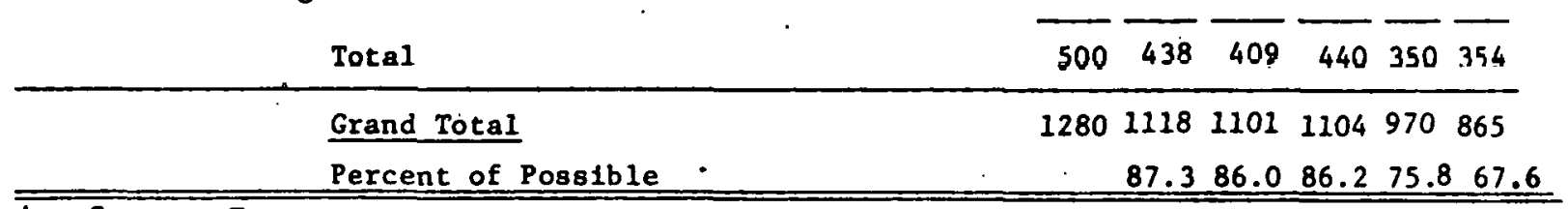

A. Compact Torus

B. Minimum Compact Torus

C. Cluster of Identical Coils

D. Cluster with Background Colls

B. Split Eccentric 
Examination of Fig. 6.6 shows that the fleld distribution in the nose region of the test coll in any of Cases $A-E$ is qualitatively quite similar to that in the EPR colls. The principal difference is that the gradients of the flelds are oriented somewhat differently near the sides of the windings. Associated with this is a larger radial component of the field in these regions. Because some flat conductors have a lower critical current in the presence of a large field component perpendicular to the face, this characteristic of the test colls results in a somewhat more stringent condition than will be encountered in the EPR.

It appears that any of arrangements $A-E$ would satisfactorily meet this criterion, little practical difference among them.

Field Distribution Around Bore - In none of the test arrangements is the ratio of maximum to minimum fields as high as in the EPR. Higher ratios are generally preferable, but the rating of arrangement $E$ was penalized because the shape of the curve (Fig. 6.11) is less like the EPR distributions.

Radial Pressure in Winding - From the standpoint of testing the winding in radial compression, the higher the peak equivalent, pressure shown in Figs. 6.12 and 6.13 , the better. The significance from the standpoint of the structure is related to both the magnitude and the shape. Arrangement $E$ is perceptibly poorer in both regards.

Out-of-Plane Forces - This criterion relates both to testing the structure for out-of-plane bending and to observing the effects of lateral forces in the windings. In the ratings the former was considered more important. Thus Arrangement E, although it offers the highest lateral pressure, is rated low because the distribution around the coil is markedly different from that in the EPR tori. Arrangement $D$ is also rated low because the shape is only slightly better and the pressure is lower. Arrangement $C$ was given top rating because the out-of-plane forces on the two outside coils, which are also test colls in this case, are very close to the equivalent pressure and distribution of forces on an EPR coil when an adjacent coil is deenergized. (See Fig. 6.16.)

Total Stored Energy - The ratings here are proportional to the magnitudes of the stored energy. (See Table 6.5.) 
Table 6.5 Stored Energy Comparison

\begin{tabular}{|c|c|c|}
\hline & $\begin{array}{c}\text { Total stored energy } \\
\text { of array } \\
\text { (Mega Joules) }\end{array}$ & $\begin{array}{c}\text { Energy per unit } \\
\text { volume of winding } \\
\text { in test coll } \\
\left(\mathrm{MJ} / \mathrm{m}^{2}\right)\end{array}$ \\
\hline $\begin{array}{l}\text { OKNL-EPR (ocaled to } \\
7.5 \text { tesla) }\end{array}$ & 14,000 & 73 \\
\hline ANL-ERR & 15,000 & 67 \\
\hline A. Compact Torus & 670 & 48 \\
\hline B. Minimum Compact Torus & 700 & 44 \\
\hline $\begin{array}{l}\text { C. Cluster of three Identical } \\
\text { colls }\end{array}$ & 390 & 55 \\
\hline $\begin{array}{l}\text { D. Cluster w1th background } \\
\text { cot } 1 \mathrm{~s}\end{array}$ & 310 & 52 \\
\hline E. Split eccentric test & 420 & 67 \\
\hline
\end{tabular}

All test colls assumed to have $3.0 \times 4.5 \mathrm{~m}$ 1nner bore. 
Unit Stored Energy - These ratings are also proportional to the magnitudes. (See Table 6.5.)

Pulsed Fields - It 18 an essential requirement that the test colls be subjected to pulsed fields similar to those in the EPR, and all five arrangements permit this. The difficulty of providing for the pulsed flelds differs among the arrangements, however. Because conceptual design has not been done in sufficient detail to permit determination of the impact on project cost, the same allowance for providing pulsed fields is included in the approximate cost estimates for all arrangements. The ratings on this criterion therefore reflect basically the relative freedom of the test coll bores from special structure that would interfere with installation of the pulsed windings.

Capabllity for Higher Field - All five arrangements can accomodate test coils in which the peak fleld reaches 11 tesla while the peak field in the other coils is 8 tesla or less. As shown in Table 6.6, however, there are considerable differences in the conditions in the other coils and the amount of conductor required for the high field test coll. The minimum compact torus was rated lowest because the other coils must operate at the highest current density and field $\left(2500 \mathrm{~A} / \mathrm{cm}^{2}\right.$ and 8.0 tesla) in order to achieve the desired 11 tesla in the test coil. The ratings of arrangement $A$ and, to a lesser extent, that of $C$ were penalized for the greater amount of conductor required.

Adaptablitity - The layouts of the clusters and tori are quite compatible with testing individual dewars modeling those in a tokamak; the split eccentric test is not. On the more important point of testing various intercoll structures, the clusters are best because the angle between coils is nearest that in a tokamak. The split eccentric, with parallel coils, is poorest.

Demonstration Value - Any of the arrangements would demonstrate the successful fabrication and reliable operation of a superconducting magnet system exceeding in many 1mportant regards anything yet built. Those arrangements for which two coils of a single design are produced in sequence will provide information on reproducibility and the improvements due to 
Table 6.6 Comparison of Higher Field Test Coil Capability

(11.0 tesla test coil parameters)

\begin{tabular}{|c|c|c|c|c|c|c|c|c|}
\hline & $a_{\mathbf{l}}$ & $a_{2}$ & $2 b$ & $\begin{array}{c}\text { Current } \\
\text { censity } \\
\text { of test coil } \\
\end{array}$ & $\begin{array}{l}\text { Ampere } \\
\text { turns }\end{array}$ & $\begin{array}{l}\text { Ampere } \\
\text { meters }\end{array}$ & $\begin{array}{c}\text { Current } \\
\text { density of } \\
\text { background } \\
\text { coils } \\
\end{array}$ & $\begin{array}{l}\text { Maximum } \\
\text { field in } \\
\text { background } \\
\text { coils } \\
(\mathrm{T})\end{array}$ \\
\hline A. Compact Torus & 1.00 & 1.948 & .534 & 2500 & $12.7 \times 10^{6}$ & $149 \times 10^{6}$ & 2000 & 7.1 \\
\hline B. Minimum Compact Tor & .98 & 1.883 & .524 & 2500 & $11.8 \times 10^{6}$ & $135 \times 10^{6}$ & 2500 & 8.0 \\
\hline $\begin{array}{l}\text { C. Cluster of three } \\
\text { identical coils }\end{array}$ & $\begin{array}{l}0.95 \\
1.05\end{array}$ & $\begin{array}{l}2.04 \\
2.04\end{array}$ & $\begin{array}{l}.42 \\
.42\end{array}$ & $\begin{array}{l}250 \mathrm{C} \\
2500\end{array}$ & $\begin{array}{l}11.4 \times 10^{6} \\
10.4 \times 10^{6}\end{array}$ & $\begin{array}{l}135 \times 10^{6} \\
128 \times 10^{6}\end{array}$ & $\begin{array}{l}2000 \\
2500\end{array}$ & $\begin{array}{l}5.9 \\
7.1\end{array}$ \\
\hline $\begin{array}{l}\text { D. Cluster test with } \\
\text { background coils }\end{array}$ & 1.05 & 1.883 & .524 & 2500 & $10.9 \times 10^{6}$ & $130 \times 10^{6}$ & 2000 & 5.2 \\
\hline $\begin{array}{l}\text { E. Eccentric test with } \\
\text { baskground coils }\end{array}$ & 1.10 & 1.883 & .524 & 2500 & $10.3 \times 10^{6}$ & $123 \times 10^{6}$ & 2000 & 5.4 \\
\hline
\end{tabular}


learning. This 18 a plus for the torl and, to a lesser extent, for arrangements $D$ and $E$ which each use two background coils.

As an easily recognizable demonstration of progress in fusion power development, the value of test operations will depend on how closely the essential features of the system approach those of a tokamak reactor. The full torus would seem most like a complete tokamak magnet, although the intercoil angle in the clusters is more representative and the cluster of identical colls thus resembles a sector of a toroidal field magnet. Reliance upon background colls, which run at lower current density than a single test coll, is felt to detract. The split eccentric test is rated lowest because its configuration is least like that of a tokamak magnet.

Schedule - Presumably the delivery date of the first coils would be the same in any case. Test program schedules were laid out in order to estimate times from start of coil installation to the two milestones of completion of full-field testing on one test coll and completion of all testing on three test coils. All necessary steps, such as changing the center coil in the three-coll arrangements, were included in the time11nes.

On criterion 4.1 , arrangements $A, B$, and $C$ all received top rating, since completion dates were all within one month of each other. (Fullfleld testing starts sooner with $C$ but takes longer because of the necessity of shifting coils.) Test completion dates for $D$ and $E$ are 8 to 9 months later, reflecting the time required to fabricate the second background coll on the same line as the first. (The delivery date of the last coil is the same as for the the 6-coll tor1, but the testing takes longer.) These two were rated at 6 .

The cluster of identical colls (arrangement $C$ ) promises the earliest completion date for full-field testing of a single coll and therefore received top rating on criterion 4.2. Because of the delay for the sequentially produced background coils, the first full-field test data from arrangements $\mathrm{D}$ and $\mathrm{E}$ would be $8-9$ months later, so they were rated considerably lower. The torl were rated at 8 because they can provide partialfield test data from three different test coils at about the same time as full-fleld data from one coll in arrangement $C$. (Substantial fields and forces can be obtalned with only three of the six coils installed in the torus framework.) 
Estimated Program Cost - Clearly the lower the better and the lowest rates a 10. The question of how low to rate the higher cost arrangements, on the other hand, must be answered in light of one's perception of the feasibility of increased funding. If several arrangements are at least acceptable from the technical standpoint, several million dollars difference in cost could be regarded not merely as penalizing but as absolutely prohibiting the higher cost alternatives. We assimed that any of the five could be funded and arbitrarily assigned a rating of 5 to the most expensive.

Non-Relevant Colls - Arrangements $D$ and $E$ must be penalized here, but since even the background colls have substantial value in advancing the technology, a rating of 6 was awarded.

Conductor Production Rate - The required production rate of 15 tons/ month for $D$ and $E$, while practical, will impose much more strain on capabilities than the 9 tons/month for Arrangement B. A rating of 5 was therefore assigned to the highest rates.

Impact of Low Performance - This criterion combines the probability of a coll or coils achieving substantially less than required current and the severity of the depreciation of the test results under reduced conditions. In the minimum compact torus, fallure of any coll to reach 1 ts nominal current rating would diminish the field attainable at the other coils, but would not preclude all testing. For this reason it was given a rating of 5 . In the compact torus and the cluster of identical coils, if one or two designs of test coil reached only $80 \%$ of nominal current. rating, the other design(s) could still be tested at full field. The same is true of arrangements $D$ and $E$, but because there is the added possibility of deficient background coils, they were rated at 8 .

Impact of Fabrication Delays - The question here is how much delay there would be in getting a full-field test of the other coils if delivery of one kind of coil were delayed. In the compact torus, it would be possible to run up the current in the available coils, compensating to a large degree for the missing coil. In cases $D$ and $\bar{E}$ delay of one test coil would make no difference on the others; delayed delivery of a background coil would, of course, hold up testing. For the cluster of identical 
colls, all three test colls must be avallable before the first can be tested so this arrangement was rated poorest.

Stray flelds - In normal operation, the torl produce very low stray flelds and only moderate stray fields with one coll deenergized. The 3-coll arrangements, on the other hand, produce high stray fields at all times and were therefore given a rating of 4 .

Coll Welght - Although there are differences in coll weights, all are within the capability that can be easily provided. All arrangements were therefore given a rating of 10 .

A detailed point-by-point evaluation of the $T$-type arrangement was not made to the same degree employed in rating the other candidate arrangements. However, comparisons were made for the criteria which carry substantial weights in order to rank this concept relative to the other candidates. Where possible, calculated data were used in this comparison. The result of this review indicates that these concepts would fall in the same range of scores developed for candidates $D$ and $E$. This conclusion applies to both the category of benefits as well as costs and program risks. The conclusions reached for the candidates which employ background coils will apply equally well for these concepts.

\subsection{Conclusions and Decision}

Sallent conclusions from the scores in Table 6.4 are as follows:

- The total scores in the area of benefits are not greatly different for the two compact tori and the cluster of identical colls. The cluster with background coils is slightly less attractive and the split eccentric is clearly the poorest.

- Total scores in the general area of costs and risks favor the compact torus and the cluster of 1dentical colls. The other three are about even.

- In view of the Inexactness of the rating process, the very small differences among the grand total scores for the compact torus, the minimum compact torus, and the cluster of Identical colls cannot be regarded as signiflcant. The score for the cluster 
with background colls is distinctly lower and the split eccentric test is lowest of all.

Analysis of the scores on Individual criterla in the area of benefits shows that the tori are in some technical respects more "realistic" than the cluster of identical colls and were judged to have greater demonstration value. The cluster is more "versatile" and provides an especlally realistic test of out-of-plane forces, but these scores are not enough to offiet lower ratings in total stored energy and simplicity of providing pulsed field windings. In the area of costs, risks, and problems the totals for $A, B$, and $C$ are not far apart. As might be expected from superficial conslderations, however, there are quite large differences in scores on individual criteria. The biggest advantage of the cluster is in program cost, although it also rates top score on impact of a low-performance coll. It suffers with regard to 1mpact of late dellvery and stray fields. The rationale for the compact torus shows in higher scores relative to the minimum torus in the impact of a low-performance or late coll.

The foregoing analysis showed that some of the pivotal scores involve judgements. That is, they depend upon the perception of values to the broad program of fusion development and the Importance of costs and schedules. Thus, although the scores were the results of a rational process and reasonably unblased, they were useful primarily as a mechanism for drawing attention to different advantages and disadvantages of the various test arrangements; i.e., the definition and weighting of the criteria and the discussion of the ratings promoted a better understanding of the technical issues.

The final decision on the type of test arrangement was based upon an understanding of the differences among the arrangements, and was made in light of the demand of the tusion program for early, definitive results and the prospects for funding. It was recommended by ORNL and accepted by DMFE that planning and conceptual design proceed on the compact torus test arrangement. 


\section{COST ESTIMATION}

The procedure used to generate cost projections for each of the candidate testing configurations evolved from several previous studies at ORNL. These include conceptual design efforts on a three-meter bore cluster test arrangement and an eccentric coll test array, investigation of the possible variations in built-up superconductor fabrication costs, and a detailed preliminary cost estimate for a reference conceptual design of a superconducting tokamak.',

The profected costs for test colls are particularly sensitive to the conductor cost calculations, which must be regarded as only approximations unt1l coll conceptual designs and conductor fabrication procedures have been determined in detall. The data presented in this chapter are useful for determining relative costs and for establishing the approximate magnitude of total program costs.

For the purpose of scaling and exploring the effects of limited variations in design, the estimated coll costs were broken down into 26 separate items, with each 1 tem further divided into material and labor categorles as applicable. Rational cost-size scaling relationships were determined for each item, with coefficients determined from previous design data or developed spectflcally for the 1tem. Several computer programs were used to calculate test and background coll operating characteristics and dimensions, geometric limitations, component part welghts, and isupporting systems requirements. These data were then used with the appropriate cost relationships to determine a scaled cost for each component and system.

Program costs are divided into the cost of the colls, the special facilities required, standard equipment, assembly of the facility and experimental components, engineering, and contingency. Basic costs are calculated in FY-76 dollars. Appropriate factors for escalation, overhead, and technical support are applied to determine a total program cost.

Coll costs include conductor and structural materlal and labor for fabrication and winding. In those cases where more than one coil of a 
particular type is to be built, a reduction factor is applied to appropriate labor items to account for potential learning associated with fabrication of an identical second item. Engineering design costs for each coil type are only applied to the first coil fabricated of any particular design.

Facility costs include material and labor for all special facilities and the standard equipment that is required. The cost projections for the various test facility configurations include costs associated with remodeling an existing bullding and coupling to existing utility interfaces. Each test configuration was evaluated separately, with vacuun enclosures, structural supports, and bullding modifications tailored to each specific concept.

Assembly costs are included for all applicable 1tems. Where the configuration requires that a sequence of colls be installed in a single test coil position, the cost of removing coils is also included. For example, the cluster test with background colls requires assembly of three coils, one test and two background, for the initial test configuration. The program assumption is that a total of three test coils would be tested in the center position. Installation of the second test coll requires removal of the first test coil and installation of the second coil in its place. This must be repeated for the third test coil.

A tabulation of the basic cost elements is given in rables 7.1 and 7.2 , with summary comments relative to the method, source of information, or the cost factors used in developing the cost projections. The four items in Table 7.1 are related to the costs of the test coils and the different conductor types which were used in determining the costs to be used for this study. Table 7.2 lists test stand cost items, other than the test coils themselves, with summary comments relative to the source of information used in developing cost projections. The paragraphs that follow develop in more detail the process followed in determining the costs for each of the items in Tables 7.1 and 7.2 . 
Table 7.1 Cost Elements for LCP Test Coils

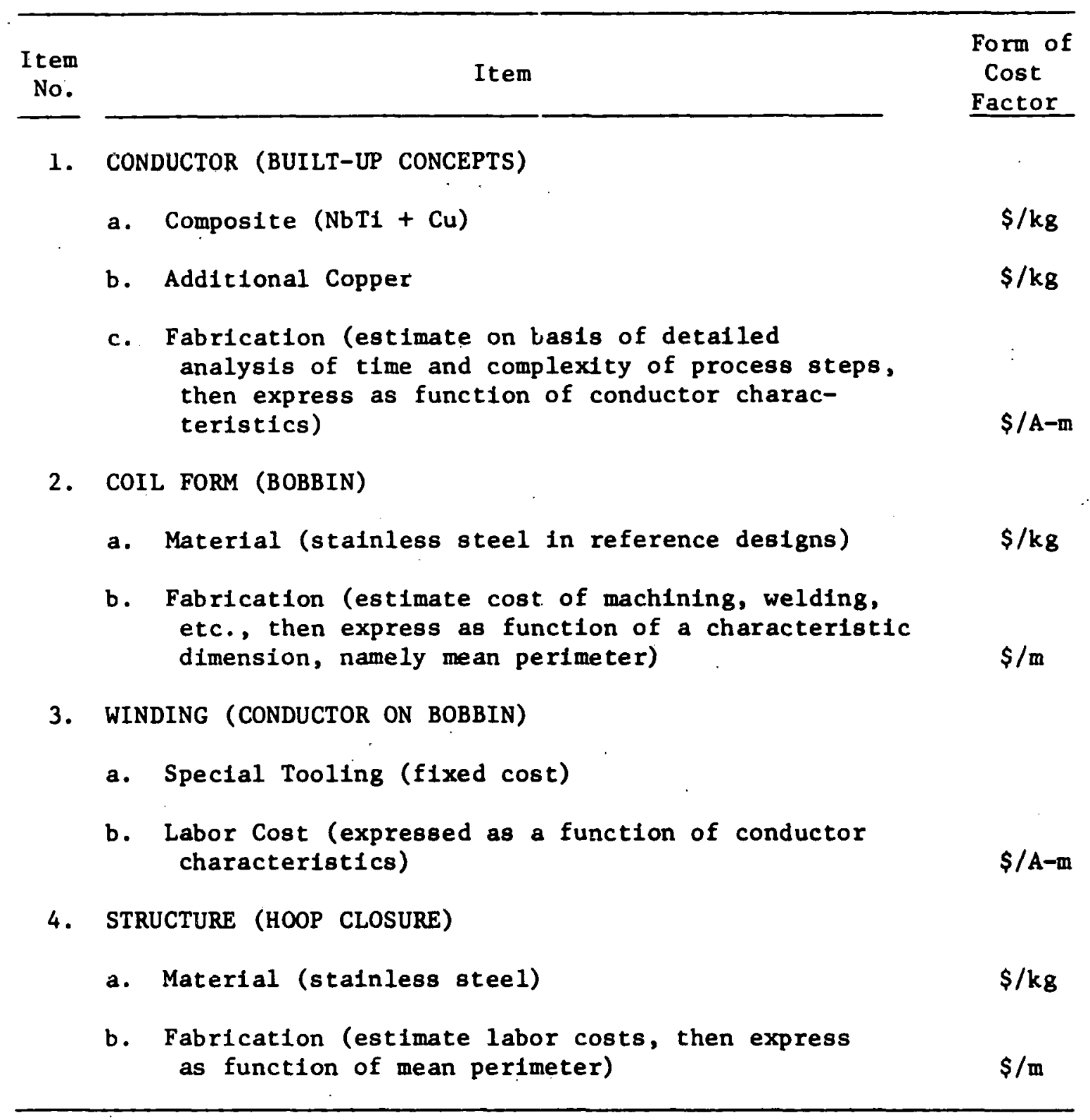


Table 7.2 Cost Elements for LCP Test Stand

\begin{tabular}{|c|c|c|}
\hline $\begin{array}{l}\text { Itein } \\
\text { No. }\end{array}$ & Item & Source of Cost Data \\
\hline $\begin{array}{l}5,6 \\
\text { and } \\
7\end{array}$ & $\begin{array}{l}\text { Coil Support structure: } \\
\text { (restraints, gravity supports) }\end{array}$ & $\begin{array}{l}\text { Engineering design, analysis and } \\
\text { cost estimates for each of the } \\
\text { contending configurations. }\end{array}$ \\
\hline & & $\frac{\text { Function of: }}{(N), \text { configuration }}$ \\
\hline $\begin{array}{l}8,9 \\
\text { and } \\
10\end{array}$ & $\begin{array}{l}\text { Vacuum System: } \\
\text { (vesse1, pumps, insulation, } \\
\text { cold wall) }\end{array}$ & $\begin{array}{l}\text { Eng. design, analysis, cost esti- } \\
\text { mates for each configuration, sup- } \\
\text { plemented by responses from in- } \\
\text { dustrial inquiries. }\end{array}$ \\
\hline & & Function of: $\mathrm{N}$, configuration \\
\hline 13 & TF Power Supplies: & $\begin{array}{l}\text { Cost based on previous estimates. } \\
\text { Function of: } \mathrm{N}\end{array}$ \\
\hline $\begin{array}{l}11, \\
12, \\
\text { and }\end{array}$ & $\begin{array}{l}\text { Pulsed Coil System: } \\
\text { (coils, supports, power supplies) }\end{array}$ & $\begin{array}{l}\text { Engineering preliminary design, } \\
\text { analysis and previous similar con- } \\
\text { cepts cost estimates }\end{array}$ \\
\hline 14 & & $\begin{array}{l}\text { Function of } \\
\text { arrangement., Pulsed coil weight, } \\
\text { and duty cycle. }\end{array}$ \\
\hline 15 & $\begin{array}{l}\text { Machine Supports: } \\
\text { (base supports other than } \\
\text { building foundation) }\end{array}$ & $\begin{array}{l}\text { Engineering analysis and cost esti- } \\
\text { mate supported by previous cost } \\
\text { estimates. }\end{array}$ \\
\hline & & Function of: Configuration and \\
\hline 16 & $\begin{array}{l}\text { Instrumentation and Controls: } \\
\text { (sensors, conditioning, readouts) }\end{array}$ & $\begin{array}{l}\text { Engineering estimates relative to } \\
\text { number and type of sensors required } \\
\text { for test coils and facility. Average } \\
\text { costs for sensors, conditioning } \\
\text { equipment, and readouts based on } \\
\text { previous cost estimates. }\end{array}$ \\
\hline & & Function of: $N$ \\
\hline 17 & $\begin{array}{l}\text { Data Handling } \\
\text { (computer hookup and control } \\
\text { room equipment) }\end{array}$ & $\begin{array}{l}\text { Based on previous cost estimates. } \\
\text { Function of: } \mathrm{N}\end{array}$ \\
\hline
\end{tabular}


Table 7.2 (continued)

\begin{tabular}{|c|c|c|}
\hline $\begin{array}{l}\text { Item } \\
\text { No. }\end{array}$ & Item & Source of Cost Data \\
\hline 18 & $\begin{array}{l}\text { Cryogenic System: } \\
\text { (tie-in to existing facility, } \\
\mathrm{LN}_{2}, \text { LHe) }\end{array}$ & $\begin{array}{l}\text { Constant cost based on previous } \\
\text { cost estimates }\end{array}$ \\
\hline 19 & Bullding Power Mods: & $\begin{array}{l}\text { Constant cost based on previous } \\
\text { cost estimates. }\end{array}$ \\
\hline 20 & $\begin{array}{l}\text { Utilities: } \\
\text { (water, } \mathrm{GN}_{2}, \text { air, } \mathrm{LN}_{2} \text { piping) }\end{array}$ & $\begin{array}{l}\text { Constant cost based on previous } \\
\text { cost estimates. }\end{array}$ \\
\hline 21 & $\begin{array}{l}\text { Building Modifications: } \\
\text { (H and V, control room, etc.) }\end{array}$ & $\begin{array}{l}\text { Constant cost based on previous } \\
\text { cost estimates. }\end{array}$ \\
\hline 22 & Standard Equipment: & $\begin{array}{l}\text { Constant cost based on previous } \\
\text { cost estimate. }\end{array}$ \\
\hline 23. & Maintenance Equipment: & $\begin{array}{l}\text { Constant cost based on previous } \\
\text { cost estimate. }\end{array}$ \\
\hline 24 & $\begin{array}{l}\text { Electrical Special: } \\
\text { (busing, cables, wiring, etc.) }\end{array}$ & $\begin{array}{l}\text { Constant cost based on previous } \\
\text { cost estinate. }\end{array}$ \\
\hline 25 & $\begin{array}{l}\text { Civil and Architecture Special: } \\
\text { (machine foundations) }\end{array}$ & $\begin{array}{l}\text { Englneering design, analysis and } \\
\text { cost estimate, supported by previous } \\
\text { cost estimates. }\end{array}$ \\
\hline 26 & $\begin{array}{l}\text { Mechanical Special: } \\
\text { (fixtures, handling equipment) }\end{array}$ & $\begin{array}{l}\text { Engineering design supported by } \\
\text { previous cost estimates. } \\
\text { Function of: welght of colls }\end{array}$ \\
\hline
\end{tabular}


1. Conductor - Costs were developed using the following approach. The cost of the superconducting composite portion of the conductor, which is made up of superconducting filaments plus some copper, was determined based on data for present costs in dollars $/ \mathrm{kg}$. Added to this is the cost of additional coper required to achleve the desired overall copper to superconductor ratio. Fabrication costs to convert these basic elements into a finished bullt-up conductor were then determined. This cost was estimated on the basis of a detalled analysis of the time and complexity of process steps and reduced to a characteristic of the conductor, namely ampere-meters. Four different conductor types were evaluated and cost factors determined for each. Coll costs for the program assume use of three different conductors and include the conductor types which resulted In the highest and lowest fabricated costs and an averaged value based on the two other conductors that were evaluated.

For the purposes of cost scaling the sum of superconducting composite, additional copper, and the fabrication process costs have been combined into a single term and expressed as a function of ampere-meters. This allows calculation of conductor costs with variations in coll size and current density.

2. Co11 Form (Bobbin) - These costs were develuped in Lwu paits. The first element is the amount of materfal (stainless steel) required which is determined from material thicknesses derived from stress calculations. The cost of this portion of the bobbin is based on $\$ / \mathrm{kg}$ of material. The second cost element is the expense associated with fabrication. This cost is based on estimates of machining, weiding, and inspection derived from a detalled cost estimate made in support of a previous superconducting coll conceptual design. ${ }^{7},{ }^{8}$ Cost scaling relationships assume that the fabitcation portion of thcoc coote can be reduced to a function of a characteristic coil dimension, namely the mean perimeter of the bobbin structure.

3. Winding (conductor onto the bobbin) - This cost is made up of two factors: special tooling and labor cost. Tooling required includes cleaning, joining, and tensioning mechanisms with costs for these items 
assessed only against the first coll manufactured of a given type. Labor costs were estimated based on analysis of tasks required and relative speed and manpower required for each. Assuming that the conductor size remains reasonably constant, the winding costs can be expressed as a function of ampere-meters plus a fixed cost for equipment.

4. Structure (hoop closure) - This cost is developed in a manner similar to that discussed for item 2 above. Material costs are based on $\$ / \mathrm{kg}$ taking into consideration the heavier section metal required, and fabrication costs are again derived from a previous conceptual design. Cost scaling is based on the mean perimeter of the enclosing structure. The sum of items 1 through 4 plus engineering costs associated with the design and fabrication of a complete coll represent the cost of a single coll.

The following cost items comprise the test facility, special equipment, standard equipment, and building modifications for the LCP. Cost; scaling relationships have been developed for each where necessary to permit cost calculations for the several testing arrangements including varlations in coil size.

5. Coll Support Structure (centering force restraint) - A bucking cylinder has been designed to resist the centering forces which 1.8 essentially a thick-walled, externally pressurized cylinder where the distributed centering forces are assumed to act as a untform pressure. The height of the cylinder is taken to be equal to the horizontal bore of the coll. Material cost is based on thicknesses derived from stress calculations converted into the mass of material required and priced in $\$ / \mathrm{kg}$. Labor costs are based on fabrication processes including rolling to shape, welding, and machining. Time and manpower estimates were made and costs determined as a function of the radius of the bucking cylinder.

6. Co11 Support Structure (Intercoil supports) - Wedged-shaped box beam type structure has been assumed for the intercoll supports for the compact torus and cluster test configurations. A systein of reinforced plates to ract the out-of-plane forces has been assumed for the eccentric test configuration. Previous conceptual designs employing similar 
structure have been reviewed to establish appropriate cost relationships for material and labor as a function of coll dimensions or test configuration characteristics.

7. Coll Support Structure (gravity supports) - A system of posts and beams from which the test array can be supported has been assumed for the cluster and eccentric test configurations. This is similar to concepts proposed in earlier conceptual design studies. Gravity support for the compact torus concepts 18 included in item $15^{\circ}$ as machine supports. Material and labor costs are determined for each candidate arrangement as a function of the weight of the colls.

8. Vacuuin System (vacuum vesse1) - A bell-jar type vacuun enclosure has been assumed and analyzed for each of the test configurations. Stress calculations were used to determine material required and the fabrication steps were reviewed to estimate the amount of forming and welding necessary. A preliminary inquiry was transmitted to industry soliciting inputs relative to cost and schedule for fabrication of a bell jar sized at the mean of the range under consideration. Responses to this inquiry were used to normalize the cost calculations used in this study. Costs were determined for the compact torus, cluster, and eccentric test arrangements as a function of coll size. Apportionment of material and labor costs were based on industry responses to the preliminary inquiry.

9. Vacuum System (vacuum pumping) - Pumping systems were assumed to be identical for the range of vacuum vessel sizes considered. Costs include diffusion pumps, backing pumps, and miscellaneous valving and piping.

10. Vacuum System (Iiquid nitrogen cold wal1) - An enclusure consisting of a liquid-nitrogen cooled copper plate was assumed to provide thermal control within the bell jar. Separate enclosures were designed for each of the test arrays and costs determined as a function of coil size: Material costs are based on the amount of copper plate and tubing whth labor costs estimated for the fabrication steps required.

11. Pulsed Colls (coil case and conductor) - A liquid-nitrogen cooled copper coll set in which one coll provides a pulsed field parallel to the 
test coil conductor while a second coil provides a perpendicular component has been defined for all the test arrangements. These coils are solenoids with a bore of $1.2 \mathrm{~m}$ and a length of $1.0 \mathrm{~m}$. The winding concept is to use commercially available conductor and wind it on a stainless steel coil form. Material costs are calculated based on the weights of copper and stainless steel required with labor costs estimated as a factor times the material cost.

12. Pulsed Coils (supports) - A stainless steel frame similar to the gravity support structure defined for the cluster and eccentric arrays is assumed adequate to support the pulsed colls. Cost factors derived for the gravity supports have been used to calculate the cost for these supports. Material cost is a function of the weights of materials involved with labor costs estimated by factoring the material cost.

13. Power Supplies (test co11s) - Power supply costs for the test colls assume that a module consisting of a 25-volt, 20-kfloamp power supply, the electrical protection circuitry and dump resistors, and the necessary bus work, cabling, and installation for a single coil would be provided for each test coll. Component part costs were estimated based on previous conceptual design studies with appropriate labor charges. also derived from these earlier cost estimates.

14. Power Supplies (pulsed co118) - Power supply costs for the pulsed coll set assume that two different power levels are required depending on the magnitude of pulsed field desired. Two 300-volt power supplies, one at 5000 amps and the second at 1000 amps rating are included in the cost profections. The costs assigned to these items reflect recent purchase price information for simflar items.

15. Machine Supports - This item includes the support structure which carries the gravity load from compact torus colls to ground. The basic concept is an array of structural beam elements fabricated into a grid of circular and radial members. Costs are estimated by calculation of the weight of structural members, which are priced in $\$ / \mathrm{kg}$, and labor costs are based on welding and fabrication requirements. Cost scaling 
factors were developed as a function of coll size and major radius of the experimental arrangement.

16. Instrumentation and Control - These costs were estimated by a detailed breakdown of elements into the following categorles: experimentrelated items which include the sensors installed on each coll, the signal conditioning from the coll sensors to the control/display interface, and the controls, readouts, and cabinetry required; facility related 1tems which include sensors associated with the vacuum system, refrigeration systems, power supplies, etc., signal conditioning from the sensors to the control/display interface, and controls, readouts, recorders, and cabinetry required. The number of sensors installed on a coll we re investigated for both test and background colls. The number and type of each sensor was determined as well as an estimate as to which may be multiplexed saving on signal conditioning. Costs were estimated for the sensors using present pricing data for similar 1tems. Remaining costs were based on estimates made in support of previous conceptual designs.

17. Data Handling - Thls item includes the cost of connecting instrumentation to existing computer system and control room equipment. The basis for the costs assigned is a detalled cost estimate made for a conceptual design of a superconducting tokamak.', A review of this estimate was made and that portion of the costs related to the toroldal field colls extracted. A cost factor was then derived from this data which allowed a cost projection to be made based on the number of colls involved plus a fixed cost which was related to the facility aspects of the experiment.

18. Cryogentcs - This is essentially a fixed cost for all the candidate test arrangements and Includes the cost of installation to an existing facility interface. Both liquid helium and liquid nitrogen piping, valving, and interface connection costs are included. Cost estimates are based on previous conceptual design studies of similar experiments installed in the same facllity. 
19. Building Electrical Power - This cost includes those changes and equipment which must be made to the basic building electrical power system to accommodate the experiments proposed. Equipment costs cover modifications to lighting, emergency power, and substations with labor costs estimated to cover installation charges.

20. Utilities - This item includes civil and architectural effort relative to piping foundations and supports and piping runs required for demineralized water, afr, and gaseous nitrogen. lengths of piping were assumed consistent with hookup to existing facility interfaces within a reasonable distance from the experiment. Cost factors for material and labor were derived from previous conceptual design studies.

21. Building Modiflcations - This 1tem includes those costs associated with modification of an existing bullding in the area of civil and architectural changes to heating and ventilation, construction of control room and utility area spaces, and modifications to the high-bay area floor to provide for an assembly area with increased floor loading capacity. Cost estimates were based on previous studies.

22 and 23. Standard and Maintenance Equipment - These are essentially fixed cost items which cover the cost of equipment items. Previous estimates were reviewed to arrive at an appropriate cost for this experiment.

\section{Electrical Special Equipment - Th1s cost covers those items} of electrical equipment which are considered to be peculiar to the experiment. This includes communication power, busing, cables, motor controls, and wiring. Costs for material and labor were taken from similar previous design studies.

25. Civil and Architectural Speclal - This item covers the cost to modify the floor structure beneath the experiment which mist withstand the combined load of the colls and bell jar. Cost estimates made in previous conceptual designs were reviewed and a cost factor determined based on the weight of the colls plus the bell jar. 
26. Mechanical Spectal - Th1s 1tem covers spectal handling equipment. which will be required to position and install the colls and factlity hardware items. Fixture costs developed in support of an eccentric coil test arrangement were reviewed and adjusted for the difference in coll size and weight.

Results - The above outlined elements and procedure were applied to each of the five candidate testing arrangements and program costs determined for oach ao a function of test coll horizontal bore. Resulls of these calculations, normalized to the cost of the compact torus at a reference size of three meters, are presented In F1g. 7.1 . 


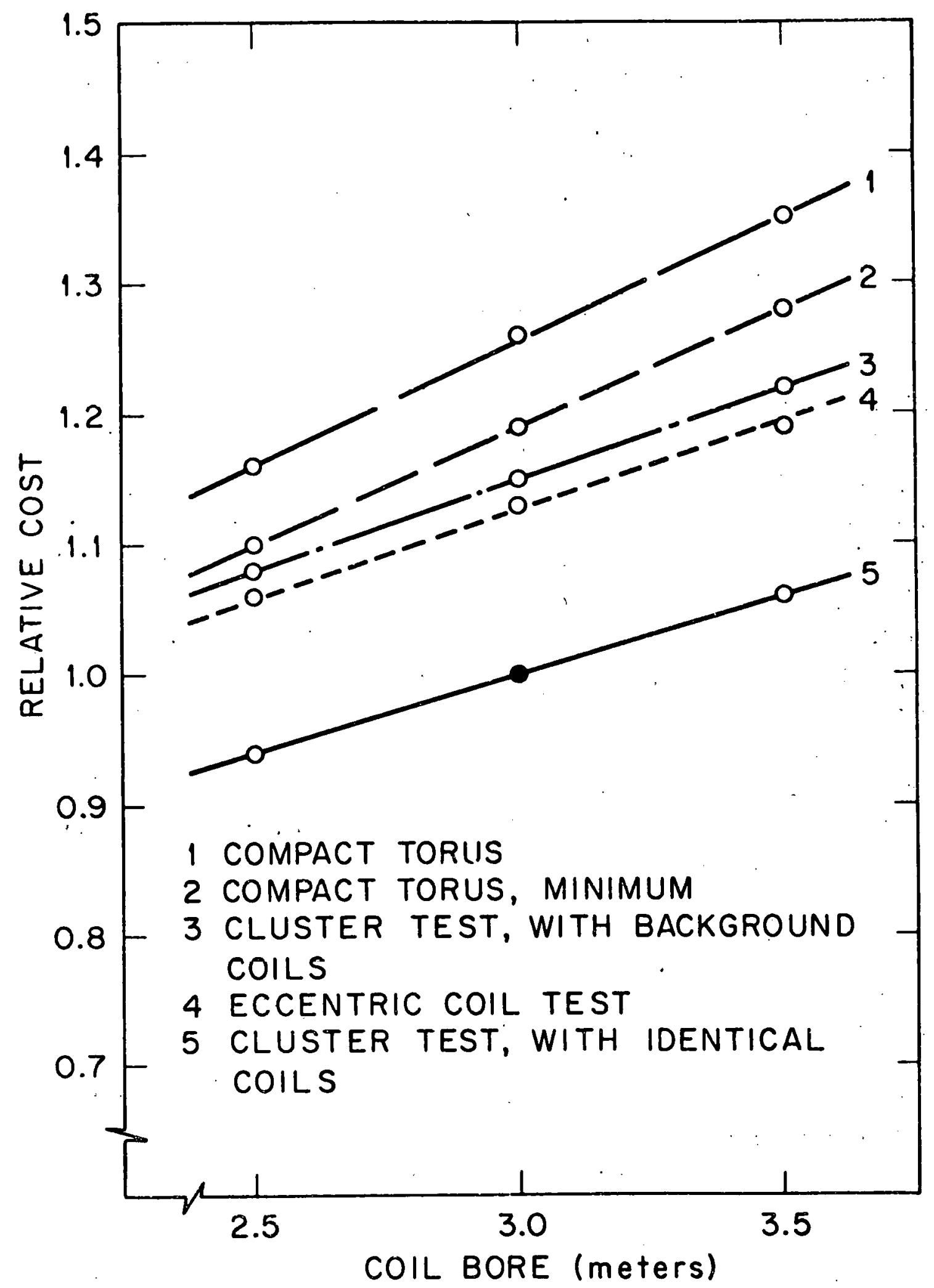

F1g. 7.1 Relative Cost of Candidate Test Arrangements versus Test Coll Bore 


\section{DESCRIPTION OF FIRST TEST COILS}

This chapter describes how the basic concepts for the first test colls were chosen and gives a few of the principal features of the technical specifications which the first test colls will be required to meet.

\subsection{Basic Concepts}

The LCP must prove the most promising concepts of toroldal field colls for TNS. The greatest uncertainty at this time in TNS requirements is the peak field. TNS configuration trade studies and evaluation of confinement physics uncertaintles are now under way to quantify insofar as possible the incentives for higher flelds. Clearly a peak fleld of at least 8 tesla is desired and the f1rst LCP subcontracts w1ll be for coils operable at 8 tesla. Decisions on possible subsequent procurement of higher-field colls, which place more stringent demands on superconducting magnet technology, w1ll be based on results of TNS studies and progress In superconducting magnet R\&D in 1977.

The bore dimensions of the TNS colls are expected to be about $5 \times 7 \mathrm{~m}$ and the TNS test colls will be half this size. The conductor and winding cross section of the test colls will be practically the same size as the TNS colls, however. For the same peak magnetic field, the required number of ampere-turns per coll in a compact 6-coll array is nearly the same as in a 16-coil TNS.

The basic features that will be investigated in the first test colls were chosen on the basis of earlier EPR magnet conceptual studies. In the EPR-TF studies connected with LCP, all three contractors chose NbTi as the superconductor for the 8-tesla case, with two concepts using poolbolling helium and one forced flow to provide cryogenic stabllization. For the high-fleld case, two contractors chose to use $\mathrm{Nb}_{3} \mathrm{Sn}$ conductor cooled by forced flow. Although finding no sharp break point in variation of coll parameters with field, each independently settled on 12 tesla as the "highest practlcable" peak fleld. The third contractor's 
"highest practicable field" concept used NbTi conductor cooled by boiling helium at $2.5 \mathrm{~K}$ to reach a maximum of 12 tesla. Widely different conductor configurations and structural concepts were envisioned by the contractors.

For the first three LCP test coils, 1t was decided that one subcontract would be awarded for the best proposal uoing "monolithic" conductor $^{*}$ cooled by pool bolling, the second would be for the best proposal using open cable cooled by forced flow of helium through and around the cable, and the third would be for the all-around best proposal by a firm not awarded one of the first two subcontracts.

\subsection{Technical Specifications}

As a basis for the first test coil subcontracts, detailed technical specifications ${ }^{\dagger}$ were prepared to insure that each resulting coll would be consistent with the objectives of the magnet development program and all would fit together in the test assembly. The particulars of the coil design and fabrication procedures were not specifled, however, but were left to the firms submitting proposals. Included in this latitude was the cholce between $\mathrm{NbT} 1$ and $\mathrm{Nb}_{9} \mathrm{Sn}$ as the superconducting material. The principal requirements of the specifications are briefly identified as follows.

The coll shall be operable at a peak fleld of at least 8.0 tesla at a design current of 10-15 kA in a 6-coil Compact Torus when the other five colls are at 0.8 of their design current.

The designer must show that his coil is stable against effects on the conductor of all credible events. No design w111 be acceptable that is not capable of recovery from a sudden normalcy extending over any half-turn.

The coil must Ile within a spatial envelope defined in the Technical Specifications. The required winding shape approximates a $D$ while the

\footnotetext{
* Monolithic here denotes conductors in which there is no possibility for relative motion of strands or other elements within the conductor.

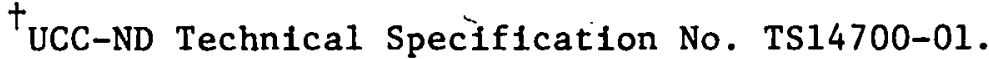


oufside of the coll case is rectangular in profile. The inboard stralght edge bears against a central hexagonal post in the test stand and has a vertical tongue that fits a groove in the post to transmit part of the overturning moment from the vertical field that will be imposed. Structural members which will be provided to transmit forces between adjacent colls will bolt to the outer corners of the coll case. The structural, electrical, and coolant interfaces indicated on F1g. 8.1 are precisely defined in the Specifications. The concept of the structure that will be provided as part of the test facllity is depicted in Fig. 8.2.

The design of the coll must be consistent with a postulated radiation environment equivalent to that expected in TNS. The stability analysis shall assume that the matrix materlal will be exposed to a fast neutron fluence of $0.5 \times 10^{1 /} \mathrm{n} / \mathrm{cm}^{2}$. Insulation capable of operation after a dose of $10^{7}$ rads must be used. The thermal design must accommodate a hypothetical nuclear heat source ranging up to $1 \times 10^{-4} \mathrm{~W} / \mathrm{g}$, with $5 \times 10^{-4} \mathrm{~W} / \mathrm{g}$ at local "hot spots."

The test coll must continue to operate in a cyclically imposed pulsed fleld with peak values of $0.14 \mathrm{~T}$ perpendicular to the conductor and $0.10 \mathrm{~T}$ parallel to the conductor, ramped up in $1 \mathrm{sec}$. 


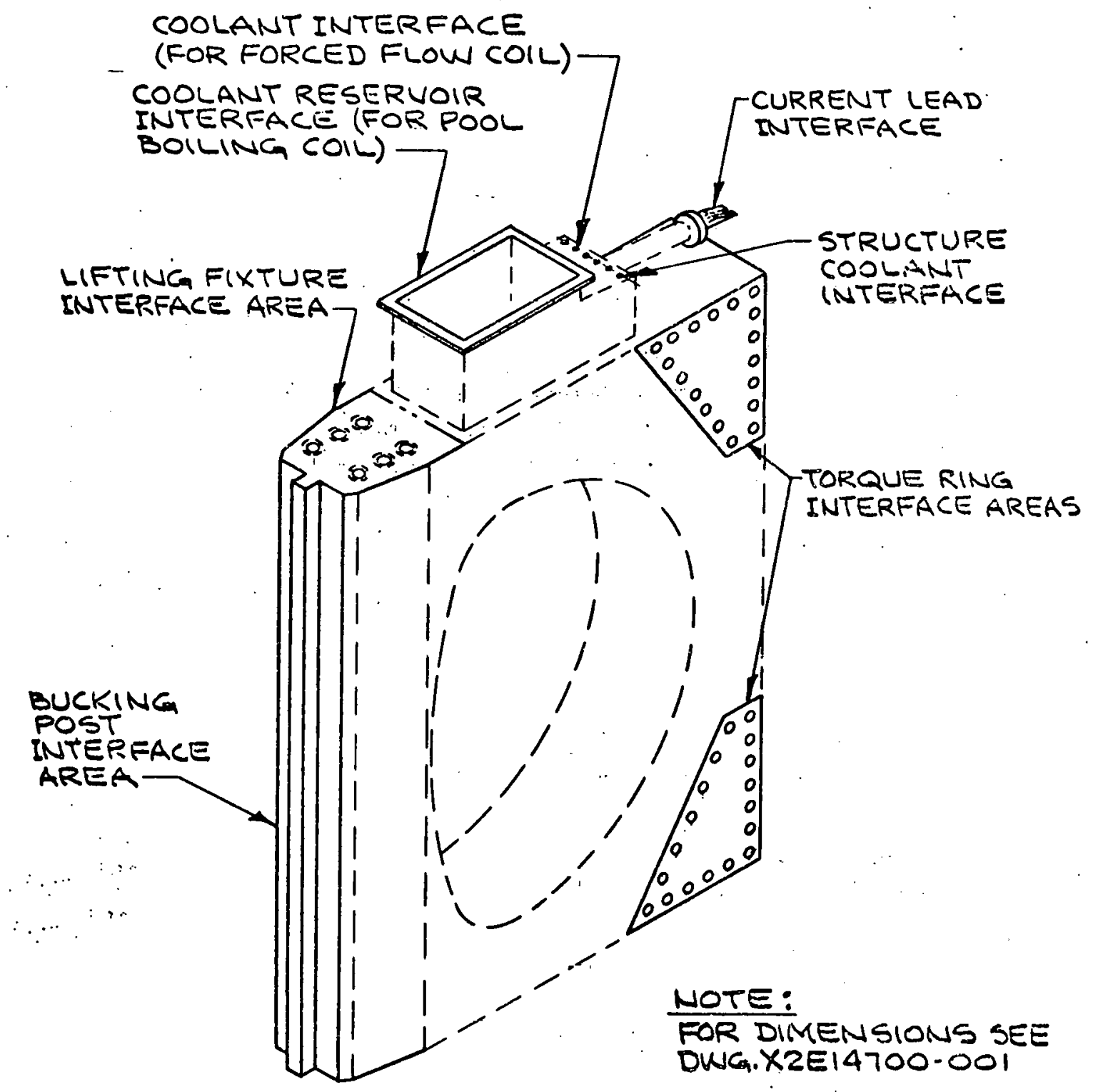

Fig. 8.1. Interface Features 

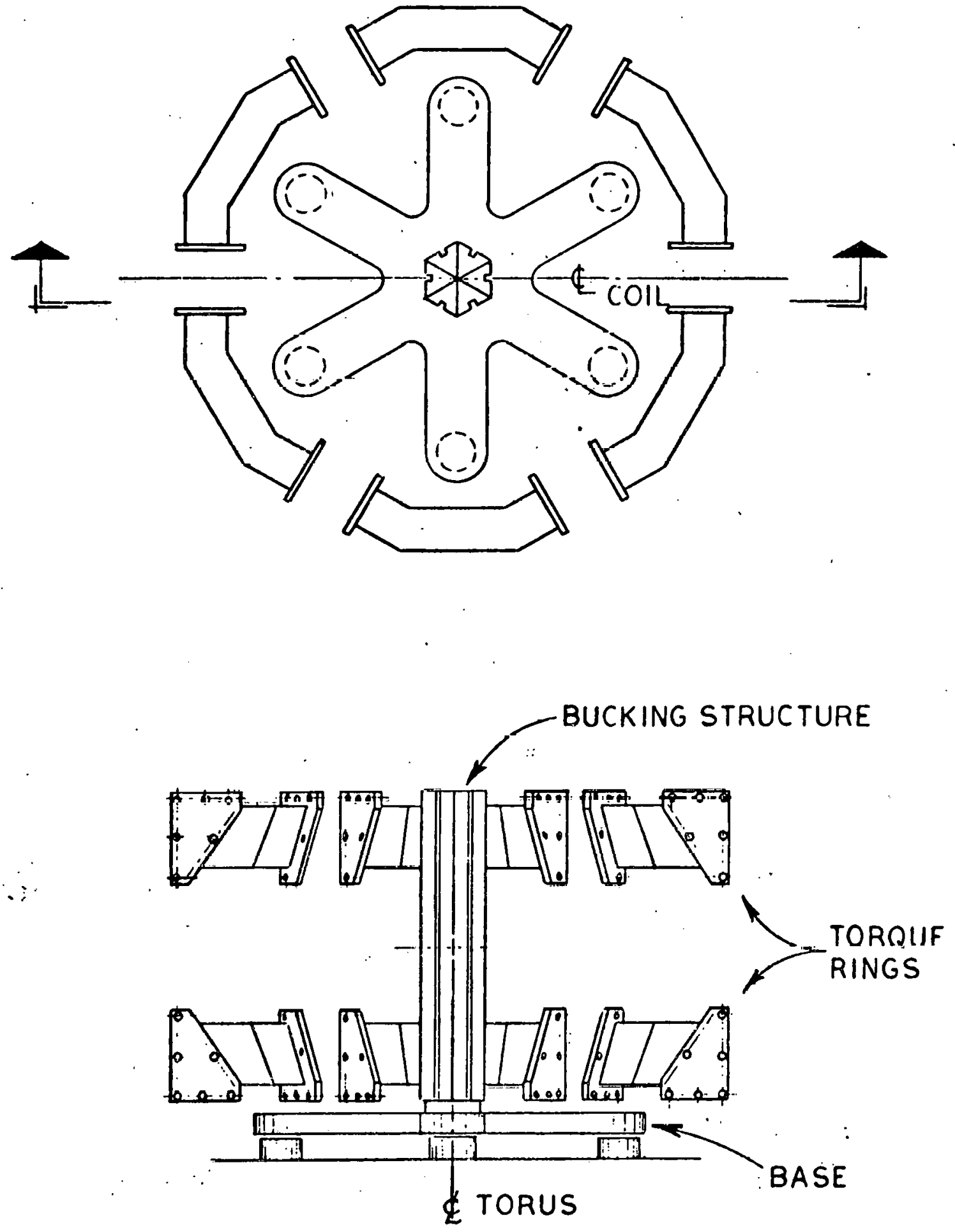

Fig. 8.2. Structural Mounting Arrangement 


\section{REFERENCES}

1. H. M. Long and M. S. Lubell (eds.), Program for the Development of Toroldal Superconducting Magnets for Fusion Research, ORNL/TM-5401, (Apri1 1976).

2. M. Roberts and E. S. Bettis (eds.), Oak RIdge Tokamak Experimental Power Reactor Study - Reference Design, ORNL/TM-5042, (November 1975).

3. W. M. Stacey, Jr. et a1., Tokamak Experimental Power Reactor Studies, ANL/CTR-75-2 (June 1975).

4. GAC Fusion Engrg. Staff, Experimental Power Reactor Conceptual Design Study - 12-month Progress Rept. for Perlod July 1, 1974 through June 30, 1975, GA-A13534 (July 1975).

5. M. Murphy and J. Neff (eds.), Workshop on Conceptual Design Studies of Experimenta1 Power Reactor-1, ERDA-89, (November 1975).

6. V. A. Zaloom, "The Delph1 Technique," Journal of Systems Management, (October 1974), p. 32 .

7. P. N. Haubenreich (ed), Description of a Reference Design Tokamak for the Technology Test Assembly, ORNL/TM-4820, (October 1975).

8. P. B. Thompson, Procedures for Parametric Studies of Costs of Superconducting Toroldal Test Assemblies, ORNL/TM-4821, (May 1976). 


\section{THIS PAGE}

\section{WAS INTENTIONALLY LEFT BLANK}


Internal Distribution

1. W. C. Anderson

2. J. K. Ballou

3. W. Becraft

4. L. A. Berry

5. R. L. Brown

6. E. H. Bryant

7. P. B. Burn

8. J. D. Callen

9. D. D. Cannon

10. J. F. Clarke

11. R. A. Dandl

12. R. S. Edwards

13. W. A. Fietz

14-23. P. N. Haubenreich

24. R. P. Jernigan

25. T. C. Jernigan

26. G. G. Kelley

27. G. A. Krist

28. C. G. Lawson

29. P. S. Litherland

30. C. J. Long

31. M. S. Lubel1

32. J. W. Lue

33. J. N. Luton
34. T. L. Mann

35. H. C. McCurdy

36. O. B. Morgan

37. J. R. Moore

38. L. W. Nelms

39. B. E. Nelson

40. M. Roberts

41. M. W. Rosenthal

42. J. L. Scott

43. T. E. Shannon

44. R. E. Stamps

45. L. D. Stewart

46. D. Steiner

47. W. C. T. Stoddart

48. P. B. Thompson

49. P. L. Walstrom

50. R. S. Ware

51. E. R. Wells

52. ORNL Patent Office

53-54. Central Research Library

55. Y-12 Document Reference Section

56-58. Laboratory Records

59. Laboratory Records Record Copy

60. Fusion Energy Division Library

\section{External Distribution}

61. Director, Division of Magnetic Fusion Energy, USERDA, Washington D. C. 20545

62. Donald J. Anthony, General Electric Company, Building 2, Room 447, 1 River Road, Schenectady, NY 12345

63. Charles C. Baker, General Atomic Company, P.0. Box 81608, San Diego, CA 92138

64. Donald S. Beard, DMFE, USERDA, Washington D. C. 20545

65. R. Boom, University of Wisconsin, 1500 Johnson Drive, Madison, WI 53706

66. F. E. Coffman, DMFE, USERDA, Washington D. C. 20545

67. R. W. Conn, Engineering Research Bullding University of Wisconsin, 1500 Johnson Drlve, Mad1son, WI 53706

68. S. O. Dean, DCTR, USERDA, Washington D. C. 20545

69. John J. Ferrante, General Electric Co., Building 2, 1 River Road, Schenectady, NY 12345

70. J. File, Princeton Plasma Physics Laboratory, P.0. Box 451, Princeton, NJ 08540 
External Distribution

(continued)

71. H. K. Forsen, Exxon Nuclear Co., Inc., 777 106th Avenue, N.E., C-0777, Bellevue, WA 98009

72. T. K. Fowler, Assoc. Dir. for CTR, University of California, Lawrence Livermore Lab., P.0. 808, Livermore, CA 94550

73. H. P. Furth, Princeton Plasma Physics Laboratory, P.0. Box 451, Princeton, NJ 08540

74. M. B. Gottlieb, Princeton Plasma Phys1cs Laboratory, P.0. Box 451, Princeton, NJ 08540

75. R. W. Gould, Department of Applied Physics, California Institute of 'lechnology, Pasadena, CA 91109

76. J. Nelson Grace, DMFE, USERDA, Washington D. C. 20545

77. E. Gregory, Airco Inc., Central Research Laboratories, Murray Hill, New Providence, NJ 07974

78. C. D. Henning, DMFE, USERDA, Washington D. C. 20545

79. G. K. Hess, DMFE, USERDA, Washington D. C. 20545

80. D. J. Jacobs, Aluminum Company of America, P. 0. Box 9.128, Alcoa, TN 37701

81. Robert B. Jacobs, 1942 Broadway, Sulte 207, Boulder, CO 80302

82. Clifford K. Jones, Manager, Cryogenics Research Laboratories, Westinghouse Electrlc Corporation, Pittsburgh, PA 15235

83. J. A. Lenhard, ORO, Oak Ridge, TN 37830

84. Michael Lotker, Northeast Utilities Service Company, P.0. Box 270, Hartford, CT 06101

85. F. E. Mills, Buflding 208, Argonne National Laboratory, 9700 South Cass Avenue, Argonne, IL 60439

86. R. G. Mills, Princeton Plasma Physics Laboratory, P.0. Box 451, Princeton, NJ 08540

87. D. B. Montgomery, MIT, National Magnet Laboratory, 170 Albany St., Cambridge, MA 02139

88. J. O. Neff, DMFE, USERDA, Washington D. C. 20545

89. J. W. Nehls, ERDA-ORO, Oak RIdge, TN 37830

90. T. Ohkawa, General Atomic Company, P.0. Box 81608, San Dlego, CA 92212

91. J. R. Purcell, General Atomic Company, P.0. Box 81608, San Diego, CA 92212

92. R. L. Rhodentzer, Intermagnetics General Corporation, Guilderland, NY 12084

93. F. L. Ribe, CTR Division; Los Alamos Scientific Laboratory, P. O. Box 1663, Los Alamos, NM 87544

94. D. J. Rose, Department of Nuclear Engineering, MIT, Cambridge, MA 02139

95. Zalman Shapiro, Breeder Reactor Division, Westinghouse Electric Corporation, P. O. Box 355, Pittsburgh, PA 15230

96. W. M. Stacey, Jr., Argonne National Laboratories, Building 208, 9700 South Cass Avenue, Argonne, IL 60439

97. 2. J. J. Stek1y, Magnetic Corporation of America, 179 Bear Hill Road, Waltham, MA 02154 
- External Distribution

(continued)

98. P. S. Swartz, Intermagnetics General, Thermonuclear Division, P.0. Box 566, Guilderland, NY 12083

99. Carl H. von Keszycki, Director, Special Projects Grumman Aerospace Corp., Bethpage, NY 11714

100. Susan Waddle, ORO, Oak Ridge, TN 37830

101. J. M. Williams, DMFE, USERDA, Washington D. C. 20545

102. H. H. Woodson, Chairman Department of Electrical Engineering, The University of Texas at Austin, Austin, TX 78712

103. W. W. Withee, Director, Energy Systems, General Dynamics, Convair Division, P.0. Box 80847, San Diego, CA 92138

104. J. Wong, Supercon Inc., 9 Erie Drive, Natic, MA 01760

105. J. L. Young, Westinghouse Electric Corporation, Research \& Development Center, Churchill Boro, Pittsburgh, PA 15235

106. E. J. Ziurys, DMFE, USERDA, Washington D. C. 20545

107- Technical Information Center, P.0. Box 62, Oak Ridge, TN 37830

133. 